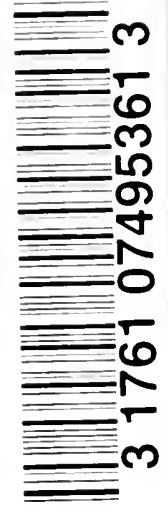

.ünsch, Richard

u einem Exiechischen Zauberpapyrus 

LEINE TEXTE FÜR VORLESUNGIN UND ÜBUNGEN HERAUSGEGEBEN VON IIANS LIETZMANN

84

\section{AUS ,EINEM}

\section{iRIECHISCHEN ZAUBERPAPYRUS}

\section{RICHARD WÜNSCH}

PREIS $0.70 \mathrm{M}$

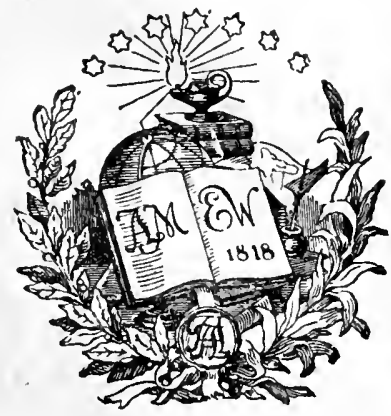

BONN

A. MARCUS UND E. WEBER'S VERLAG

I9I I 


\section{KLEINE TEXTE FÜR VORLESUNGEN UND ÜBUNGEN}

\section{HERAUSGEGEBEN VON HANS LIETZMANN}

I Das Muratorische Fragment und die monarchianischen prologe zu den evangelien, herausgegeben von Prof. Lic. Hans Lietzmann. 2. Aufl. I6 S. $0.30 \mathrm{M}$.

2 Die Drei ältesten Martyrologien, herausgegeben von Prof. Lic. Hans Lietzmann. 2. Auf. I8 S. $0.40 \mathrm{M}$.

3 Apocrypha I: Reste des Petrusevangeliums, der Petrusapocalypse und des Kerygma Petri, herausgegeben von Prof. Lic. Dr. Erich Klostermann. 2. Aufl. $16 \mathrm{~S}$. $0.30 \mathrm{M}$.

4 Ausgewählte Predigten I: Origenes Homilie $\mathrm{X}$ über den propheten Jeremias, herausgegeben von Prof. Lic. Dr. Erich Klostermann. $16 \mathrm{~S}$. $0.30 \mathrm{M}$.

5 Liturgische 'Texte I: Zur geschichte der orientalischen taufe und messe im 2. und 4. jahrhundert, ausgewählt von Prof. Lic. Hans Lietzmann. 2. Aufl. $16 \mathrm{~S}$. $\quad 0.30 \mathrm{M}$.

6 Die Didache, mit kritischem apparat herausgegeben von Prof. Lic. Hans Lietzmann. 2. Aufl. I6 S. $0.30 \mathrm{M}$.

7 Babylonisch-ASSYrische TeXte, übersetzt von Prof. Dr. Carl Bezold. I schöpfung und sintflut. 2. Auf. $24 \mathrm{~S}$. $0.40 \mathrm{M}$.

8 ApocrypHA II: Evangelien, herausgegeben von Prof. Lic. Dr. Erich Klostermann. 2. Aufl. 2I S. $0.40 \mathrm{M}$.

9 Ptolemaeds Brief an die Flora, herausgegeben von Prof. D. Adolf Harnack. Io S. $0.30 \mathrm{M}$.

ro Die Himmelfahrt des Mose, herausgegeben von Prof. Lic. Dr. Carl Clemen. $16 \mathrm{~S}, 0.30 \mathrm{M}$.

II APOCRYPHA III: Agrapha, Slavische Josephusstücke, Oxyrhynchusfragment, herausgegeben von Prof. Dr. Erich Klostermann. 2. Aufl. $26 \mathrm{~S}$. $0.50 \mathrm{M}$.

12 Apogrypha IV: Die apokryphen briefe des Paulus an die Laodicener und Korinther, herausgegeben von Prof. D. Adolf Harnack. $0.40 \mathrm{M}$.

I3 Ausgewählte Predigten II: Fünf festpredigten Augustins in gereimter prosa, herausgegeben von Prof. Lic. Hans Lietzmann. I6 S. $0.30 \mathrm{M}$.

I4 Griechische PAPyri, ausgewählt und erklärt von Prof. D. Hans Lietzmann. 2. Aufl. 32 S. 0.80 M.

15/I6 Der Prophet Amos, Hebräisch und Griechisch, herausgegeben von D. Johannes Meinhold und Lic. Hans Lietzmann. $32 \mathrm{~S}$. $1.00 \mathrm{M}$.

i 7/18 Symbole DeR alten Kirche, ausgewählt von Prof. Lic. Hans Lietzmann. $32 \mathrm{~S}$. $0.80 \mathrm{M}$.

19 Liturgische Texte II: Ordo missae secundum missale romanum, herausg. von Prof Lic. Hans Lietzmann. 2. Auf. 32 S. $0.40 \mathrm{M}$.

20 Antike Fluchtafeln, ausgewählt und erklärt von Prof. Dr. Richard Wünsch. 2. Ault. 31 S. $0.70 \mathrm{M}$.

2 I Die Wittenberger U. Leisniger Kastenordnung I522, I523, herausgegeben von Prof. Lic. Hans Lietzmann. 24 S. $0.60 \mathrm{M}$.

22/23 DIE JÜDISCH-ARAMÄISChen PAPYRI vON AsSUAN sprachlich und sachlich erklärt von Lic. Dr. WV. Staerk. 39 S. r.00 M.

24/25 Martin Luthers geistliche Lieder, herausgegeben von Prof. Dr. Albert Leitzmann. 31 S. $0.60 \mathrm{M}$.

26/28 LATEINISCHE CHRISTLICHE INSCHRIFTEN mit einem anhang jüdischer inschriften ausgewählt und erklärt von Prof. Dr. Ernst Diehl. $48 \mathrm{~S}$. I.20 M. 
KLEINE TEXTE FÜR VORLESUNGEN UND ÜBUNGEN HERAUSGEGEBEN VON HANS LIETZMANN

84

\section{AUS EINEM}

\section{GRIECHISCHEN ZAUBERPAPYRUS}

$\operatorname{VON}$

RICHARD WÜNSCH

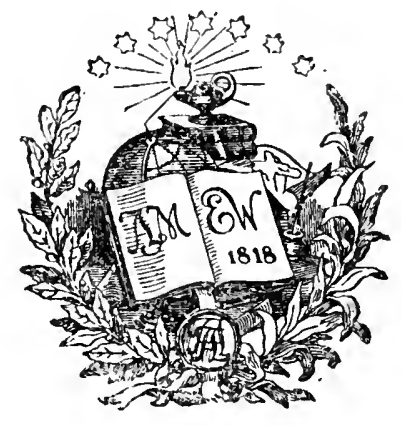

BONN

A. MARCUS UND E. WEBER'S VERLAG

I 9 I I 


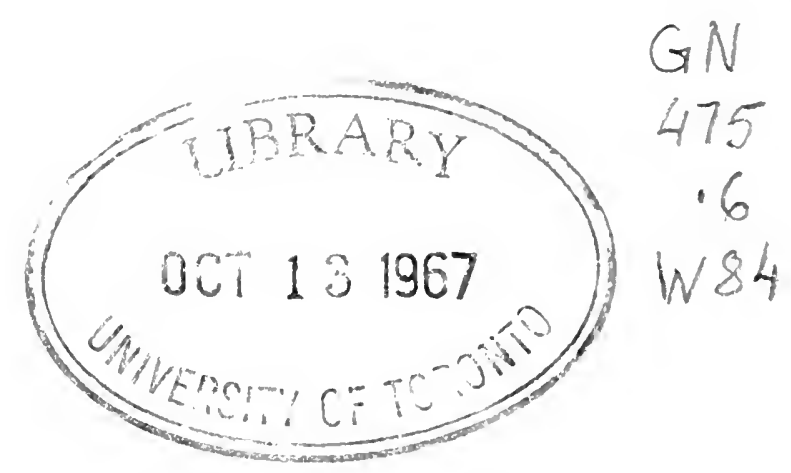

EINLEITUNG

Die Griechen haben wie alle primitiven völker den zauber gekannt. Sie glaubten daran, daß der mensch aus eigener macht, vermittels der verborgenen kräfte der natur oder durch götterzwang übermenschliche wirkungen erzielen, sich liebe, glück, reichtum und macht sichern, den feind mit krankheit und tod heimsuchen könne. Soweit die im alten Hellas üblichen zauberhandlungen und zaubersprüche erhalten blieben, sind sie einfach und primitiv. Erst als man in hellenistischer zeit die orientalische magie kennen lernte, wurden durch die nachahmung dieses fremden zaubers die handlungen kompliziert, die formeln $z u$ langen litaneien, die vielfach aus nichtgriechischen sprachen übernommen wurden: Auf diese weise werden die vorschriften, wie man zu zaubern habe, derartig umständlich, daß man sie nicht wie zu anfang mündlich tradiert, sondern schriftlich aufzeichnet. Mit der zeit wachsen die einzelnen rezepte zu großen rezeptbüchern zusammen, deren uns aus der letzten zeit des altertums etwa ein dutzend erhalten sind (übersicht bei R. Wünsch, Antikes Zaubergerät aus Pergamon, Jahrb. Arch. Inst. Erg. Heft VI I9). Das bedeutendste ist der im vierten jahrhundert n. Chr. geschriebene papyrus der Nationalbibliothek in Paris, Suppl. gr. 574 (s. C. Preisendanz Philol. LXVIII 1909, 575), ediert zuerst von C. Wessely, Denkschriften der Wiener Akademie, philos.-hist. Cl. XXXVI I 888 , S. 44 ff. (weitere literatur bei B. Kuster, De tribus carminibus papyri Parisinae magicae, Diss. Königsberg I9II, 6). Daraus habe ich in diesem heft v. $244 \mathrm{I}-2707$ wiedergegeben, ein stück, das für die art dieser texte besonders lehrreich ist. Es läßt deutlich die regelmäßig wiederkehrenden teile des zauberrezepts erkennen: Anpreisung und gebrauchsanweisung, angabe der zauberhandlung ( $\pi \rho \tilde{\alpha} \xi ! s)$ - hier ist es ein rauchopfer (ė $\left.\pi^{\prime} \hat{0} \cup \mu \alpha\right)$, das sonst auch neben der handlung als selbständiger teil erscheint - des zauberspruchs (2.0́\%૬) und der schutzmittel ( uzaxtńpıa) gegen die gerufenen geister. Ferner erkennt man das nachwirken des alten zusammenhangs zwischen geisterbindung und zauberlied (ह่ $\left.\pi \alpha 0 \_\delta \dot{\eta}\right)$ : manche beschwörungen sind zaubergesänge, teils eigens zu magischem zweck gedichtet, teils aus älterer sakraler poesie (s. namentlich die orphischen Hymnen, Orphica 
rec. E. Abcl, Lipsiac et Pragae 1855 ) ibernommen und durch leichte umdichtung dienlich gemacht. Endlich sieht man, wie ein solcher zauberpapyrus entstand. Fiir ein und denselben zweck - hier ist es cin liebeszauber - gab es verschicdene, einander ähnliche rezepte: sie finden alle, wie verschiedene rezensionen desselben textes, nebeneinander platz und werden höchstens durch überleitende formeln lose zueinander in beziehung gesetzt.

Der edition ist Wessely's ausgabe zugrund gelegt; wenn ich an wenigen stellen dem papyrus andere lesungen gebe, so geschicht das auf grund einer scharfen photographic, die ich mir von den platten besorgt habe, welche aus dem nachlasse A. Dieterich's in die Heidelberger Universitätsbibliothek gekommen sind. In den erklärungen sind für die parallelstellen die Indices von Wessely (a. a. O. S. I 54 ff.) dankbar benutzt worden. Den kommentar habe ich ausführlicher gehalten, da für manches noch nicht auf zusammenfassende werke verwiesen werden kann. Vollständigkeit der belege, durchführung der quellenforschung und aufsuchung der gründe für die einzelnen gedanken des zaubers ist nicht angestrebt.

Die zeilen des originals sind durch | abgeteilt, || bedeutet den beginn der fünften zeilen. Am rande stehen die zahlen der ausgabe Wessely's, der aus versehen 244 I doppelt und 2529 gar nicht zählt. Die bedeutung der klammern ist die in literarischen texten übliche, $\langle>$ sind zusätze der herausgeber, [] unrichtige zusätze des papyrus. Abkürzungen sind aufgelöst, ohne daß klammern zugesetzt wären. $P$ bedeutet den papyrus, We Wessely, Wü den herausgeber dieses heftes; vH ist van Herwerden, Mnemos. N. S. XVI I $888,329 \mathrm{ff}$. 


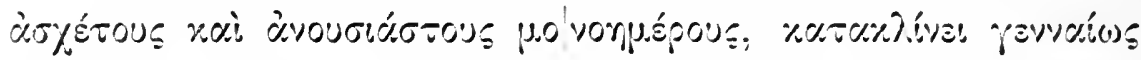

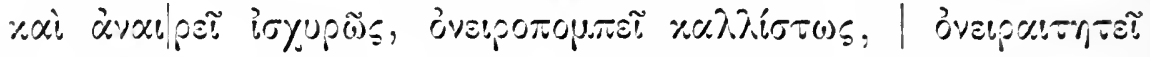

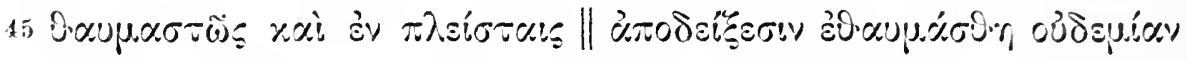

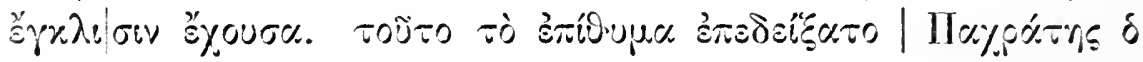

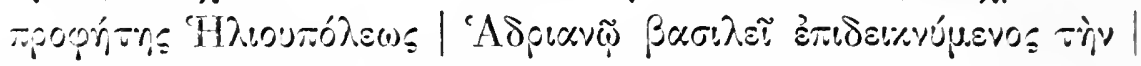

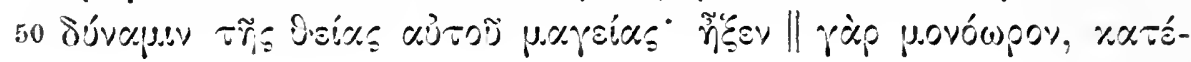

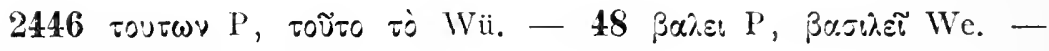

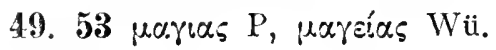

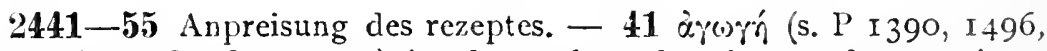
$1928,2006,2708,289 \mathrm{I}, 2943$ ) ist der zauber, der einen anderen zwingt,

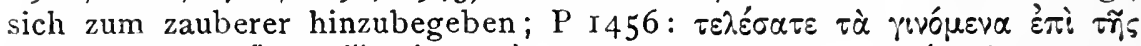

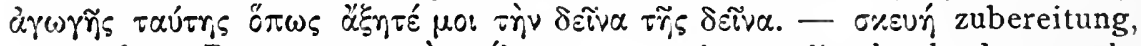

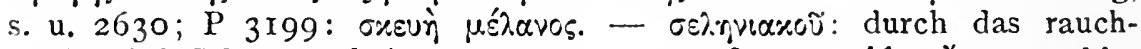

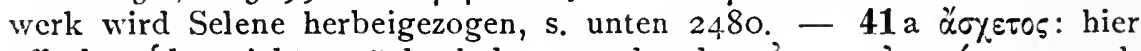
offenbar 'der nicht zurïckgehalten werden kann'. - dvovoíarvos noch

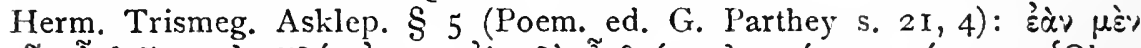

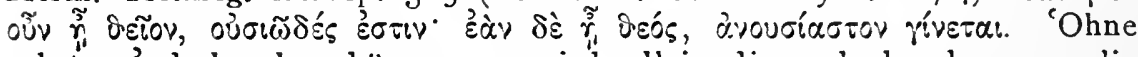
substanz' d. h. ohne körper; es wird allein die seele beschworen, die

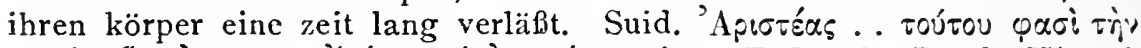

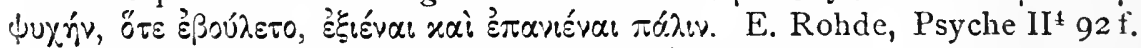
Im folgenden ist von dieser eigenart der $\alpha \gamma \omega \gamma \eta \dot{n}$ nicht mehr die rede. y.ovorifuspos 'an demselben tage', an dem der zauber vorgenommen wird, stellt sich der àyórevos ein. Diese bedeutung ergibt sich aus dem gegen-

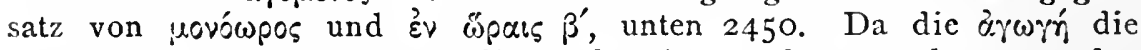
wunderbare macht besitzt, die seele eines nebenmenschen vor den zauberer zu zwingen, so werden ihr auch weitere, ähnlich einen menschen beeinflussende kräfte zugeschrieben: ihn krank zu machen (xaraxikive:y

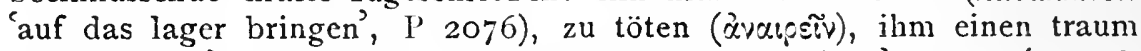

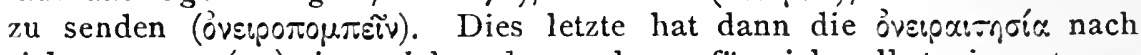
sich gezogen (44), in welcher der zauberer für sich selbst einen traum auswirkt. - 45 š $\gamma \times$ i. 015 Neigung, abweichung vom graden wege, der zum Ziele führt. - $\mathbf{4 7}$ Ilayoó.ms ist identisch mit Pankrates, von dem Lukian Philops. $34 \mathrm{ff}$. allerhand wundergeschichten erzählt, s. Reitzenstein Hellen. Wundererz. 5 ; Abt, Die Apologie des Apuleius, Rel. gesch. Vers. Vorarb. IV 227. Römische Kaiser ließen sich öfter zauberkünste vorführen, so Vespasian von Eleazar, Jos. ant. VIII 2, 5. Hadrian, der uibernatürliches wissen hochschätzte (Vita Hadr. I6; C. Wessely, Wiener Studien VIII I88), wird bei seinem aufenthalt in Ägypten I $30 \mathrm{O}$. Chr. sich diesen propheten haben lrommen lassen. Das jahr ist der terminus post quem für die schlussredaltion des papyrus. - 49 irsías: die zauberei ist göttlich, weil ihr wissen von den göttern stammt und sie dem ausübenden göttliche kraft verleiht. -

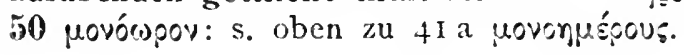




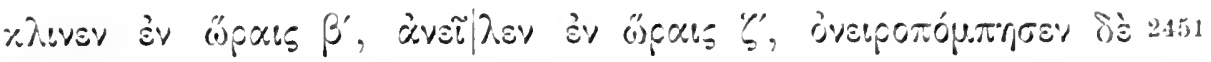

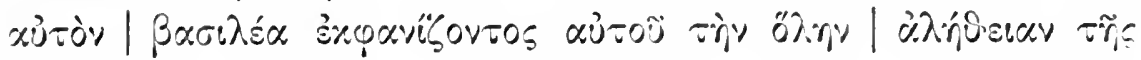

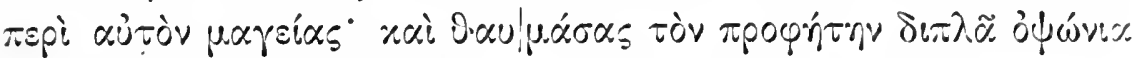

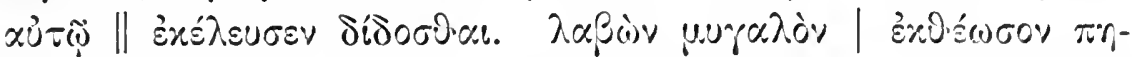

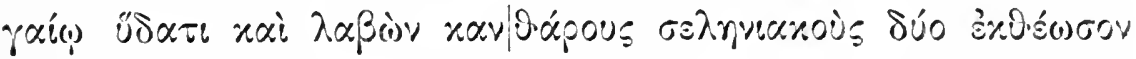

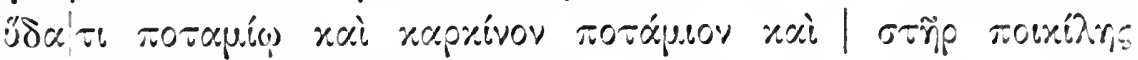

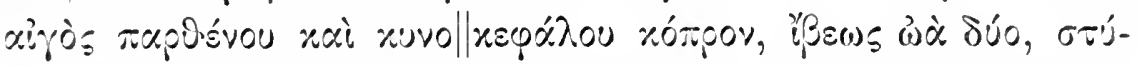

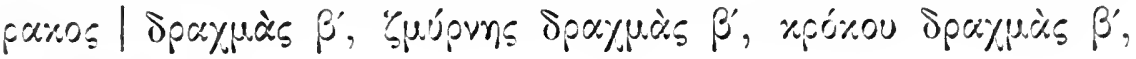

2450. $51 \omega$ und $\rho$ in ligatur als abkürzung von ש̈pa:s P. 51 a $\tau^{-} \mathrm{P}$, eine am schluß der zeile häufigere abkürzung. - $52 \varepsilon \% \delta \omega-$

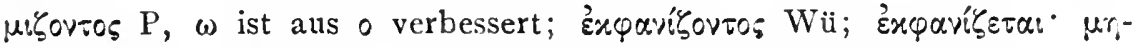

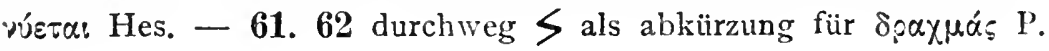

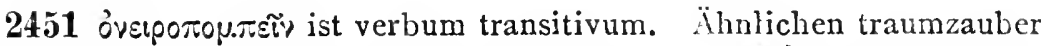

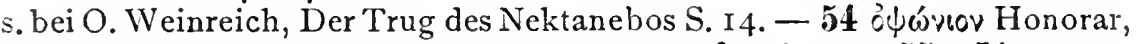
van Herwerden, Lex. graec. supplet. et dial. II ${ }^{2}$ IOSI. - 55- 71 Rezept

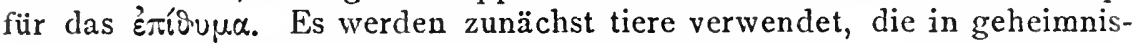
vollen beziehungen zum monde stehen und daher die mondgöttin an-

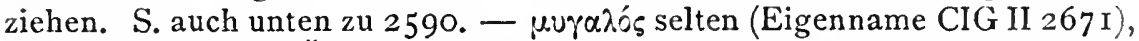
üblicher $\mu \cup \gamma \alpha \lambda \tilde{\eta}$. Über den aberglauben von der spitzmaus s. E. Riess

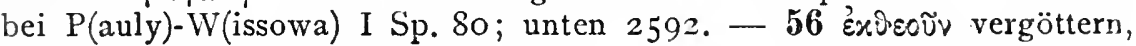

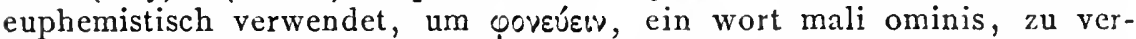

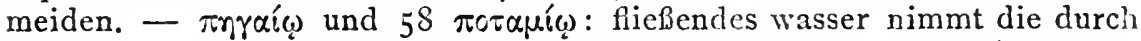
die tötung entstehende befleckung weg; E. Rohde, Psyche $\mathrm{II}^{4} 405$. -

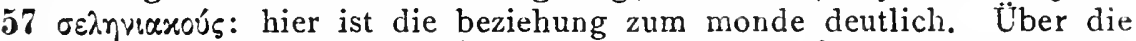

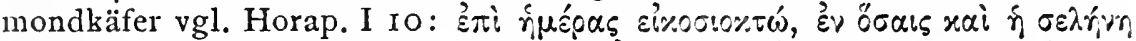

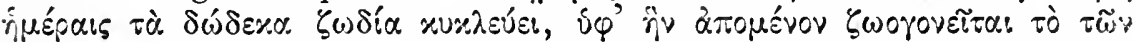

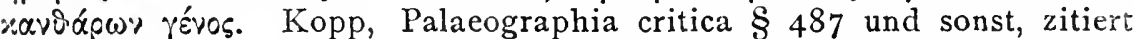
von Wessely S. I78 u. xávíapos. - 58 Zur verwendung von krebsen in der medicina popularis s. Riess a. a. O. 74. Der Selene als astrologisches zeichen geweiht, Roscher, Selene und Verwandtes I09. 59 Die ziege ist das reittier der Selene (Roscher, Selene und Verwandtes 43) und das heilige tier der Hekate, s. P 2884; Hekate

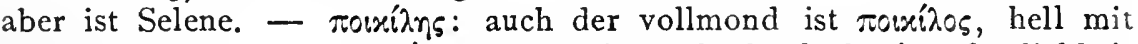

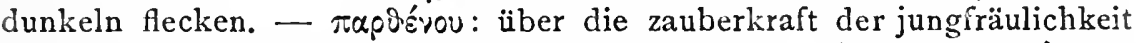

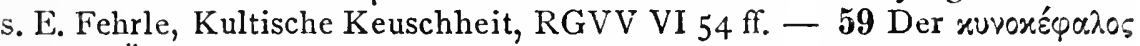
war in Ägypten mit den mythen der mondgöttin verbunden, s. Roscher, Selene 107 und unten 2600 . - 60 ' $\beta \varepsilon \omega s:$ s. unten 2587 ; Lyd. de mens.

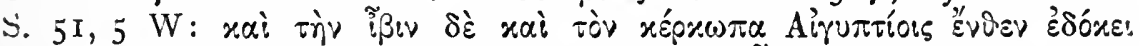

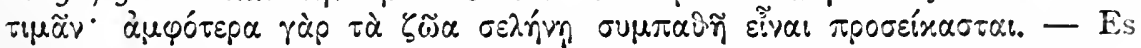
folgen pflanzenstoffe, die meist auch sonst als rauchwerk dienen. 61 Guúpuns: zur schreibung s. E. Mayser, Gram. der griech. Pap. aus der Ptol.-zeit 204. 


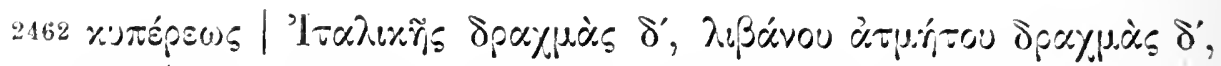

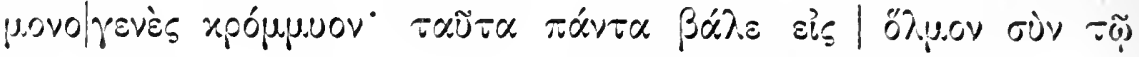

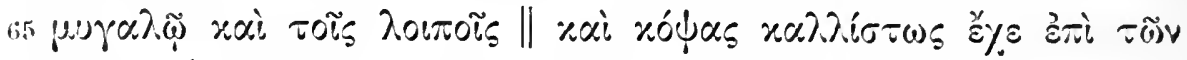

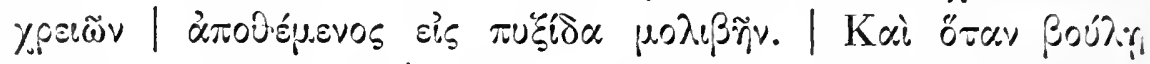

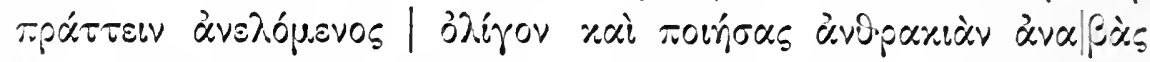

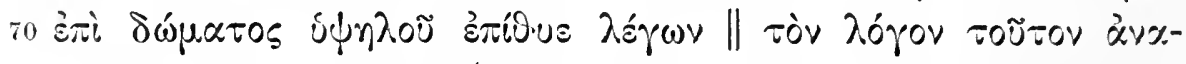

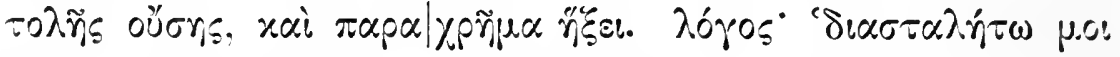

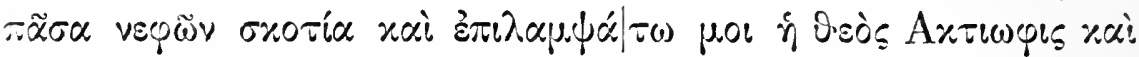

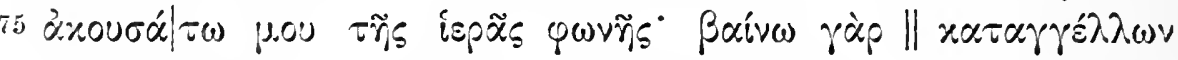

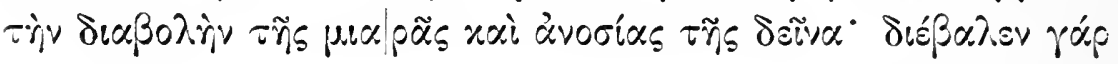

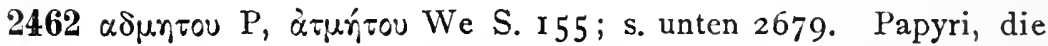
in Ägypten geschrieben sind, verwechseln media und tenuis häufig,

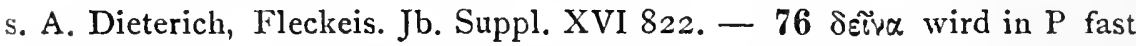
stets abgekürzt: $\Delta$ mit einem strich unter der mitte der basis.

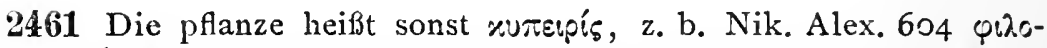

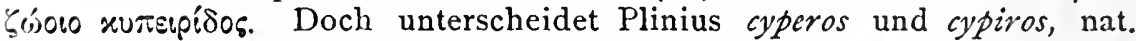
hist. XXI II5; des letzteren wurzel cyperida vocant, magni in medicina zisus (I I 7). Plinius nennt unter den fundstellen der pflanze Italien nicht, wohl aber Ägypten. Über ihre beziehung zu Selene s. Roscher, Selene 56. -

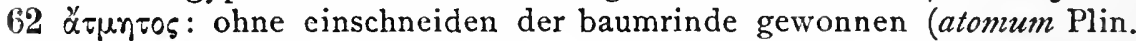

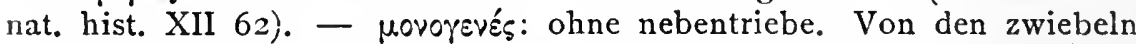

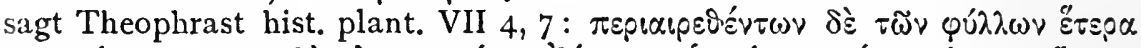

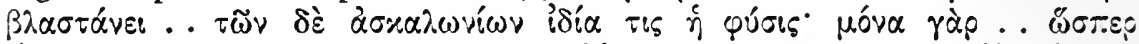

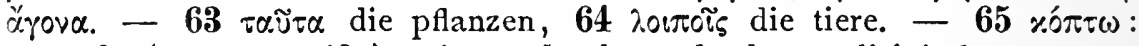
stampfe (s. unten 2680): ein ausdruck auch der medizinischen rezepte (z. b. Dioskor. IV I 54), an deren sprache hier vieles erinnert. - z. $0 . \lambda$ -

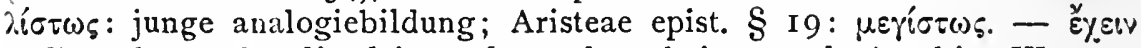
aufbewahren, für die dringenden gelegenheiten, vgl. A eschin. III 220:

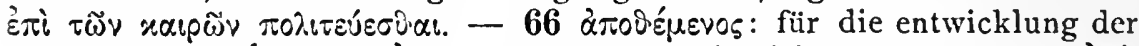
bedeutung von 'apotheke' zu beachten. - 67-71 Verwendung des '̇ $\pi$ '

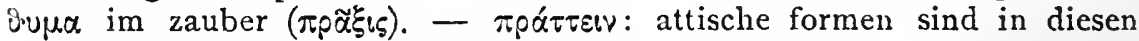
texten selten; gerade bei diesem verbum, das von der vollziehung der

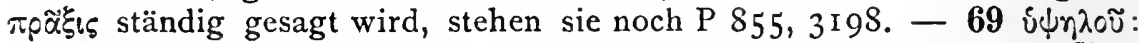

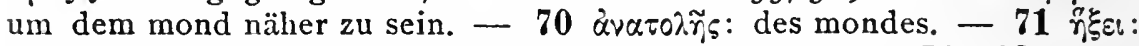

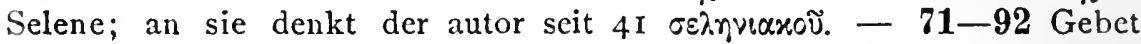

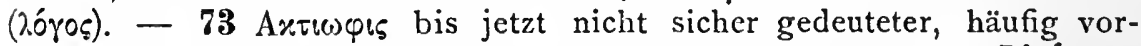
lsommender name einer göttin; s. unten 2484. 260I. 2664. - 74 iep a.s: s. oben 49 zu bría.s. - Zu $\beta \alpha i v \omega$ mit dem part. vgl. Kühner-Gerth,

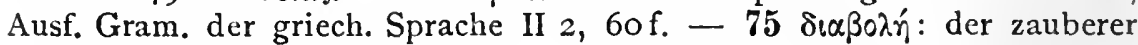
will, daß die göttin die ăyouévm quälen und $z u$ ihm hinscheuchen soll. Damit die göttin sich dazu hergibt, wird ihr vorgeredet, dab jenes weib sich gegen die göttin vergangen habe. Dadurch wird der zorn der Selene 


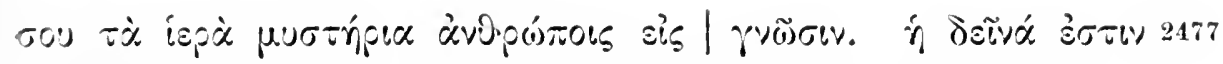

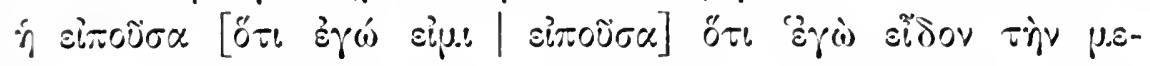

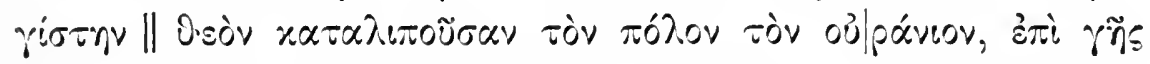

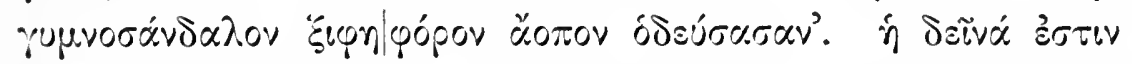

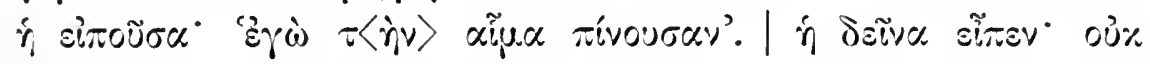

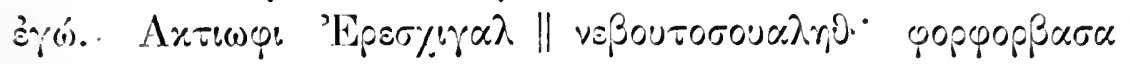

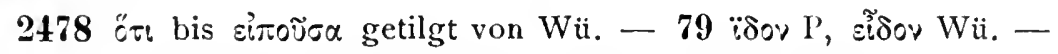

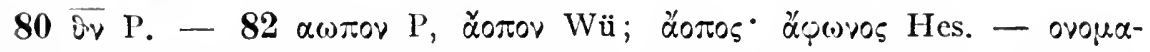

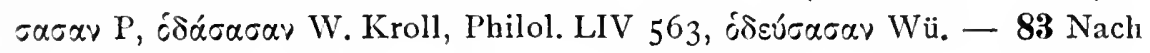

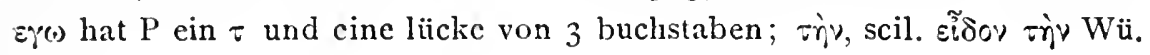

und ibre rache geweckt: um die gottlose zu haschen, beginnt sie das

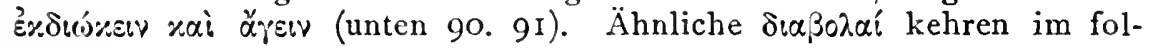
genden wieder, $2574 \mathrm{ff}$., $2622 \mathrm{ff}$.; sonst heißt das wort, daß der zauberer das objekt des zaubers verleumdet, hier, daß die betreffende die göttin verleumdet hat. - 76 Für $\delta$ siv $\alpha$, dem das N. N. moderner zaubertexte cntspricht, wird im einzelnen falle der zutreffende name eingesetzt. Nur an eine frau wird gedacht, weil die $\grave{\gamma} \omega \gamma^{\prime} \eta^{\prime}$ meist im liebeszauber ver-

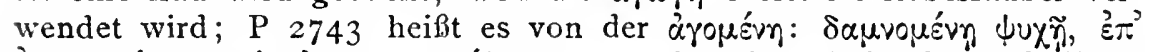

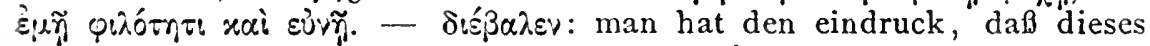

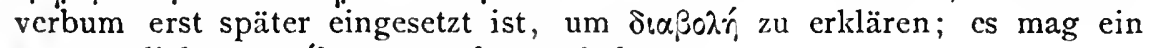
ursprüngliches $\pi \alpha \rho \varepsilon \delta \omega x \varepsilon \nu$ verdrängt haben.

$2477 \mu v \sigma \operatorname{rop}_{0}<$ : ihr ausplaudern an ungeweihte ist religionsfrevel,

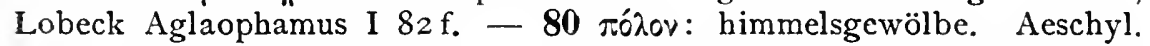

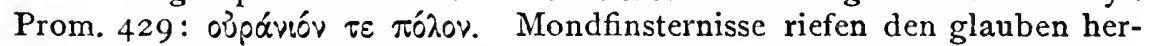
vor, daß die göttin ihren himmlischen sitz verläßt, und auf erden wandelt. Weil die mondgöttin diese bewegungsfreiheit besitzt, kann sie vom zauberer herabgezogen werden, wie es hier geschieht; s. Abt a. a. O.

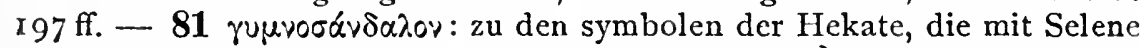

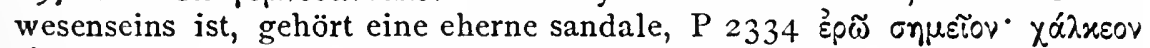

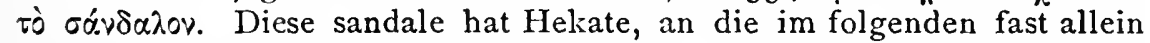

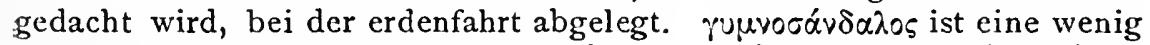

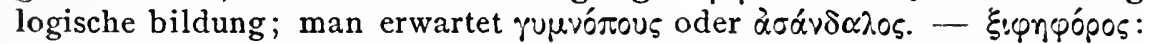
das schwert hat Selene gleichfalls deshalb, weil sie Hekate ist, s. Antikes

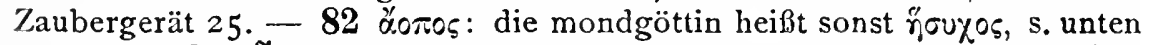

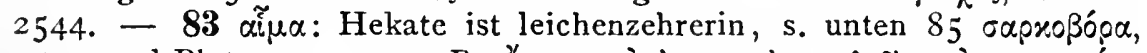

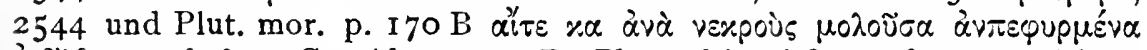

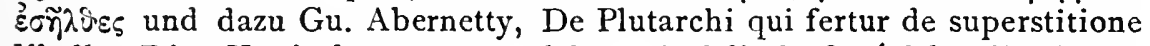
libello, Diss. Königsberg I9 I I, $56 \mathrm{f}$. - Auf die $\delta \propto \alpha \beta 0 \lambda \eta_{1}$ folgt die eigentliche beschwörung. Die göttin wird mit namen angeredet, die noch

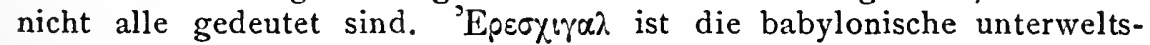
göttin, in dem folgenden namen steckt vielleicht der babylonische gott Nebo, s. R. Wünsch, Antike Fluchtafeln (in diesen texten heft 2o) zu nr. 4 z. 42, ebenda zu ßopßopọópßa 'die sich vom kot nährt': davon

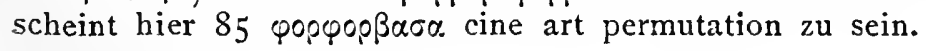




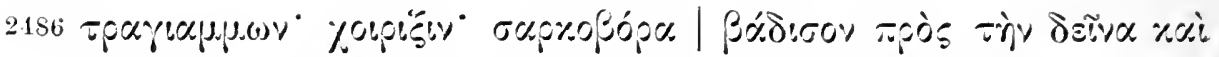

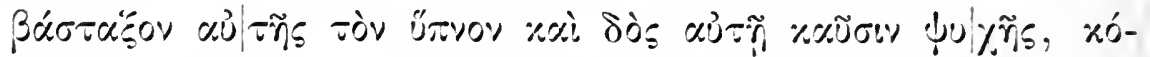

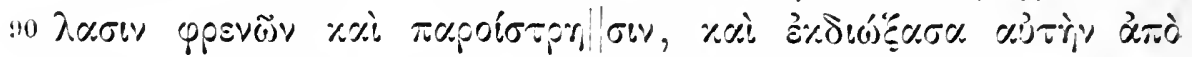

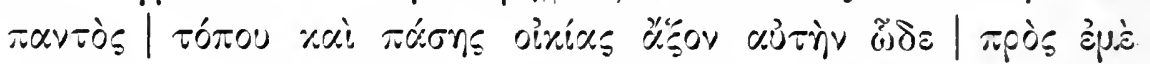

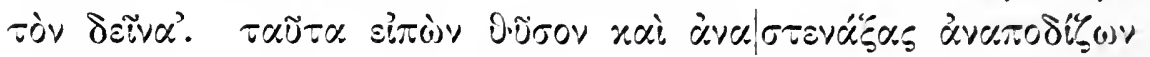

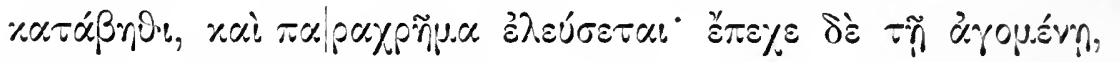

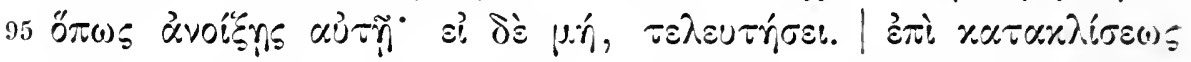

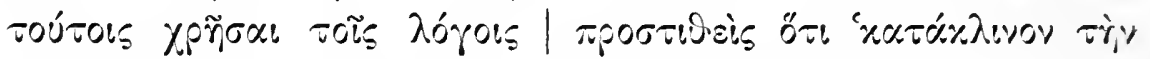

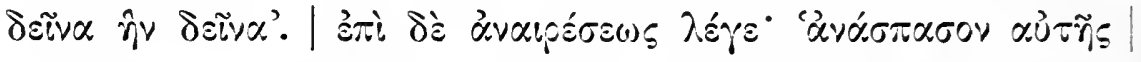

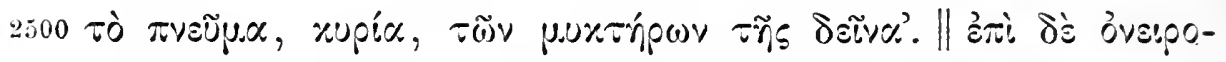

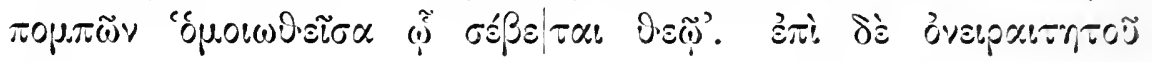

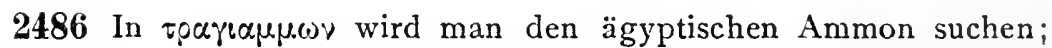
tpapt- wird kaum mit tpáros zusammenhängen, Ammons heiliges tier ist

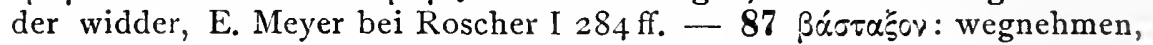

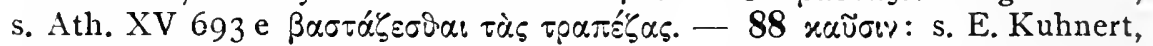

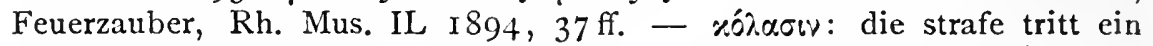

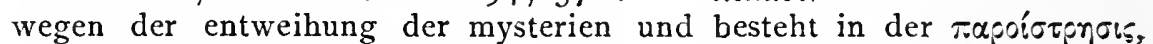
in der unruhe des wahnsinns (s. H. Lewy Oistros, Roscher III 803 f.), der die betroffene dem magus zutreibt. Von der inneren glut, die Eros

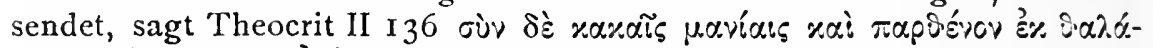

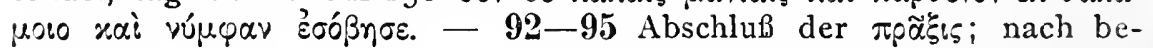
endigung des gebetes wird noch einmal rauchwerk ins feuer geworfen

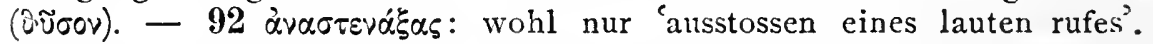
Das macht die gottheit aufmerksam und zieht sie herbei, A. Dieterich,

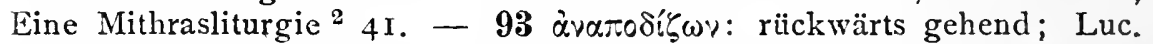
Nec. 7 nach vollendung der katharsis führt der zauberer den entsühnten

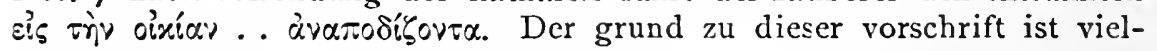
leicht die furcht, daß ein zurückschreiten in der üblichen weise ein zurücknehmen, also ungültigmachen der zauberhandlung bedeute; s. Hor.

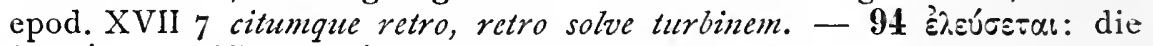

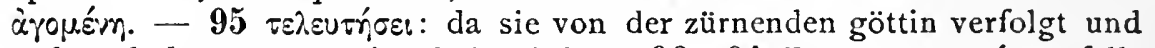

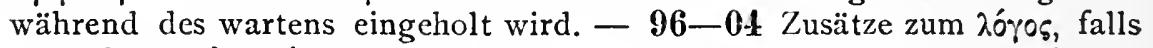
er nicht zur $\dot{\gamma} \gamma \omega \gamma \eta \dot{n}$, sondern zu einem andern der oben $42 \mathrm{ff}$. angegebenen

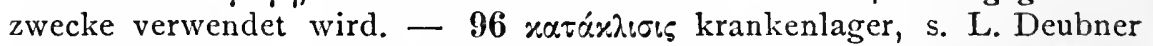

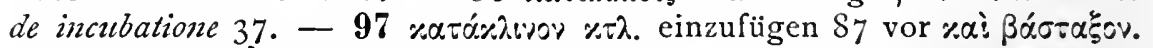

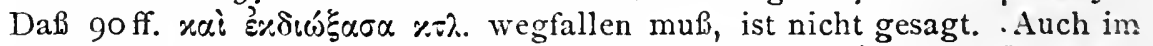

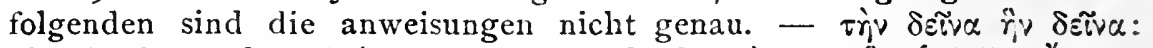

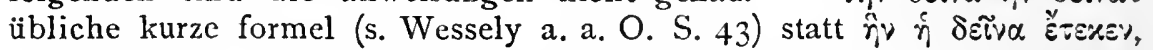
zur bezeichnung der verzauberten nach der mutter (s. dazu Antike Fluchtafeln nr. 2 z. 3). - 99 xupía: auch heidnische anrede der gottheit,

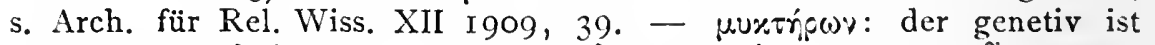

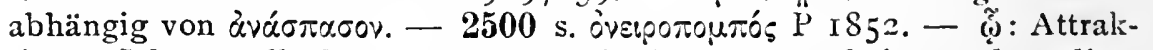
tion. Selene soll der träumenden als der gott erscheinen, dem dicse

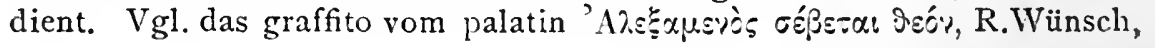




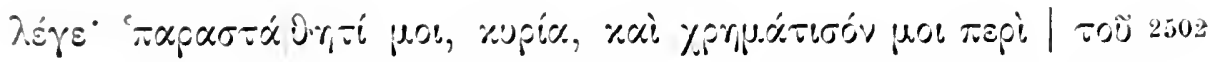

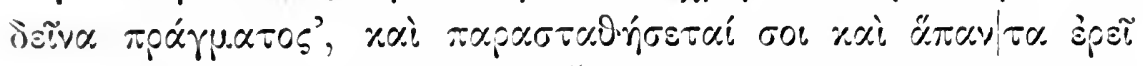

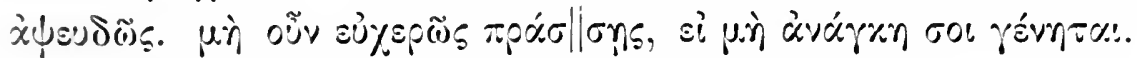

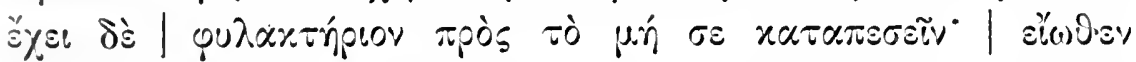

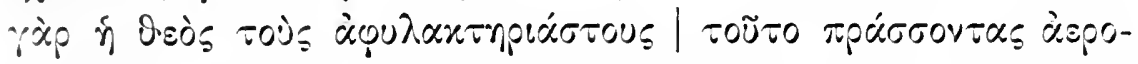

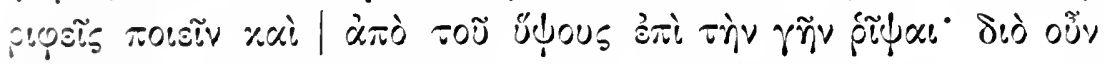

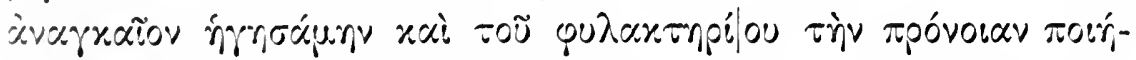

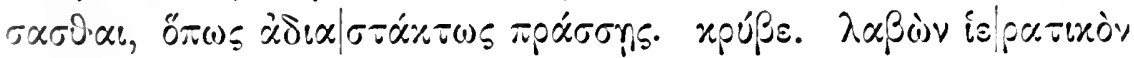

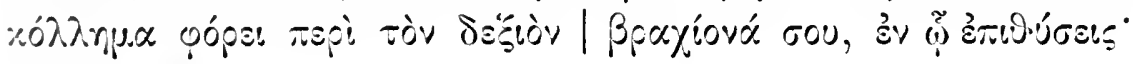

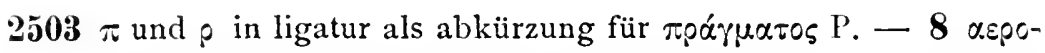

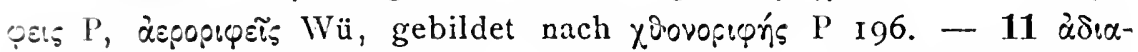

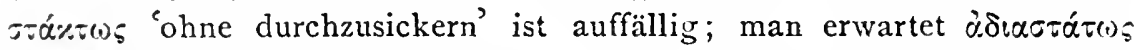

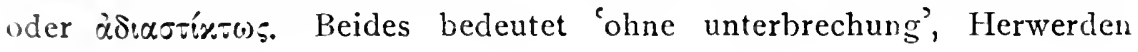
Lex. I 27.

Sethianische Verfluchungstafeln II I. Dieser zusatz tritt an stelle dessen, was 87 auf $\beta$ ádisov folgt. - 1 s. Pap. Leid. V, VI I 5 (Fleckeis. Jahrb. Suppl. XVI 805) óverpatontóv. L. Deubner de incub. $30 \mathrm{ff}$.

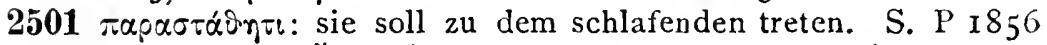

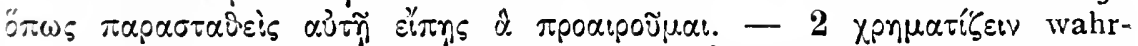
sagen, s. Wessely a. a. O."S. 206. Das jverpartク̃ó bezweckt also

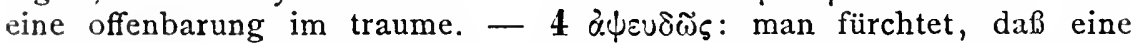
solche traumerscheinung auch unwahres künden kann (s. den traum Agamemnons, Il. II $26 \mathrm{ff}$ ); auf dem Scarabaetus von Tusculum, Bull.

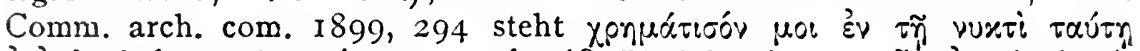

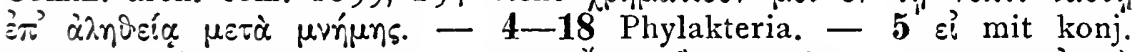

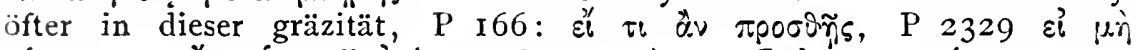

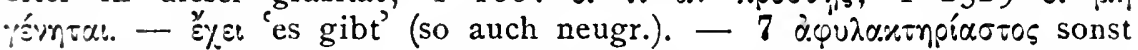
nicht belegt. Die stelle zeigt deutlich, wessen sich die zauberer von den geistern, die sie riefen, versahen. - 11 iǹ

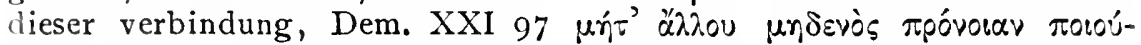

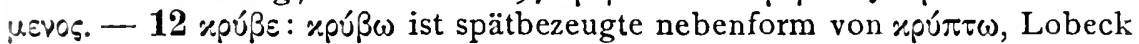
Phryn. 3I7. Geheimhalten der zaubermittel wird den adepten häufig zur pflicht gemacht: meist dürfen sie nur einem einzigen tradiert werden, dem eigenen sohn, s. A. Dieterich, Mithrasliturgie ${ }^{2}{ }^{2}$. So heißt es $I_{7}$

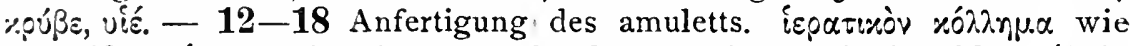
$P$ 2068. xód.n. nua ist das aus einzelnen streifen geklebte blatt (Poll.

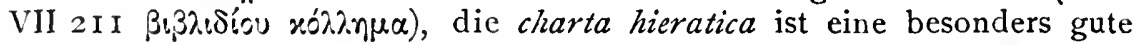
sorte papyros, zu diesem zweck geeignet, weil sie religiosis tantum voluminibus dicata ist, Plin. nat. hist. XIII 74. - pópst: die meisten amulette werden am leib getragen, Antikes Zaubergerät S. 39. Hier muß der rechte

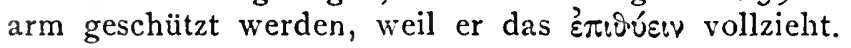




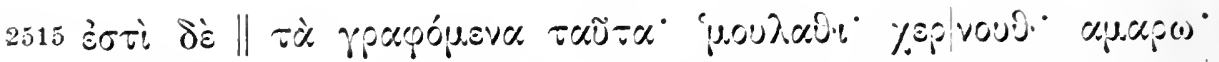

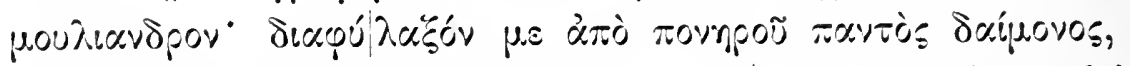

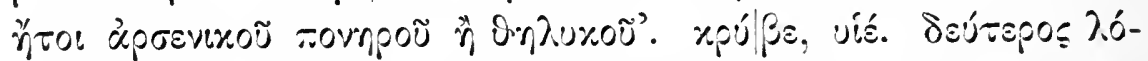

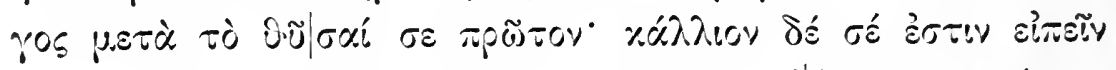

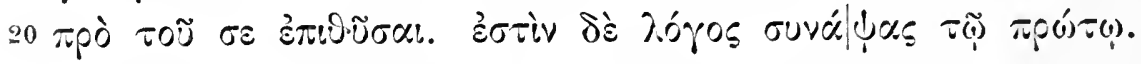

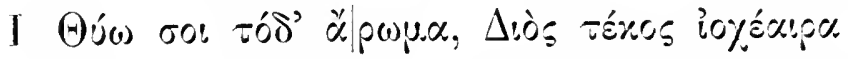

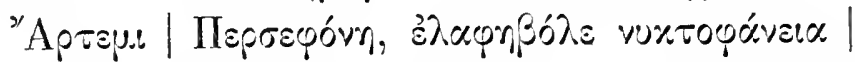

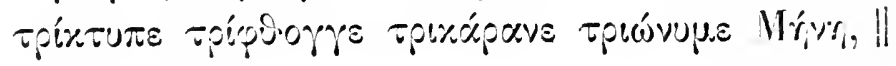

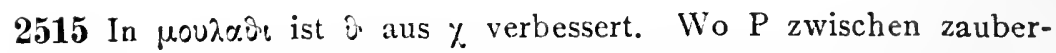
worten einen punkt setzt, ist er in der ausgabe beibehalten worden. -

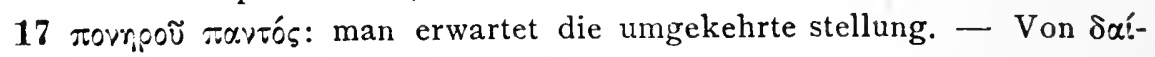

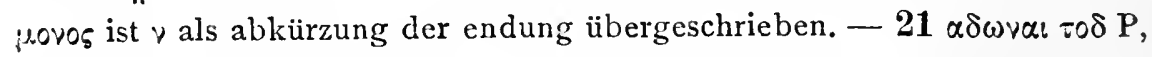
verbessert von We nach 2852 . - Vers 2-6 kehren P 28I 8 f. in besserer

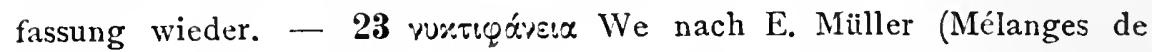
littérature grecque I868, $437 \mathrm{ff}$.) $\mathrm{zu} 28 \mathrm{I}$. - - Vers 3-9 ediert von

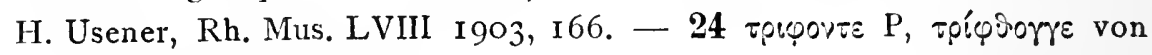
We nach 2820 korrigiert.

2515 Diese zaubernamen eines gottes, der noch mächtiger ist als Selene, sind nicht deutbar (A $\mu \alpha \rho \alpha$ P 827, dazu Dieterich Mithraslit. ${ }^{2} 22$ I). Der text des gebetes ist der übliche, s. z. b. unten 2698 und P $1079 \delta$ i $\alpha$ -

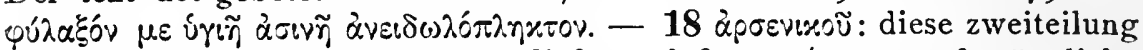

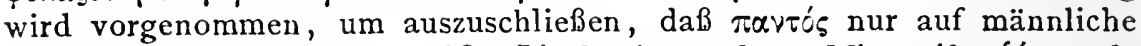

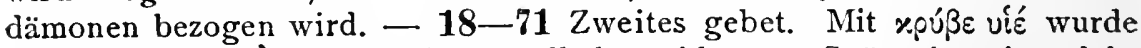
ursprünglich die 'A $\gamma \omega \gamma$ ' wirkungsvoll abgeschlossen. Später hat ein redak-

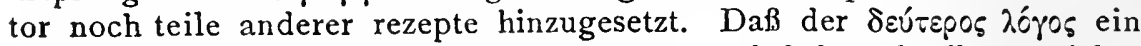
jüngerer zuwachs ist, geht schon daraus hervor, daß der schreiber unsicher ist, an welcher stelle der handlung er gesprochen werden soll, $18 \mathrm{ff}$.: der

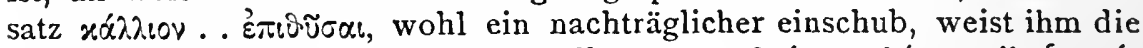

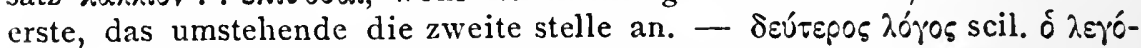

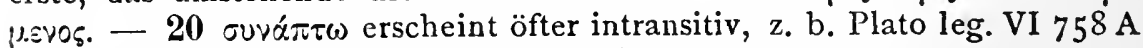

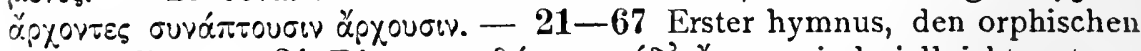

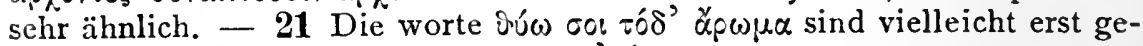

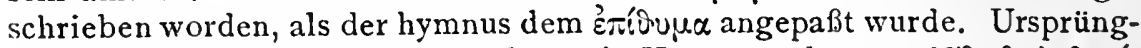
lich mag der anfang gelautet haben wie Hymn. orph. 9, I $x \lambda$ ขึi

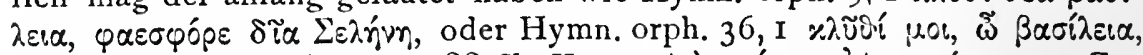

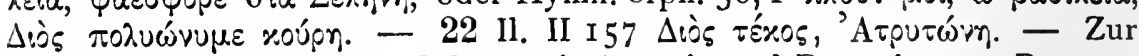
gleichsetzung von Hekate-Selene mit Artemis und Persephone s. Pergam.

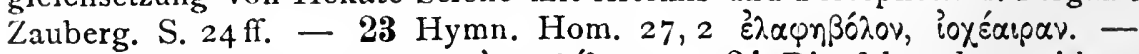

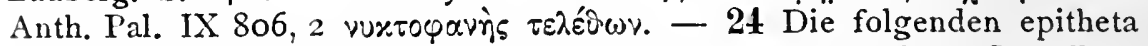
beziehen sich auf die dreileibigkeit der Hekate, s. Ant.Zauberg. S. $23 \mathrm{ff}$. - 


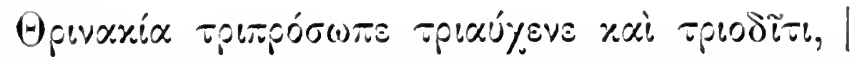

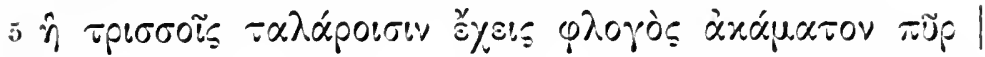

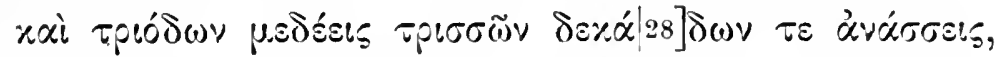

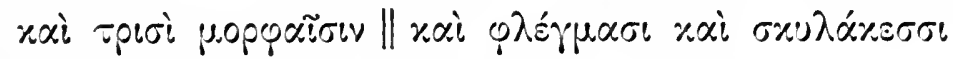

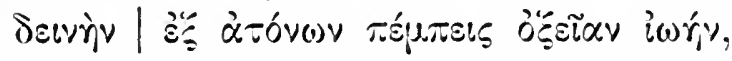

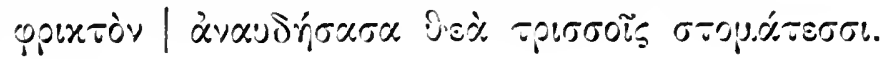

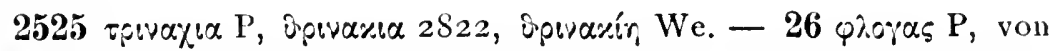

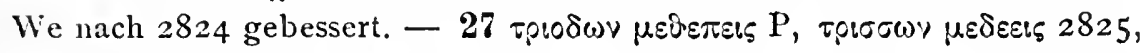

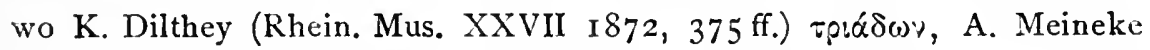

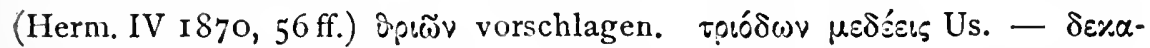

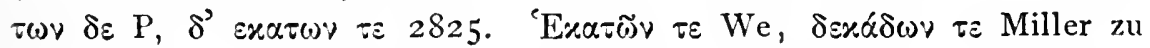

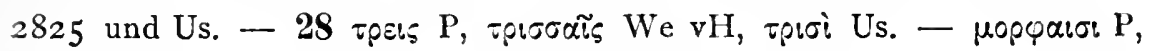

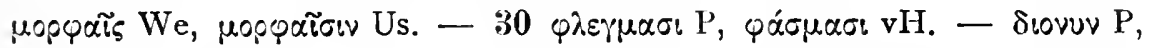

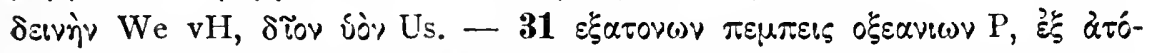

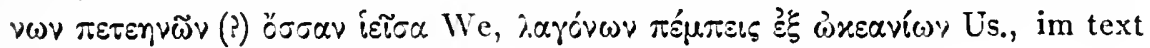

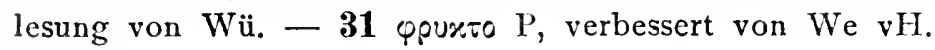

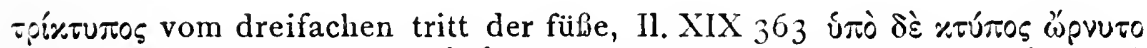

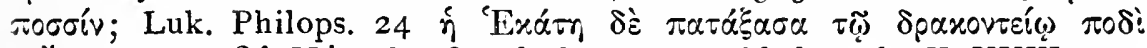

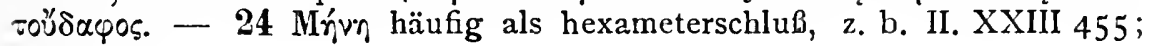
P 2815.

2525 Op:vaxía ist eine nebenform von 'Tptvaxpía (Etym. magn. 456,8

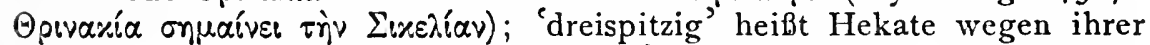

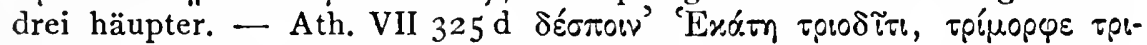

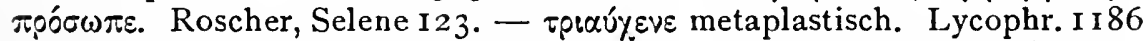

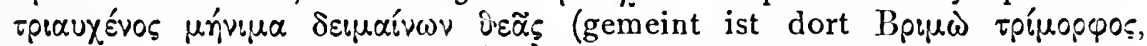

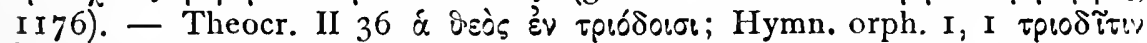

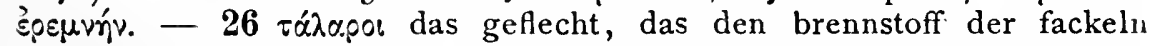
umschlieBt. Hekate ist mit solchen fackeln ausgestattet Ant. Zauberg.

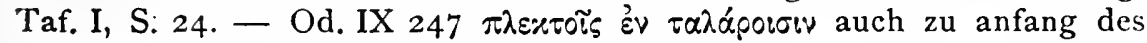

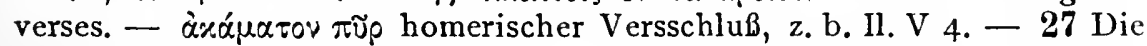
dreifache dekade ist der monat. s. das Paroemiographenexzerpt bei

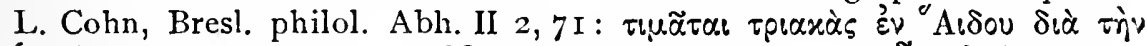

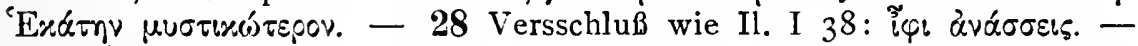

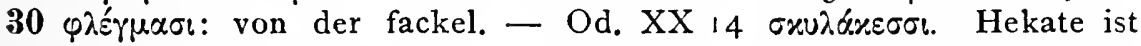
von einer meute gespenstiger hunde umgeben, Fleckeis. Jb. Suppl. XXVII

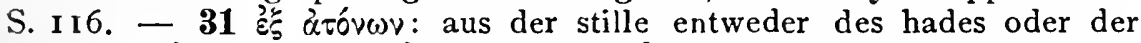

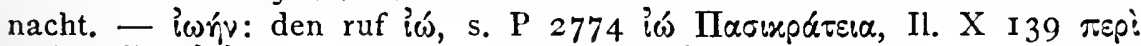

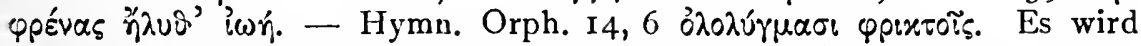
eine schilderung der aus dem hades unter getöse (Verg. Aen. VI 255: sub pedibus mugire solum) ausfahrenden göttin gegeben. 


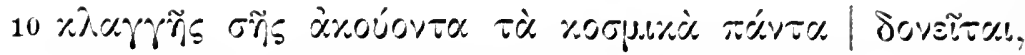

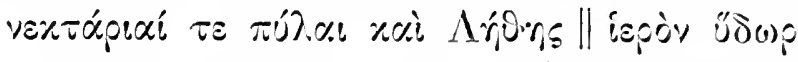

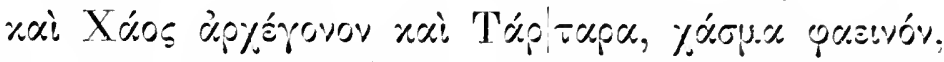

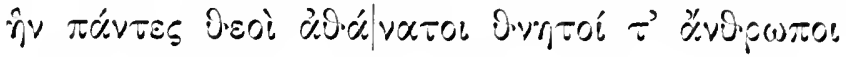

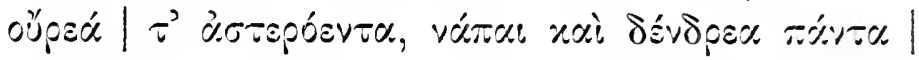

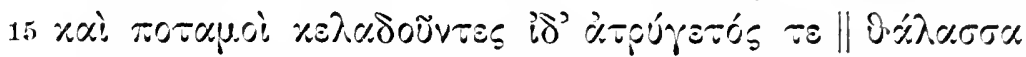

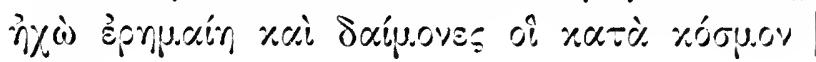

Vers IO-I 7 ediert von A. Dieterich, Fleck. Jb. Suppl. XVI 775.-

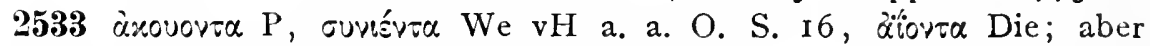
kürzung des diphthongs vor vokal ist möglich, Pind. Pyth. VIII 35 'ixyeú(.) v

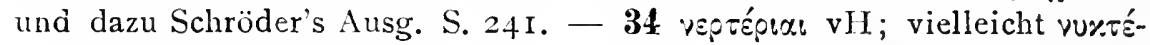

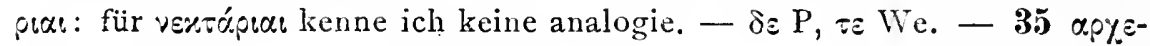

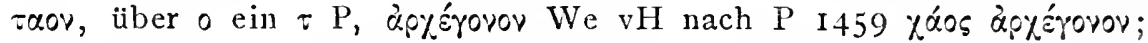

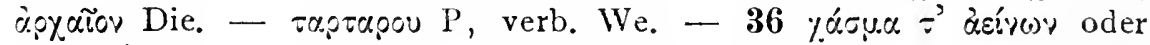

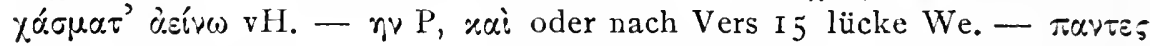

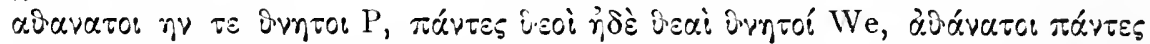
junroí Die, im text lesung von Wü. - $37 \tau \varepsilon \mathrm{P}, \tau$ We. - 38 - $\mathrm{P}$,

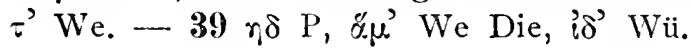

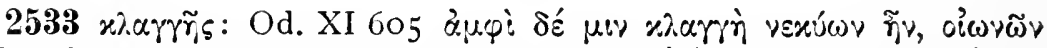

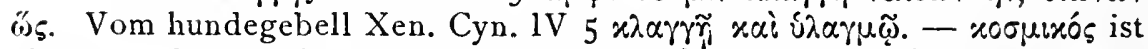

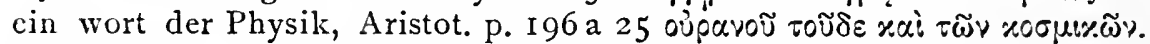
Dergleichen ist nach Poseidonios in die religiöse Poesie gekommen (A. Dieterich, Mithraslit. ${ }^{2}$ 202): das ist ein terminus für die zeit der

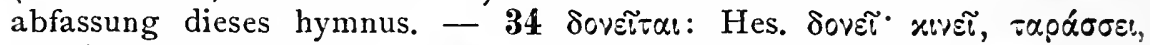

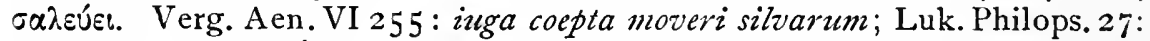

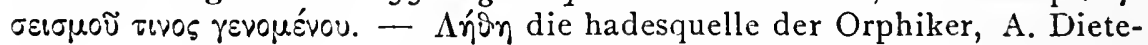

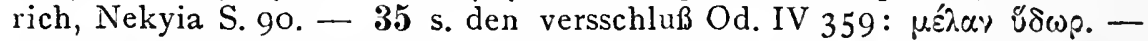
Vergil nach griechischer vorlage Aen. VI $265 \mathrm{Di}$ quibus imperium est animarum umbraeque silentes | et Chaos et Phlegethon, loca nocte tacentia late. E. Norden in seinem kommentar zitiert dazu obige stelle. - Xáos der gähnende schlund der tiefe; das beiwort nach Hes. Theog. I I 6 n̆ro:

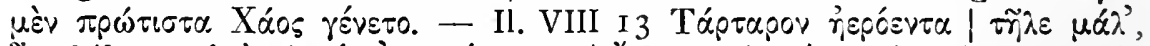

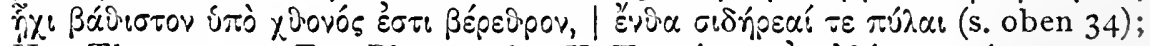

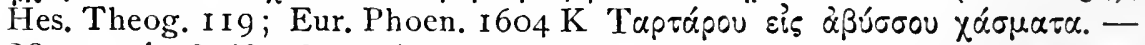

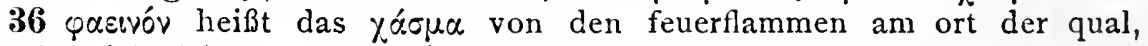
Dieterich Nek. 35 und 201 (Verg. Aen. VI 742 scchus aut exuritur igni). 37 oúpea: die ionische form ist aus dem epos beibehalten, Il. I 157

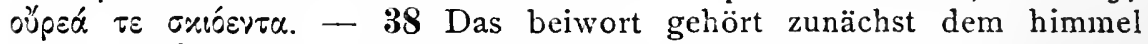

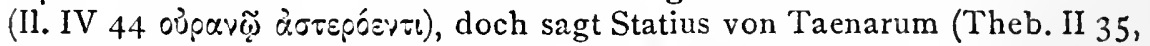
vgl. W. GundeI RGVV III 210 ) fessis insiditur astris. - Od. V 238

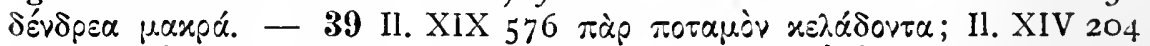

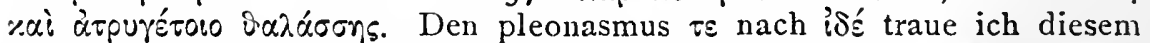

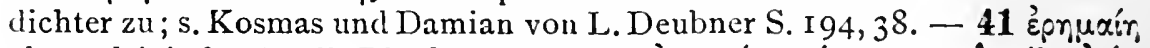

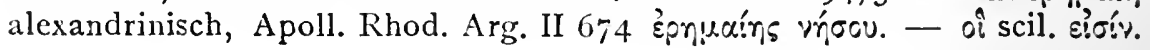




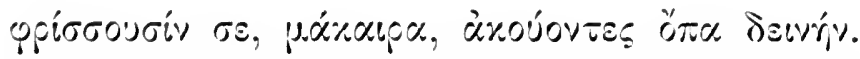

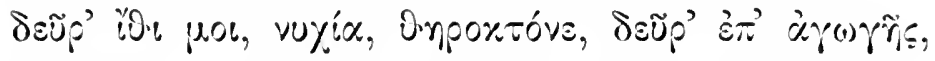

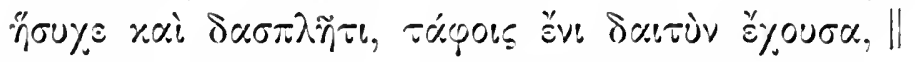

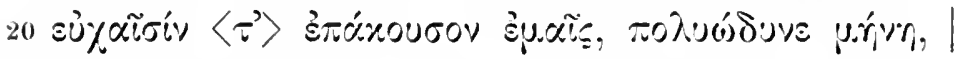

45

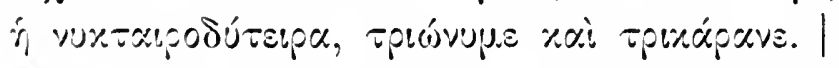

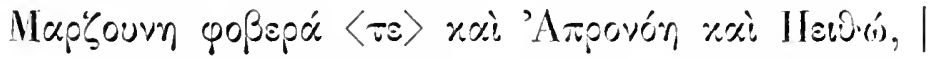

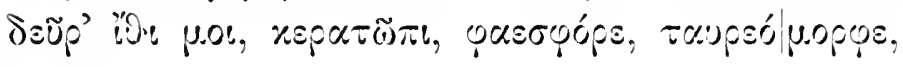

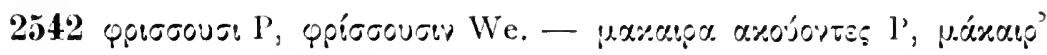

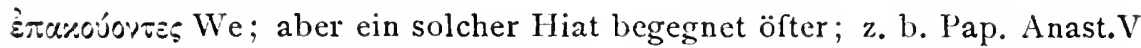

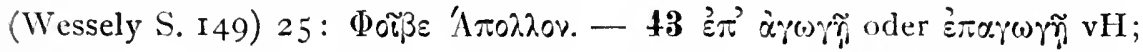

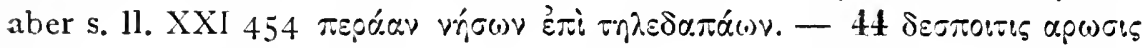

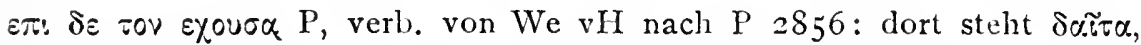

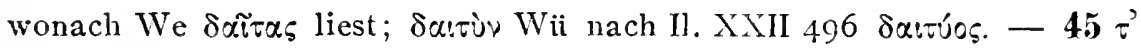

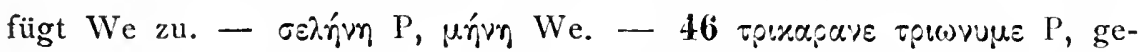
ändert von We; vielleicht ist der echte schluß verloren gegangen und

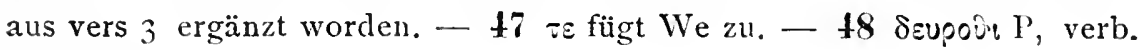
von We.

$25 \$ 2 \mathrm{Daß}$ die dämonen vor der gottheit zittern, ist typisch, Dieterich

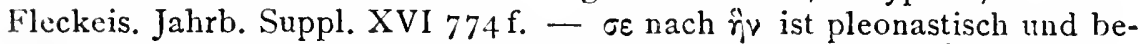

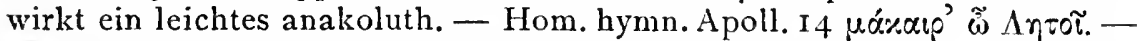
43 Nuyía ist name der Hekate auf dem Pergamenischen Zaubergerät,

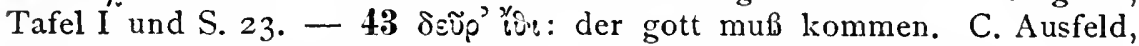
De graec. prec. quaest., Fleckeis. Jb. Suppl. XXVIII $5 \mathrm{I} 6 \mathrm{f}$. - Hymn.

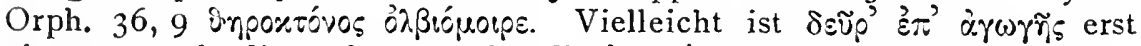

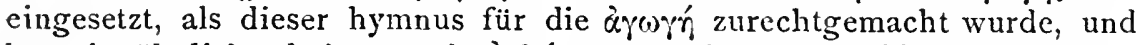
hat ein ähnliches beiwort wie òßßóporpe verdrängt. - 44 Theokr. II I I

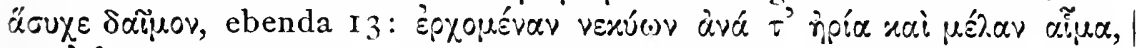

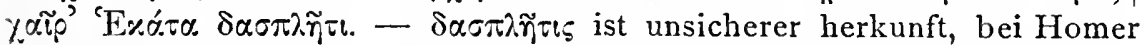
beiwort der Erinys (Od. XV 234), also wohl 'furchtbar' (s. Hesych unter

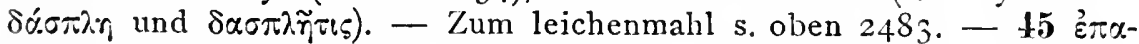
zoústy mit Dat. öfter in den zauberpapyri, s. Wessely S. I 7I. - Theocr.

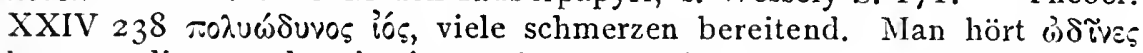
heraus, die mondgöttin ist auch göttin der geburt, PW II I347.- 46 'Die nachts aufgeht und untergeht' vH. - 47 Map'50um sieht, wie Chr. Bartholomae mir bestätigt, iranisch aus. Persisches in solchen hymnen hat P 29I9. 23, s. B. Kuster a. a. O. 68. 70. - Mpovón ist Hes. Theog. 26I eine Okeanide; 'Atpovón ist die 'nicht vorausbedenkende'. Hekate ist auch Aphrodite (s. 57 und $\mathrm{P} 2832$ ) und der liebe das nichtvorausbedenken eigentümlich. Aphrodite wird Hymn. Orph. 55, 9 an-

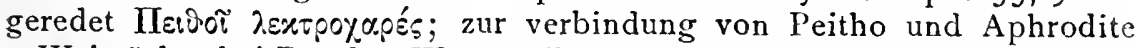
s. Weizsäcker bei Roscher III I 797 ff.; Roscher, Selene 82 f. - 48 «sp б (o) $\pi$ : heißt Selene auch Manetho IV 9I; Artemis durch die hörnerartige 


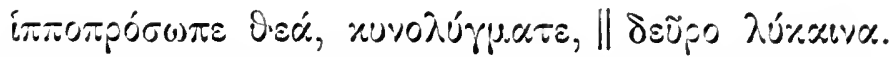

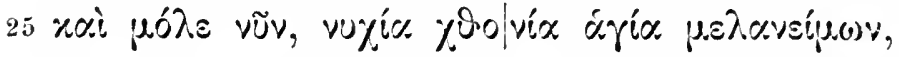

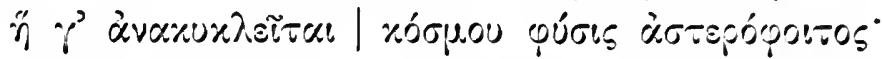

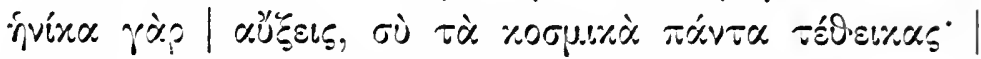

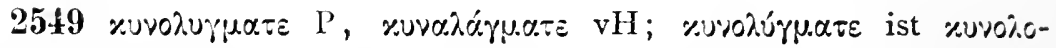

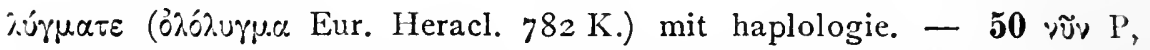

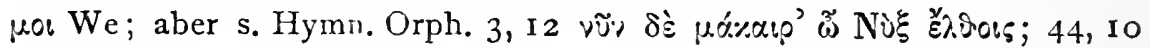

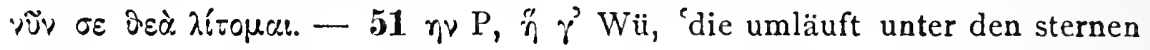
als natur der welt', denn wie sie zunimmt, nehmen auch die dinge der

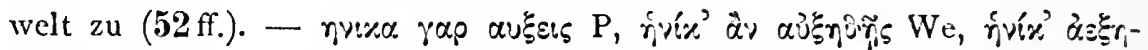
uñs vH; aber die dehnung von ráp durch den ictus ist unanstössig, z. b.

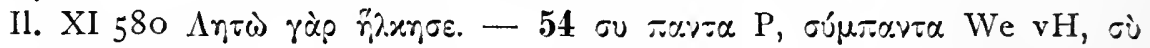

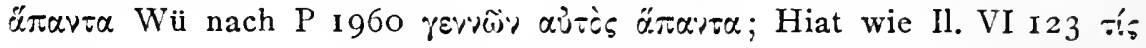

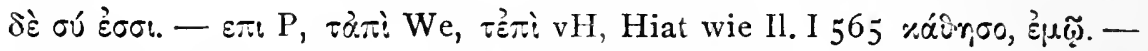

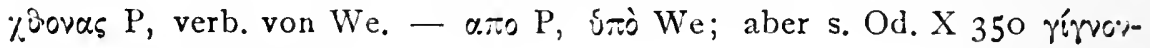

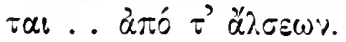

sichel als mondgöttin bezeichnet bei S. Reinach, Répert. de la statuaire

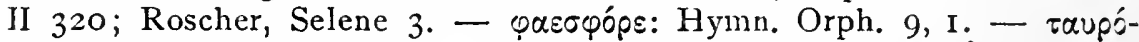

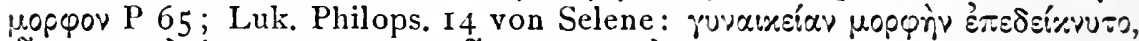

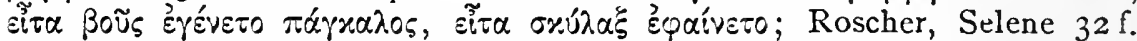
Gerade im dienst der unheimlichen Hekate haben sich viele spuren alter theriomorpher vorstellungen gehalten, ohne dab wir überall deren herkunft und die beziehungen dieser tiere zur gottheit deutlich erkennen; Usener, Rhein. Mus. XXIII I868, $334 \mathrm{ff}$. handelt ausführlicher darüber.

2549 Die roßgestalt des mondes erinnert an die pferdeköpfige Demeter Melaina in Phigalia, Paus. VIII 42,3. - Über die hunde der

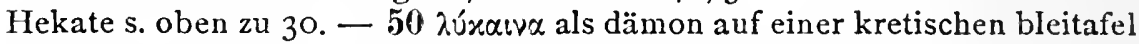
Rhein. Mus. LV S. S6 Z. 6. - vuxía s. oben 43. - xôvia: im innern der erde hausend, s. IG III 3 (Defixionum tabellae Atticae) p.VI; Roscher, Selene 48; Usener, Rhein. Mus. XXIII, 358. - 51 ushaveíu.

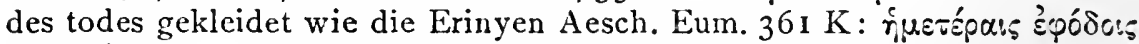

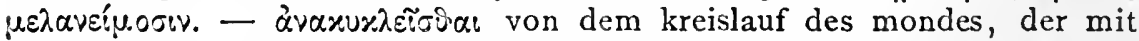
zunahme und abnahme verbunden ist, so wie die dinge des weltalls sich im kreislauf befinden und dabei zu- oder abnehmen, s. Macrob. Somn. Scip. I I I, 7. Ausgeführt wird das im folgenden nur für die zunahme; vielleicht sind die verse über die abnahme weggefallen. - 52 púaı: wohl gleichfalls erst nach Poseidonios zum religiösen begriff geworden,

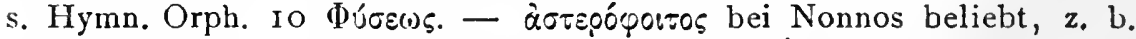

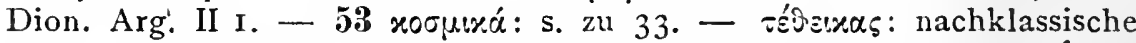
form, Kühner-Blass, Ausf. Gramm. der griech. Sprache II IS6. 'Zum dasein bringen', wie Il. XVIII 54 I है, $\delta$ ' ह่ 


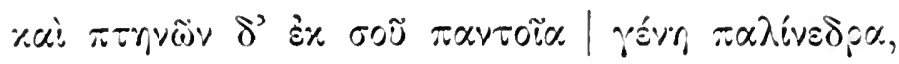

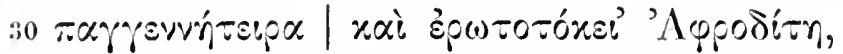

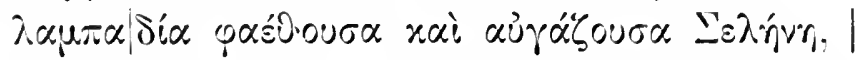

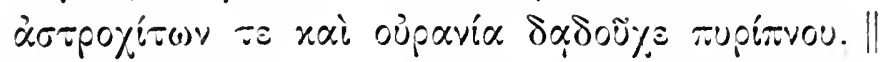

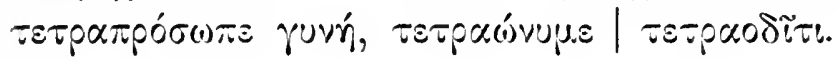

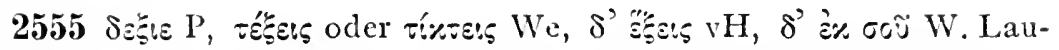

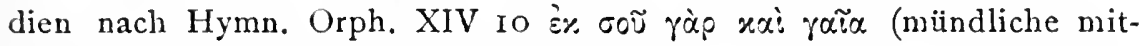

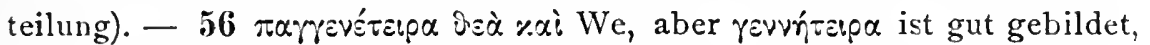
das $\alpha$ unter dem ictus gelängt. - 57 ép() roróxєı $\mathrm{P}$, geändert von We.-

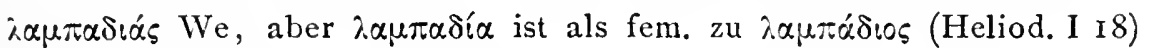

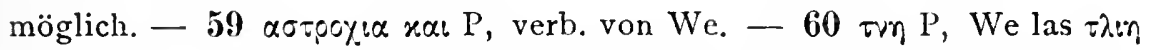
und schrieb $\delta i n, \delta \delta i n v H$, rư' Wii : 'mit vier gesichtern und dem körper eines weibes'.

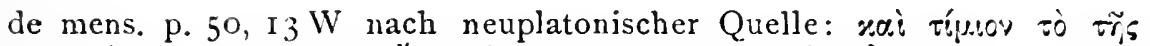

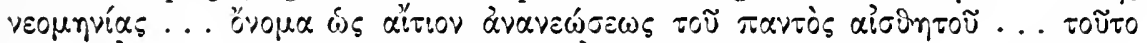

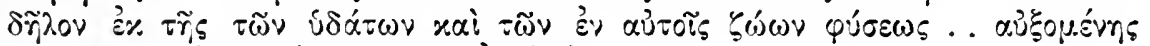

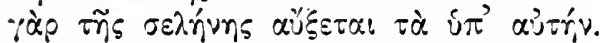

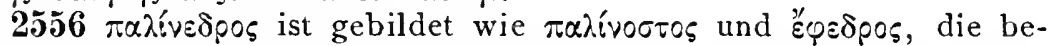
deutung unklar (wieder brïtend, zum neste kehrend); vH im Lexikon II I09I

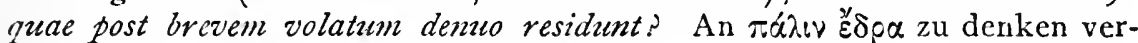
bietet sich, da $\delta: \delta$ ob.oxe:v nur als kompositum vorkommt. - Der gedanke, daß der mond die kosmika bewirkt, ruft die gleichsetzung der mondgöttin mit der alleszeugenden liebesgöttin hervor. Über die beziehungen des mondes zu Aphrodite vgl. Usener, Rhein. Mus. XXIII 342 ff. (der aufsatz erscheint demnächst mit den nachträgen Useners in dessen 'Kleinen Schriften' Bd. III zu anfang). - Antipater Anth. Pal. XII $97 \pi \alpha \gamma \gamma \varepsilon-$

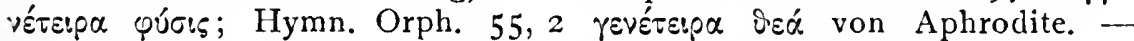

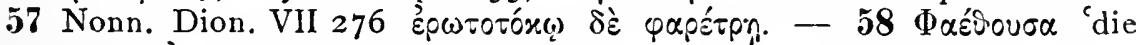
leuchtende', eine Heliade Od. XII 132. - Orph. Hymn. VII Io u. ö.

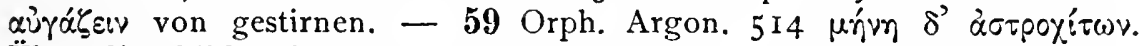
Über dies bild vgl. Rob. Eisler, Weltenmantel und Himmelszelt I05. oüpavía wird auch auf Aphrodite bezogen. $-\delta \alpha \delta 0 \tilde{u} \chi \varepsilon$ : Selene Hymn.

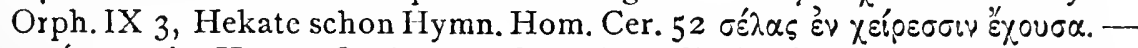

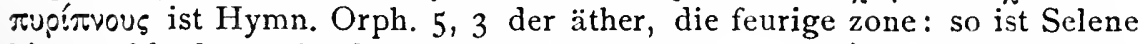
hier wohl als göttin der ätherzone aufgefaßt. - $\pi$ upítvou als verschluß

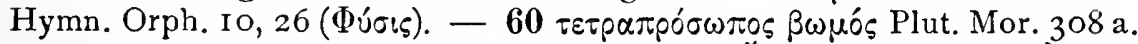

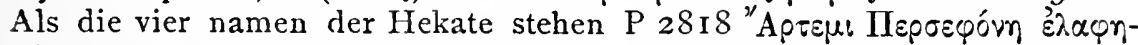

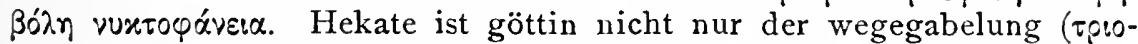

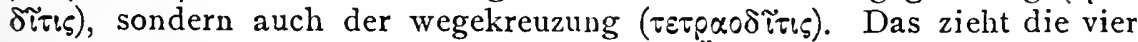
gesichter und die vier namen nach sich. Über vierköpfige wegegötter s. Usener Rhein. Mus. LVIII 340. Man erwartet nicht, im selben hymnus dreizahl (25) und vierzahl ohne erklärung nebeneinander $z u$ finden. Vers $35 \mathrm{f}$, kchren $P 2853 \mathrm{ff}$. wieder. 


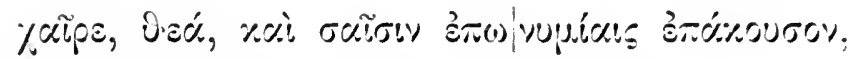

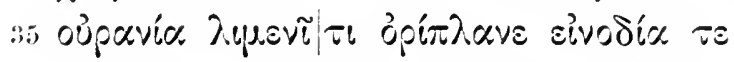

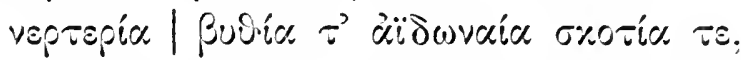

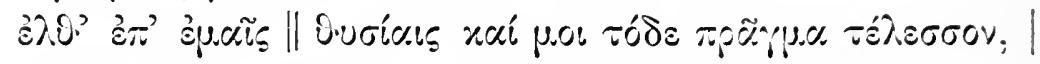

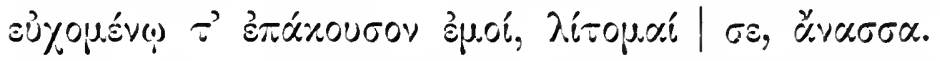

Toú

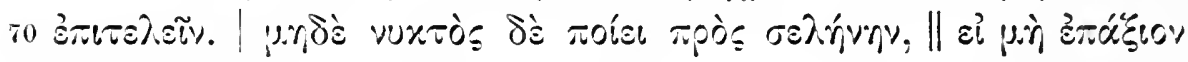

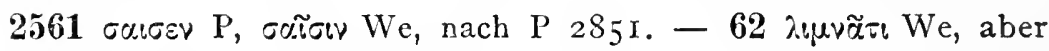

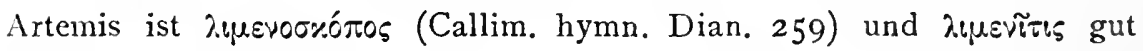

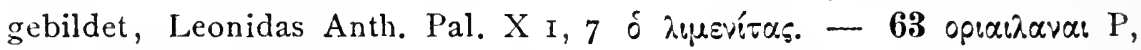

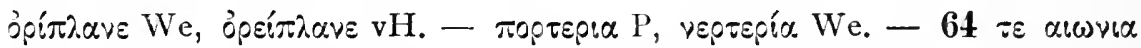

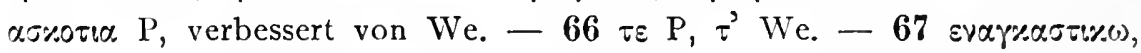
$\Rightarrow$ in $\pi$ verb. $\mathrm{P}$, geändert von Wü. - $68 \mu \eta \delta \varepsilon \mathrm{P}, \mu \gamma_{i} \delta \dot{c} \nu$ We.

2561 хатр巳 ist ständiges wort der hymnenpoesie, s. Fr. Adami, De poetis scaenicis Graecis hymnorum sacrorum imitatoribus, Fleckeis. Jb. Suppl. XXVI S. 227 , eine arbeit, die überhaupt für die struktur dieser hymnen einzusehen ist. - Éráxovoay versschluß Il. II I43. Zum vorkommen des verbums in der hymnensprache s. K. Ziegler, De precationum apud Graecos formis, Diss. Breslau I905 S. 63 f. - 62 oupavía: s. 59. Die wiederholung desselben beiworts innerhalb desselben hymnus ist bei so kurzem zwischenraum aufällig. Die aufzählung von vier beiworten in einem hexameter findet sich sehr oft in den orphischen hymnen. -

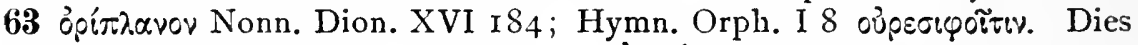
beiwort gehört der jägerin Artemis. - Eivodí $\alpha$ ist Trivia schon bei Sophokles, frg. 492 Nauck; s. auch Anth. Pal. VI I99, I. - 61 3uíi $\alpha$ in den

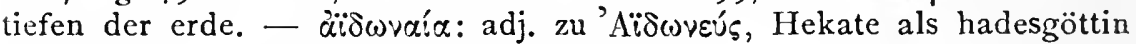

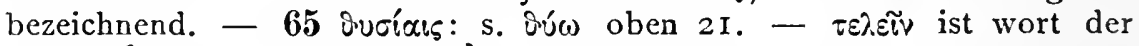
magie, 'zauberkräftig machen', s. Wessely S. 200. Schon Theocr. II It

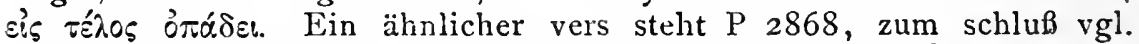

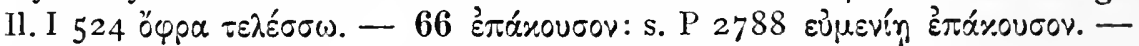

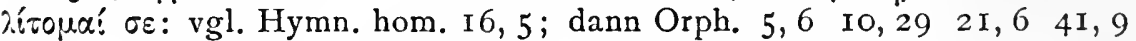
44 , Io $62,985,9$. Der hymnus erinnert ïberhaupt so stark an die orphischen hymnen, daß man annehmen kann, daß der dichter einen, wahrscheinlich aber mehrere (s. die bemerkungen $\mathrm{zu}$ 60. 62) ältere hymnen auf Hekate, die in 'orphischer' weise komponiert waren, benutzt, und sie an einzelnen stellen (s. zu $21,43,65$ ) durch umdichtung seinem

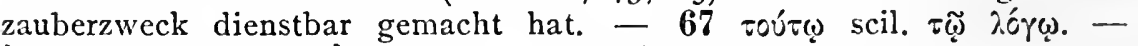

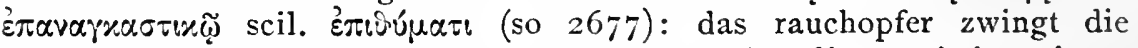
göttin, dem magus zu gehorchen. Fast aller zauber dieser zeit ist geister-

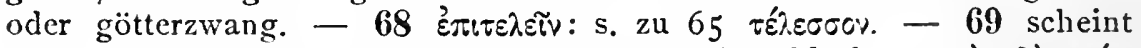

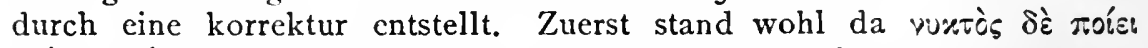

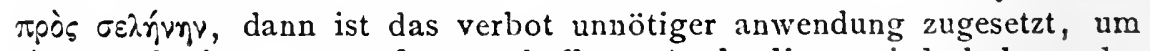
eine analogie $\mathrm{zu} 2504 \mathrm{f}$. zu schaffen. Auch diese wiederholung der anwendungsvorschrift zeigt, daß der zweite $\lambda o ́$ yos ursprünglich ein selbständiges rezept war. 


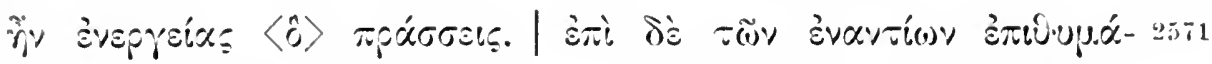

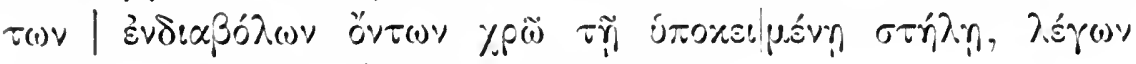
0ี๊

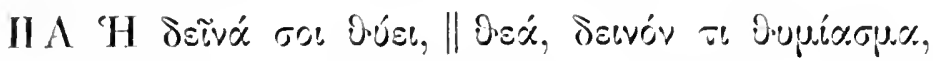

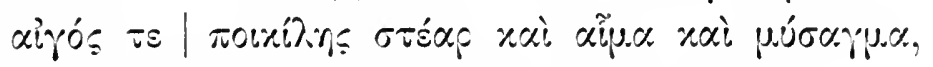

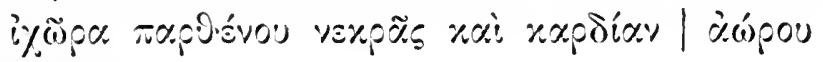

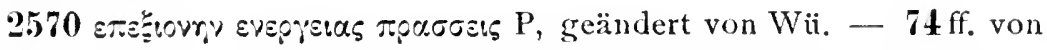

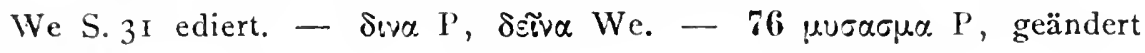

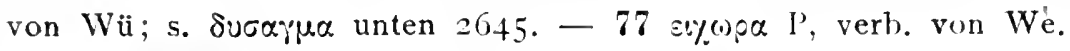

2570 ₹iv: bei den verben der schuldigkeit und ähnlichen tritt in der späteren Kowń eine vermischung des ind. praes. und imp. ein.

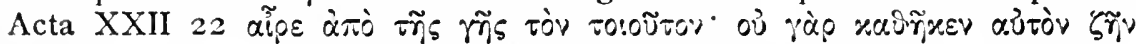
(Blass, Gram. des NT. Griech. ${ }^{2}$ 2 I I). - $71 \mathrm{ff}$. Hilfe gegen etwaigen gegenzauber. Der gegner will, um sich vor behexung zu sichern, gleichfalls durch ein Ėrísuua den schutz der Hekate gewinnen. Der zauberer vereitelt das, indem er der göttin vorredet, jenes érécupa. sei ein frevel.

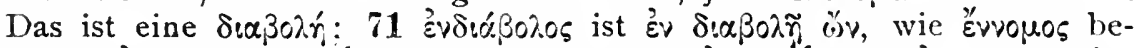

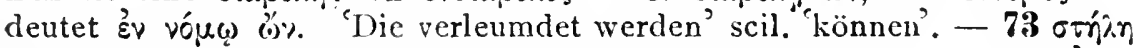
lat. columna, textkolumne, oft in diesen papyri, Wessely S. I98. - 74 $\dot{\varepsilon} \pi \dot{\alpha}-$ vorxos zwingend, s. zu 67. - 74-2621 Zweites gedicht, vou anfang an als zaubersang verfertigt; in jamben, dem für die schmähende $\delta\left\llcorner\alpha \beta 0 \lambda \dot{r}_{\text {. }}\right.$ besonders geeigneten versmaß. Das metrum weist die freiheiten späterer zeit auf. Eine zweite rezension derselben verse s. unten $2643 \mathrm{ff}$. -

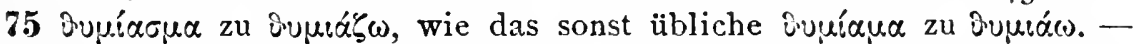
Warum die im folgenden genannten bestandteile des opfers der göttin verhaßt sind, läßt sich nicht überall ermitteln; zum teil sind diese Súpara der göttin sonst genehm, aber hier nicht: da glaubt sie wohl ihre mysterien profaniert. So wird 2459 und 2686 fett einer bunten ziege im wirklichen é $\pi$ í $u \mu \alpha$ vorgeschrieben (s, auch P I332 und 2874

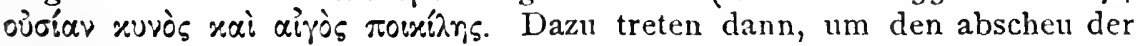
göttin zu steigern, besonders schauerliche, unsaubere dinge, denen endlich zur füllung harmlose medikamente der volksmedizin zugesellt werden. -

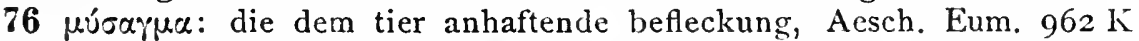

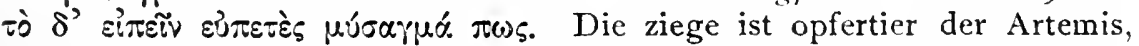
Wernicke PW II I 440. - 77 Wer vor der ehe stirbt, erreicht das ziel nicht, das ihm von natur bestimmt war. Er muf umgehen, bis seine

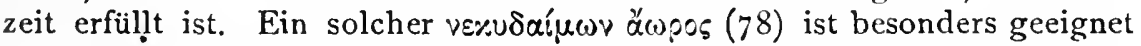
zum zauber: er hört noch die menschen, weil er auf erden geistert, und hat doch schon die macht des toten, s. IG III 3 p. XXI, Abt a. a. O. S. I 29. Wenn er selbst zauberkräftig ist, ist es auch sein seelensitz, blut (ixwe) und herz (\%,o $\left.\delta^{\prime} \alpha\right)$. An und für sich sind diese dinge der leichenzehrerin Hekate, die gerade jungframen nachstellt (Abernetty S. 55) nicht verhabit.

Wünsch, Zauberpapyrus. 


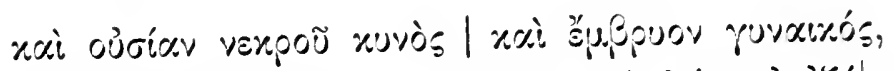

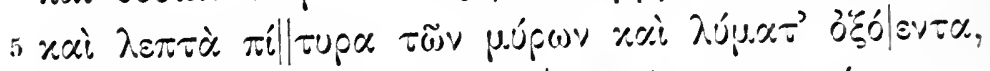

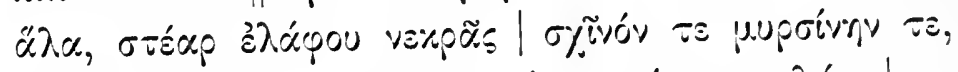

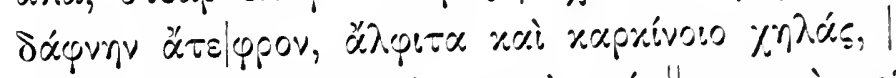

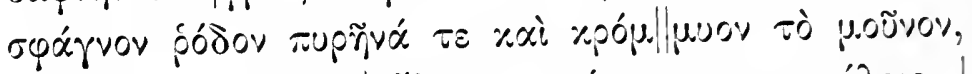

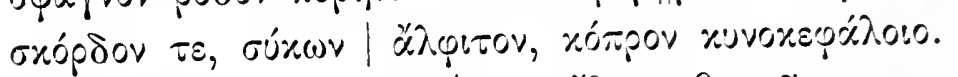

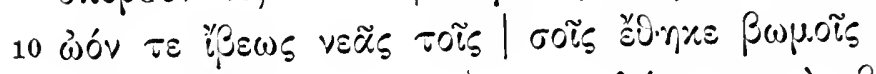

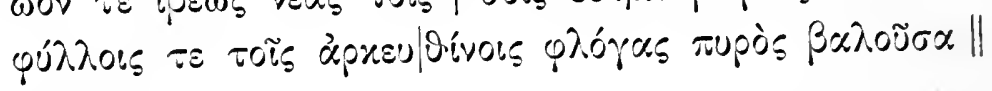

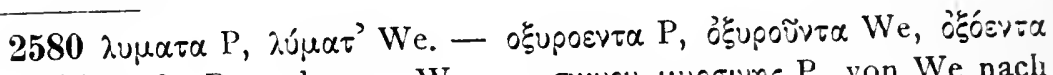

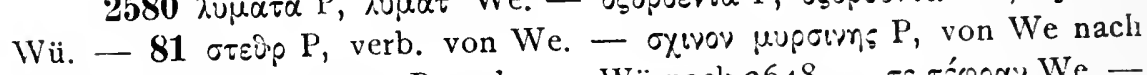

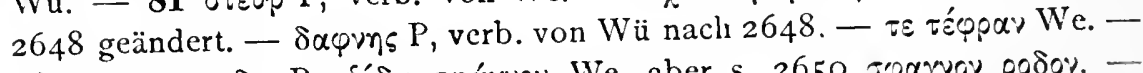

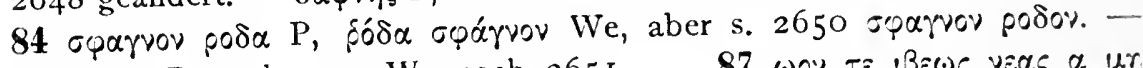

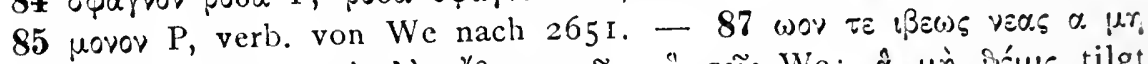

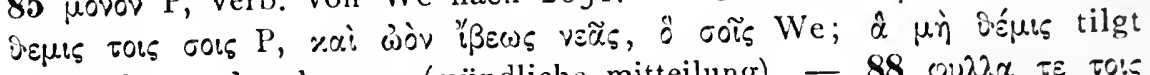

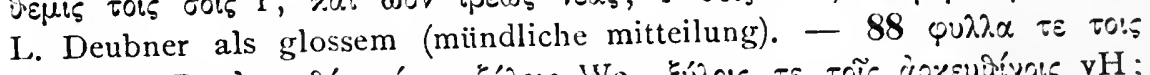

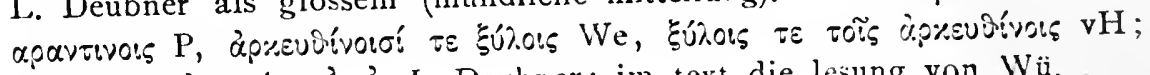

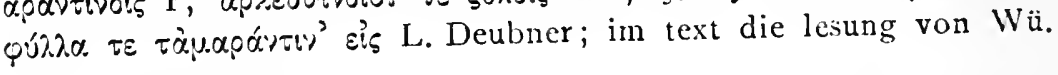

2578 ojoí: stoff, hier verwesungsstoff, Kuhnert, Rhein. Mus. IL 45,6 . - 79 š gestellt auf dem bild bei Daremberg-Saglio, Diction. des antiqu. III S. I 5 I

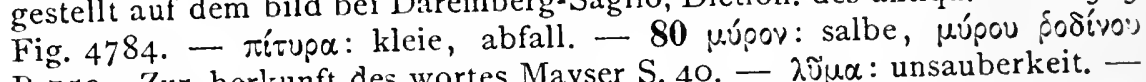

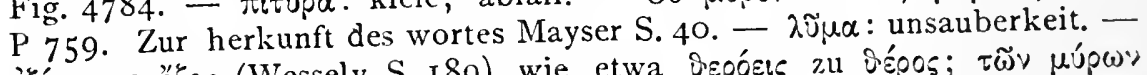

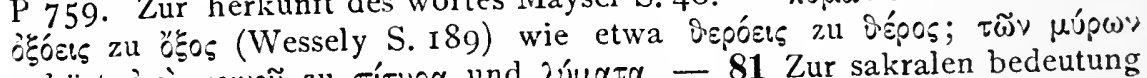

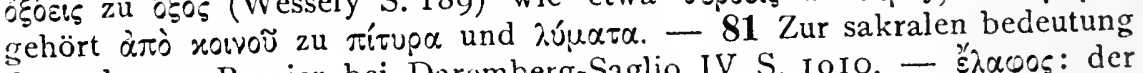

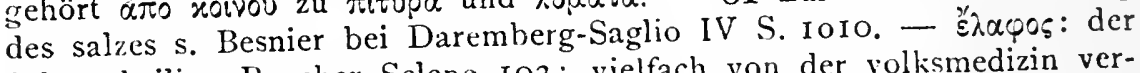
Selene heilig, Roscher Selene IO3; vielfach von der volksmedizin verwertet, Plin. nat. hist. XXVIII I 50. Ebenso die meerzwiebel (82), s. G. Kropatscheck, De amuletorum apud antiquos usu capita duo, Diss. Münster 1907, 67. Der mondgöttin heilig, Roscher Selene II7. - Mupóín:

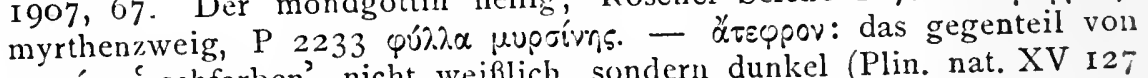

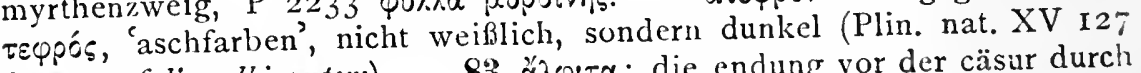
laurum folio albicantem). - 83 $\alpha \lambda(p: \tau \alpha$ : die endung vor der cäsur durch

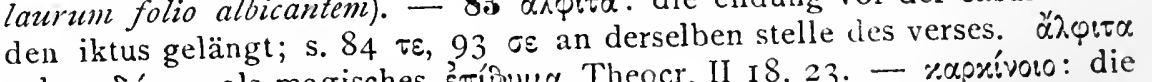

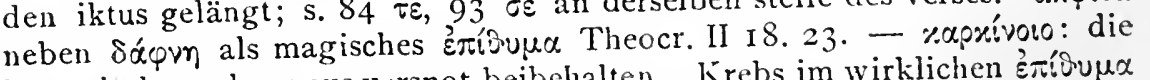
homerische endung aus versnot beibehalten. Krebs im wirklichen Ė $\pi$ ío $u \alpha \alpha$

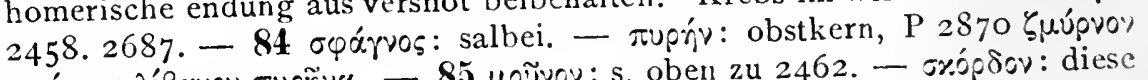

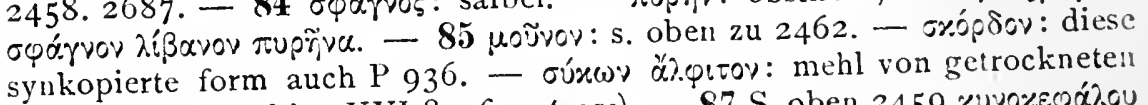

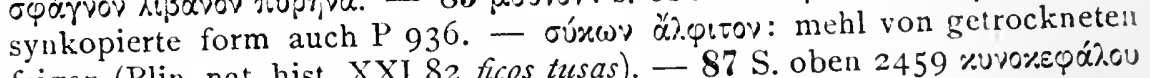

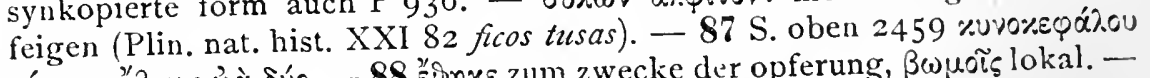

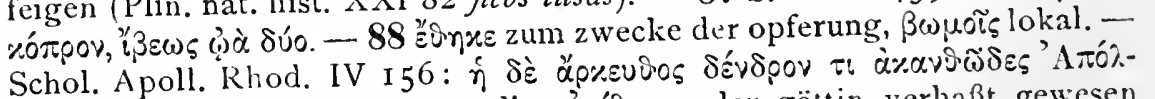

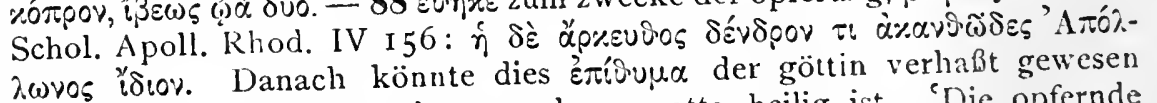

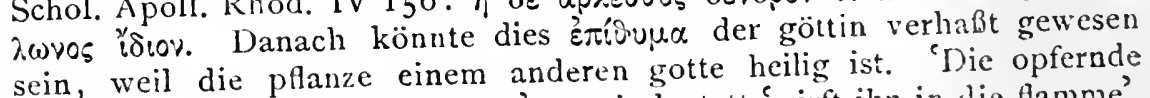
sein, weil die pflanze einem anderen gotte heilig ist. 'Die opfernde trifft mit wachholder die flamme' poetisch statt 'wirft ihn in die flamme'. 


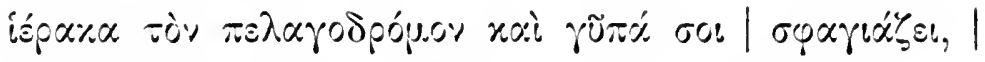

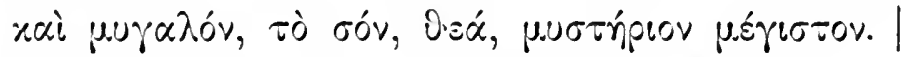

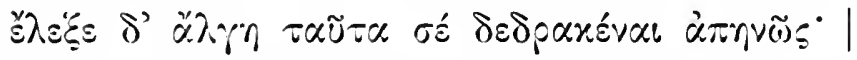

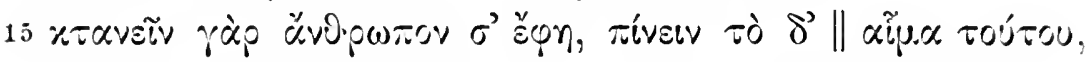

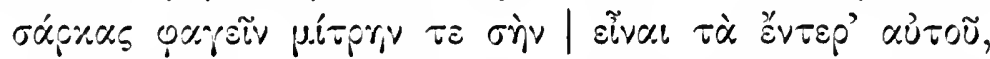

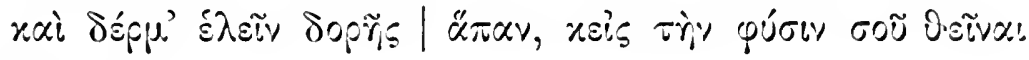

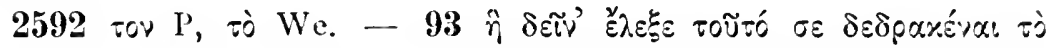

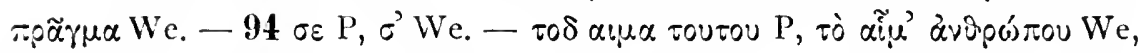

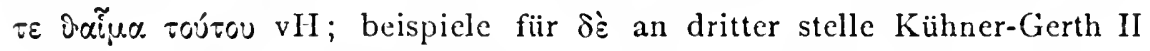

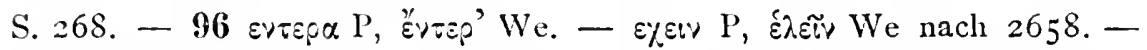

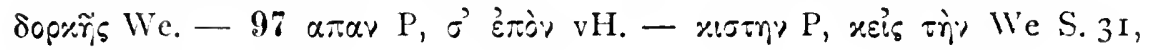

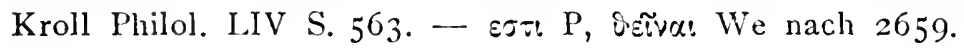

Vers 2590 beginnt anapästisch, s. Aristoph. Equ. 1052 $2 \lambda \lambda^{\prime}$ 'épur.s.

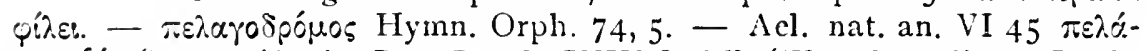

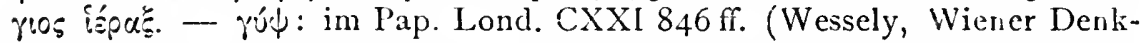
schr. XLII) sind unter den erscheinungsformen der Selene in einem

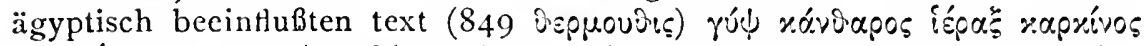

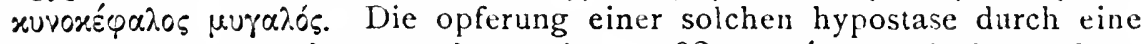
unberufene erregt den zorn der göttin. - 92 juotŕpıcy: mit dem nebensinn 'geheimes wirken'. Plin. nat. hist. II Io9 soricum ( $\mu$ r $\alpha \lambda . \tilde{\omega} v)$ fibras respondere numero lunae exquisivere diligentiores. Deutlicher Lyd. de

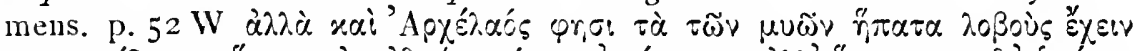

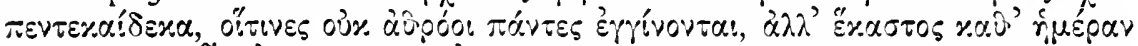

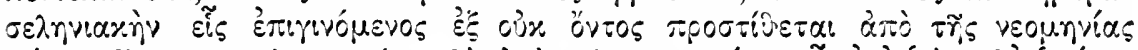

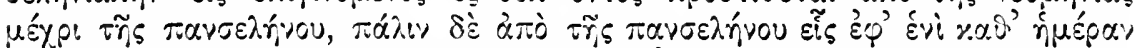

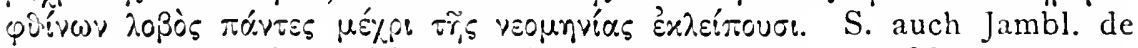
myst. p. 208 Parthey, zitiert von Roscher, Selene I89. - 93 Schmähung der göttin nicht mehr durch die tat, sondern durch worte. Die verleumdete hat das geheime wissen von Hekate der menschenfresserin offen ausgesprochen, vielleicht auch durch erfundene einzelheiten iibertreibend

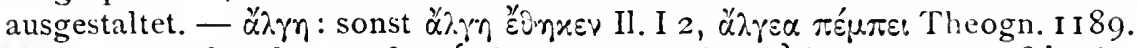
Mit $\delta \rho \tilde{u} v$ verbunden muß es 'schmerzerregende tat' bedeuten. - 94 Dieselben schauerlichen sagen deutet Lucan VI $739 \mathrm{ff}$. an; vgl. Abernetty $53 \mathrm{ff}$.

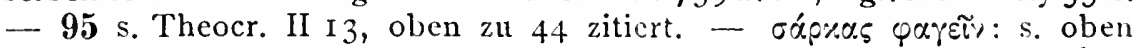
zu 2483 und A. Dieterich Nekyia S. 52 f., der hinweist auf P 2864: aifo-

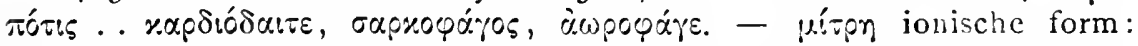
gürtel, binde, namentlich für das haupt, Poll. IV I 54. - 96 socá: abgezogene menschenhaut, Plut. Pelop. XXI, $\delta \varepsilon ́ p \mu \alpha$ nähert sich Od. II 29 I

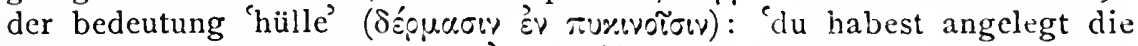
ganze hülle der menschenhaut'. - 97 qúcıs: s. Horap. Hierogl. I I I

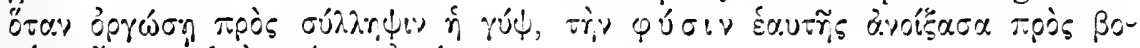

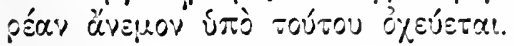




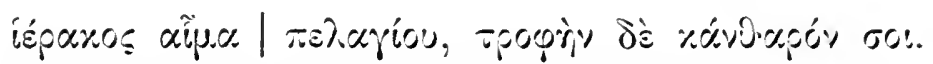

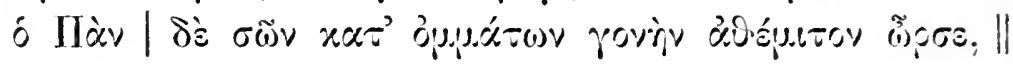

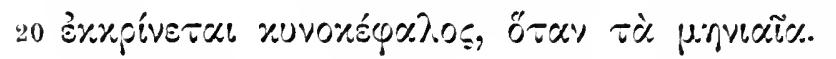

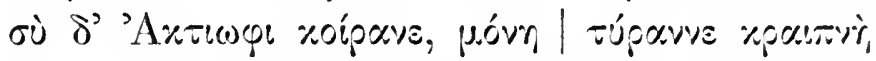

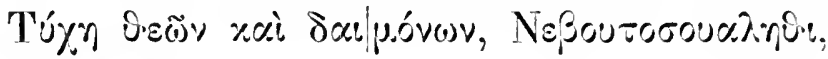

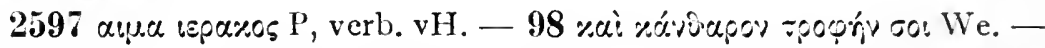

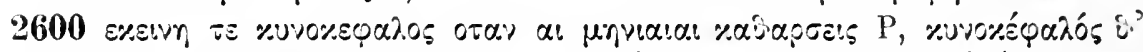

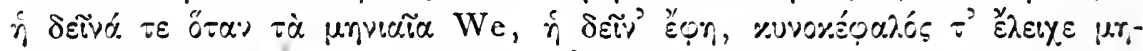

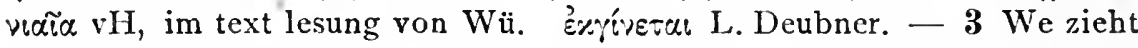

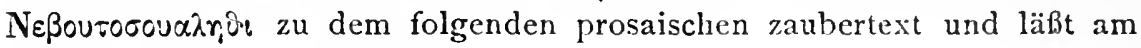
ende des verses eine lücke.

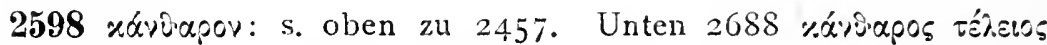

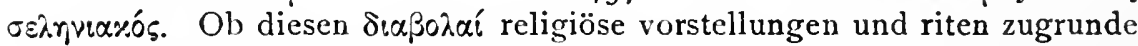
liegen oder nicht, vermag ich nicht zu sagen. Das folgende deutet, wohl nach ägyptischer vorlage, einen mythos von der liebe des Pan zur Selene an, derselben art, von welcher der griechische mythos über Hephaistos

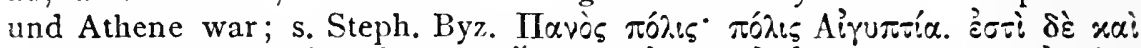

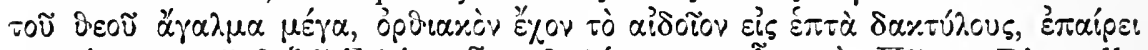

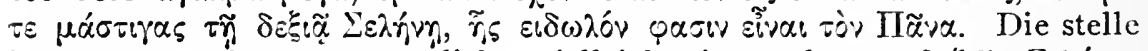

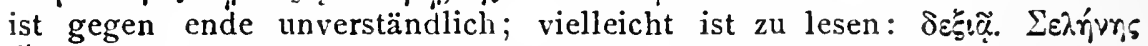
ही $\delta \omega \lambda$ ov (s. Drexier bei Roscher II 2977). Aber sie zeigt, daß der ägyptische Pan erotisch und in beziehung zu Selene gedacht wurde. In der alexandrinischen erotik erscheinen Pan und Selene verbunden, Verg. georg. III 39I, Wernicke bei Roscher III 1466, Roscher Selene I $48 \mathrm{ff} .-$

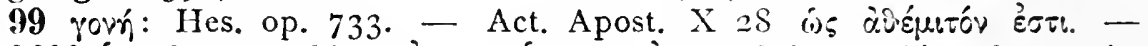
2600 'wird ausgeschieden' oder 'geboren' von Selene. Diese lesung ist paläographisch die nächstliegende; mit belegen zu stützen vermag ich

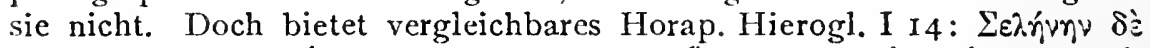

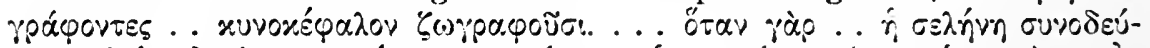

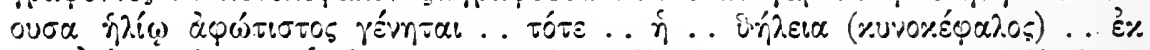

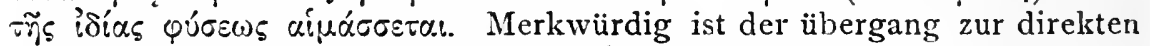
rede. Vielleicht fehlt hier etwas; $̋ \sigma: \nu$ wird im nebensatz nur selten

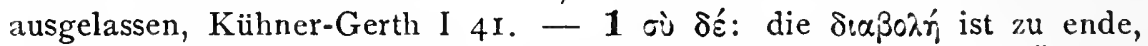

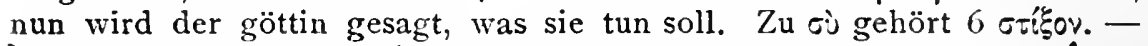

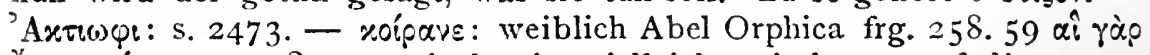

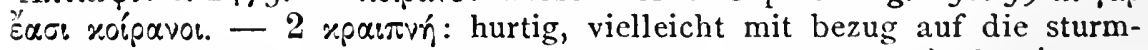

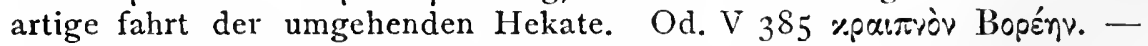
Die mondgöttin ist auch sonst das geschick; A. Dieterich Nekyia S. 96 spricht über den zusammenhang von schicksal und licht. Túyn: s. Hymn. Orph. 72. Sie ist in späteren zeiten alleinherrscherin im weltall; F. Cumont, Les religions orientales dans le paganisme romain $1907,216 .-$ 3 Zum folgenden zauberwort s. 2485. Dann kommen formeln, die sich nicht in den vers bringen lassen. Die vorlage von $\mathrm{P}$ hat weitere óvó$\mu \alpha \tau \alpha \beta \alpha$ áp $\beta \alpha \rho \alpha$ beigeschrieben, die sie in einer prosaischen beschwörung $z u$ Neßoutocova $\lambda \eta \dot{v}$ hinzugefügt fand. Die einzelnen namen sind unver-

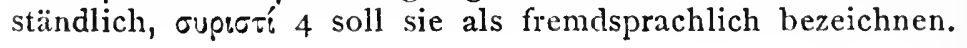




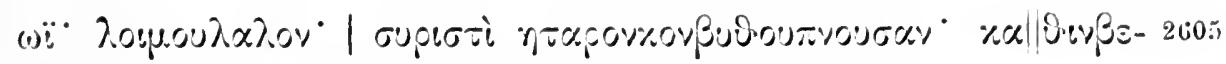

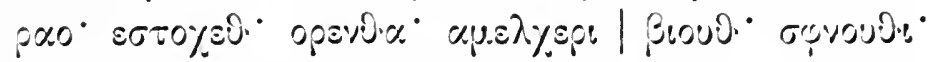

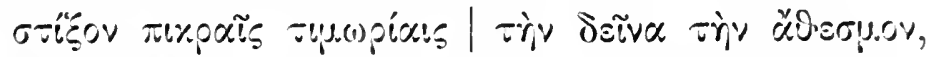

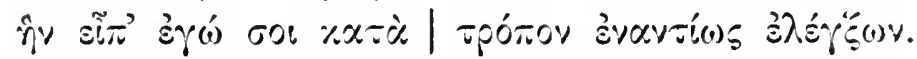

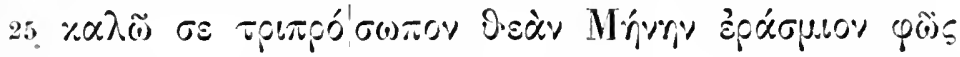

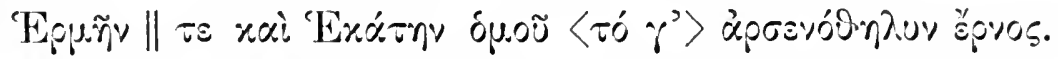

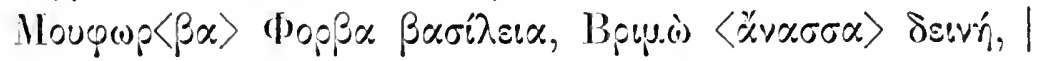

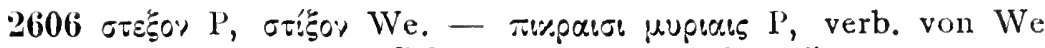

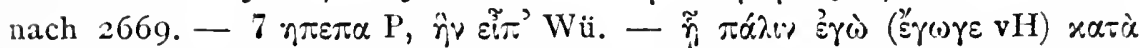

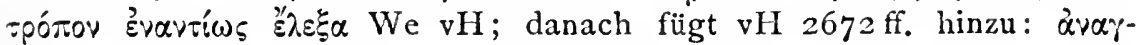

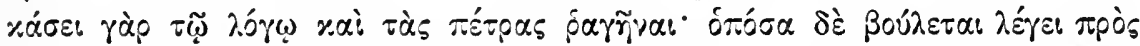

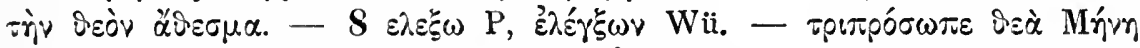

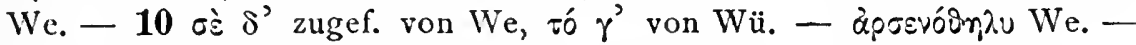

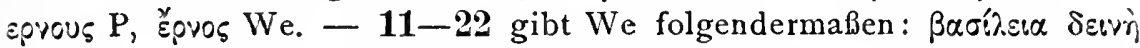

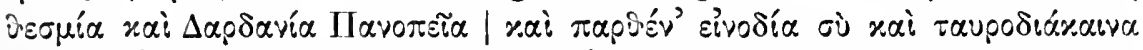

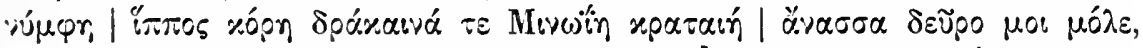

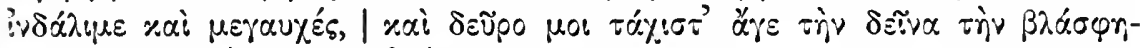

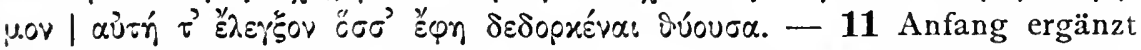

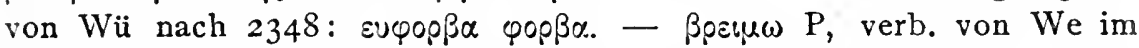
index. - gegen ende ergänzt von Wü nach Apoll. Rhod. III 862 : Botu(i)

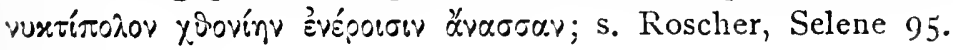

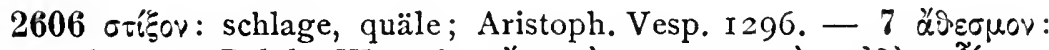

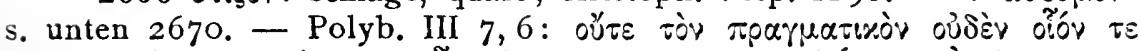

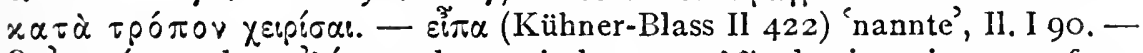

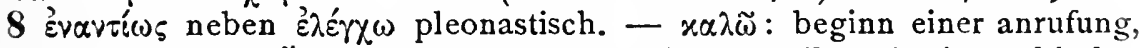
deren $z w e c k$ das $\alpha \gamma \varepsilon$ in 19 ist. Zunächst folgen epikleseis, in orphischer

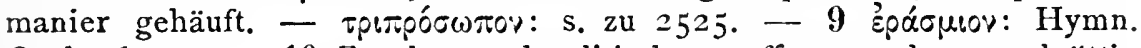
Orph. 60, 4. - $10 \mathrm{Zur}$ hermaphroditischen auffassung der mondgöttin

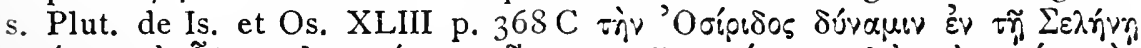

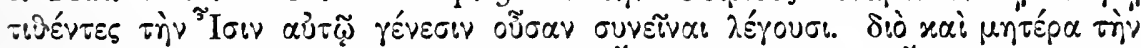

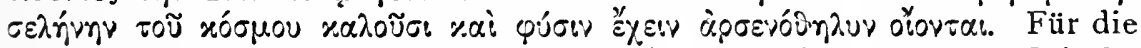
ägyptische mannweiblichkeit Isis (Selene) und Osiris setzt der Grieche seine eigenen götter: Hekate (Selene) zieht den Hermes nach sich, mit dem sie als chthonische göttin eng verbunden war, IG III 3 praef. p.VI. docevóonnduv: das neutrum hat sein $\nu$ durch analogiebildung erhalten,

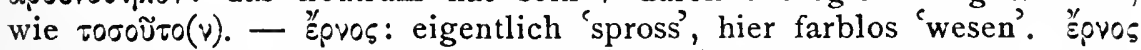
in ähnlicher abgeblaßter bedeutung (frucht) steht bei Koluth. 147. 11 Hekate ist Proserpina (oben 2523) und darum königin der unterwelt; die formel 2348, die zur textkritik benützt ist, gehört der kore. Brimo ist unterweltsgöttin (Kern PW III 853) und wird öfter in diesen texten genannt: 2276, 229I, 2964. Mit Hekate verschmilzt sie auch bei Lyko-

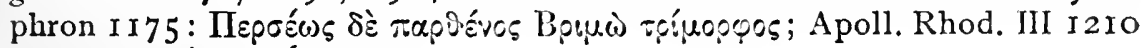

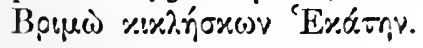




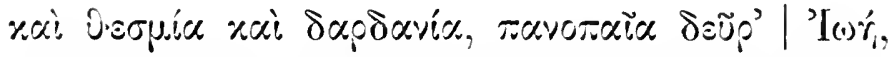

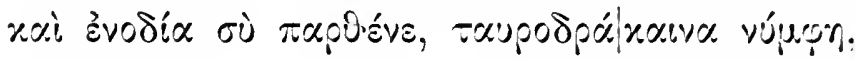

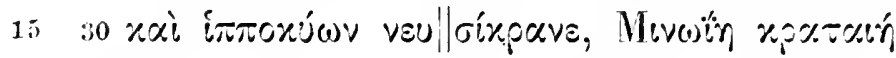

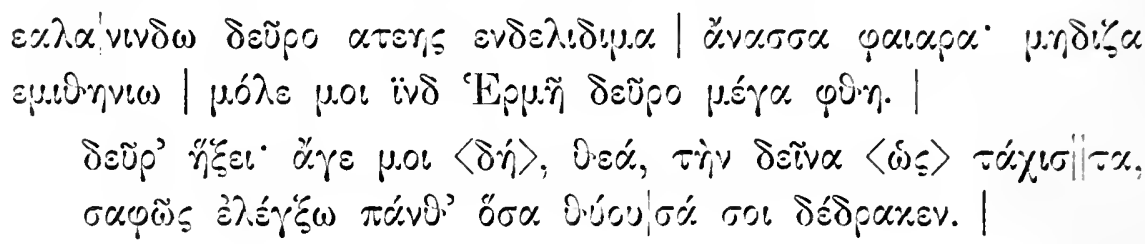

2613 เ

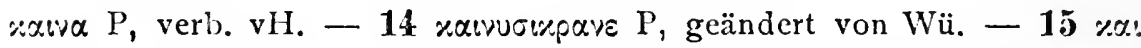

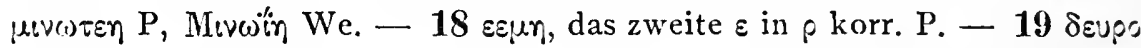

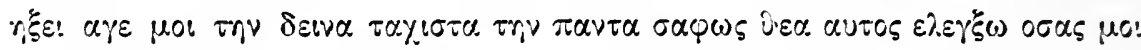
Sucuca $\delta \varepsilon \delta 0$ prev $\mathrm{P}$. Man erkennt den iambischen tonfall; ob die oben von Wü gegebene wiederherstellung im einzelnen das richtige trifft, ist zweifel-

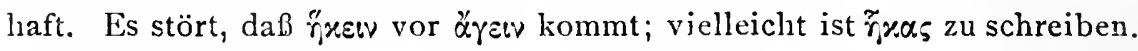
L. Deubner nimmt als hebung das $\alpha$ in $\alpha$ $\gamma \varepsilon$ an; dann ist $\delta \dot{\eta}$ unnötig.

2612 irøuí $\alpha$ : beiname der Demeter in Pheneos, Paus. VIII I 5, 4. -

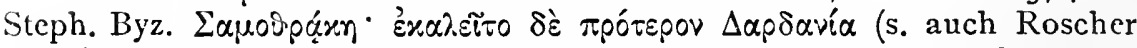
I 96I). Auf Samothrake hatte Hekate einen berühmten kult, Strabo X

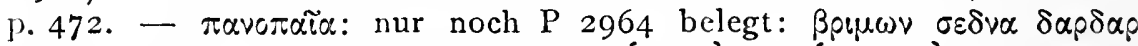

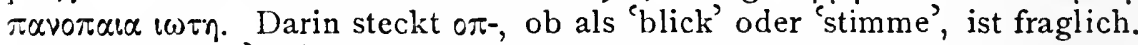
Die nähe von 'I $\omega$ '́ (s. dazu oben 253I) läßt eher an das letztere denken. Vielleicht ist nicht 'I $\omega \dot{\eta}$ als name der Hekate, sondern $i \omega \tilde{\eta}$ zu schreiben,

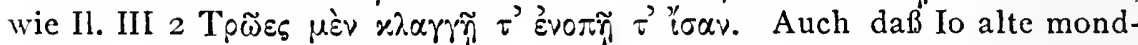
göttin ist (H. Usener, Rhein. Mus. XXIII 332), könnte eingewirkt haben.

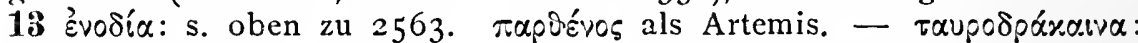
ein tiergestaltiges mischwesen, wie gleich darauf $i \pi \pi 0 x \dot{v} \omega v$. Das sind kombinationen der verschiedenen formen, in denen sich die göttin offen-

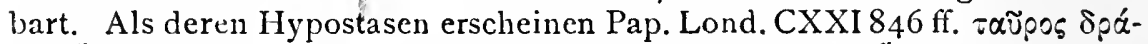
\%

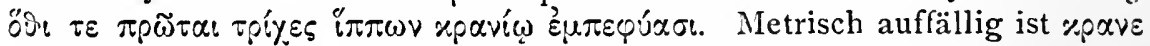
als vicrter fuß. Aber $\varepsilon$ ist unter dem iktus gelängt, und für die länge des $\alpha$ war wohl der zeit, die das gedicht schuf, das gefühl verloren gegangen; s. B. Kuster S. 125. - 15 Mevow nicht sichere lesung; Apoll. Rhod. IV I689: ipòv'Ainvaíns Mivetísos ípúsavto. Artemis wurde auf Kreta verehrt, Callim. Hymn. Dian. 204f. - Es folgen wieder später zugesetzte prosaische zauberformeln, die das metrische gefüge sprengen.

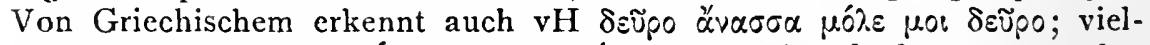
leiclit außerdem noch ${ }^{~} E$ E $\mu \tilde{n}$ und $\mu \varepsilon_{\gamma} \alpha$. Bei ờn denkt man an den Hierogrammateus Thphe, Dieterich Abraxas S. 202 Z. $24 .-19 \alpha{ }^{\gamma} \varepsilon$ : der zweck ist wieder eine $\dot{\alpha} \gamma \omega \gamma \gamma^{\prime}$, wohl ein liebeszauber. Aber der göttin gibt der magus einen andern grund an: er will die sünderin ihres frevelhaften opfers überführen. 


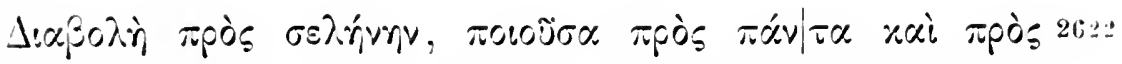

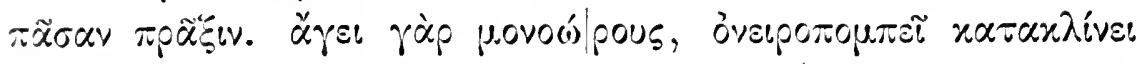

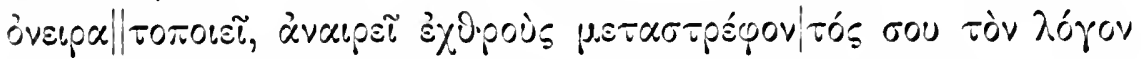
25

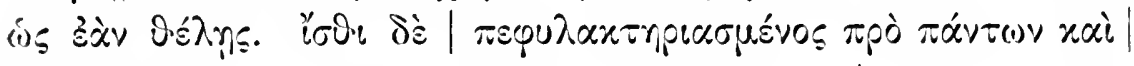

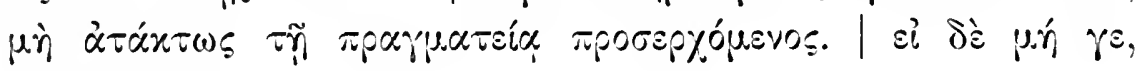

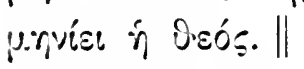

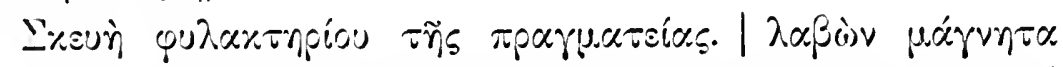
30

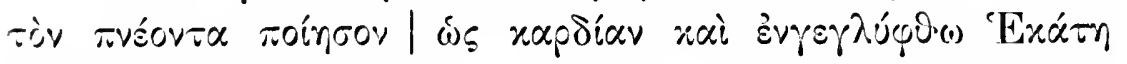

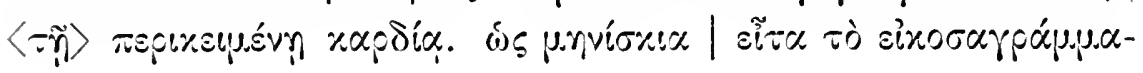

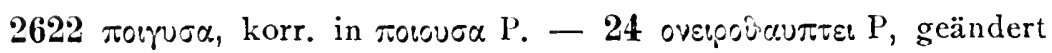
ron Wü nach P 3 I 79, wo ovsipous a $\pi$ rnons steht ( $\mathrm{v}$ über der zeile), was von $\mathrm{P}$

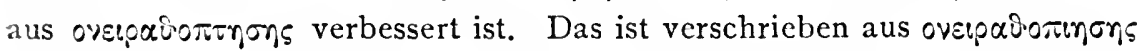

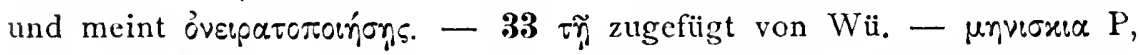
unve $\sigma \% \alpha$ We, der wohl an den schatten im monde denkt: ws unvi

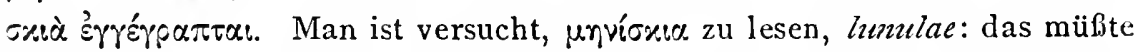
dann zum folgenden gehören, und عiّ $\tau \alpha$ wäre falsch oder doch wenigstens

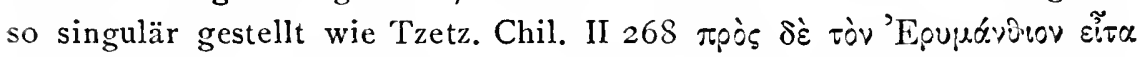

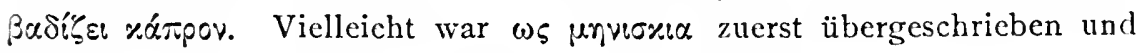
wurde dann an unrichtiger stelle in den text gesetzt.

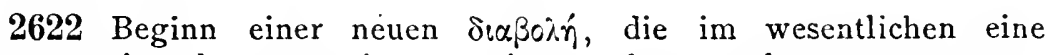
andere rezension der ersten ist, aus einer anderen vorlage zugesetzt. 22-26 Anpreisung des rezeptes, wahrscheinlich nach 244I ff. gemacht.

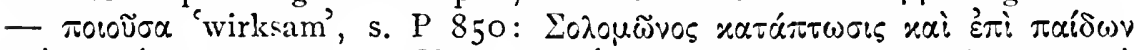

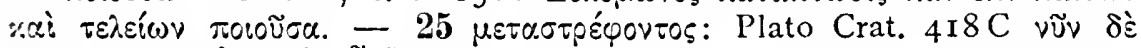

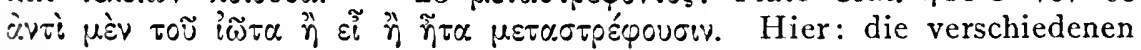
formeln einsetzen, die $2496 \mathrm{ff}$. vorgeschrieben sind. Sie treten an stelle des $\ddot{\alpha} \gamma \varepsilon($ I9). $-26 \dot{\varepsilon} \dot{\alpha} \nu$ : spätgriechisch statt $\ddot{\alpha} \nu$, s. Antike Fluchtafeln no. 3 z. II, Blass Gramm. des neut. Griechisch ${ }^{2}$ S. 64. - 26-29 Die übliche

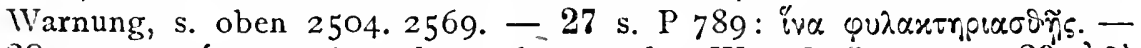

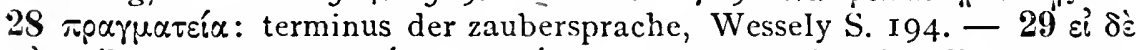

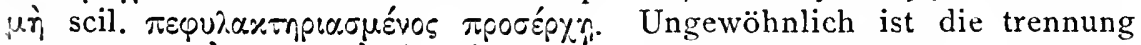
des $\gamma \varepsilon$ von $\varepsilon \hat{\imath}$, aber $\varepsilon \hat{\imath} \delta \dot{\varepsilon} \mu \eta^{\prime} \gamma \varepsilon$ steht ebenso bei Jamblich, vit. Pyth. p. 54, 6 und 7 I, 9 Nauck (nachgewiesen von L. Deubner). - 30 Die

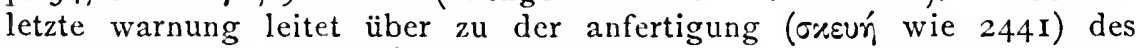
Phylakterion. - $31 \pi v v_{\text {ó }} \tau \alpha$ : s. die erklärung des magnetischen Phänomens bei Lucr. VI I035 hic igitur, penitus qui in ferrost abditus aër| sollicito motu semper iactatur eoque | verberat anellum dubio procul et ciet intus. Dazu Fritzsche, Der Magnet und die Athmung in antiken Theorien,

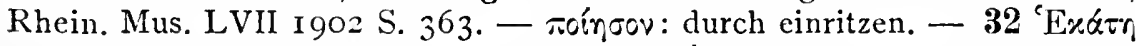
ist ja die göttin, an die sich die $\pi p \alpha \gamma \mu \alpha \tau \varepsilon^{\prime} \alpha$ wendet; hat man ihr bild, so hat man sie selbst in der gewalt, s. Arch. für Rel.-wiss. XII I909 S.2 I. -

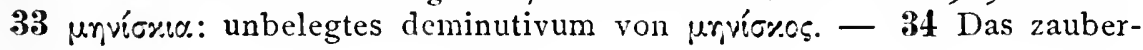




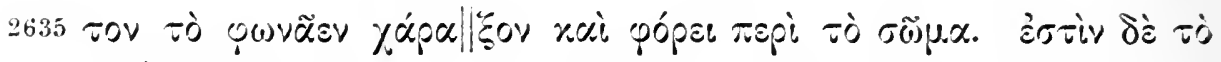

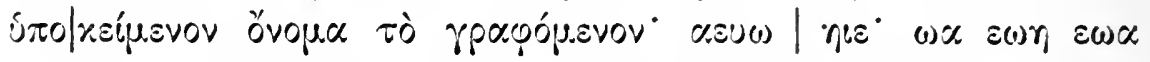

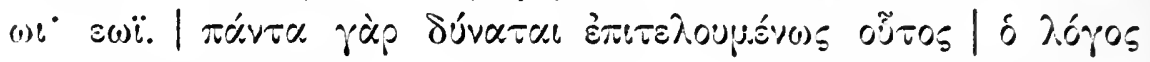

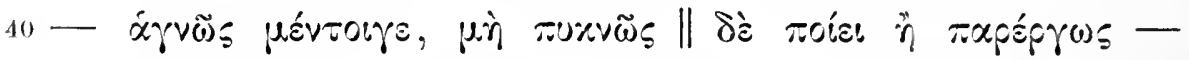

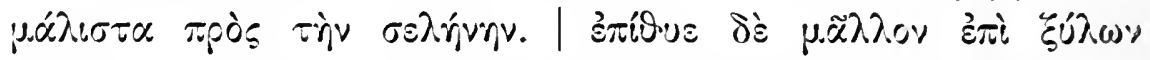

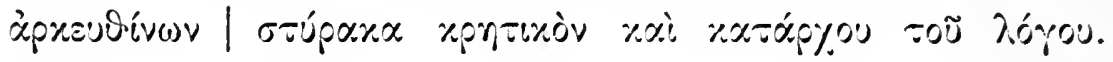

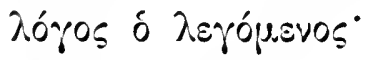

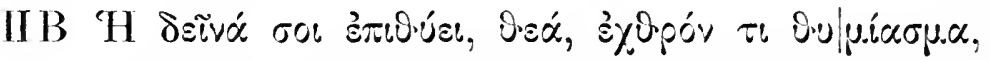

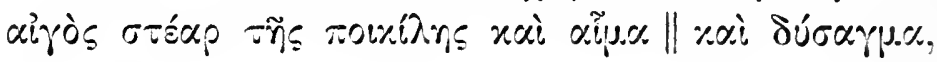

2634 Vielleicht $\langle\dot{\varepsilon} v\rangle \chi \alpha \dot{\rho} \rho \alpha \xi \sigma\rangle$ - 37 Nach $\omega \alpha$ sind drei buchstaben in $\mathrm{P}$ getilgt. - $43 \lambda \varepsilon \gamma \sigma \mu \cdot$ P. - S. die redaktion A oben $2574 \mathrm{ff}$. 45 Gemeint ist :uv́ourux, s. oben 2576.

wort soll so geschrieben werden, daß sich monde, das heilige bild der mondgöttin, ergeben. Es ist wohl gemeint, daß in jeder der beiden hälften die buchstaben halbkreisförmig angeordnet werden sollten. S. die so gruppierte beischrift des zauberrings Arch. für Rel.-wiss. XII r9. -

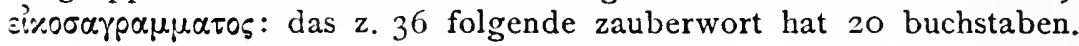

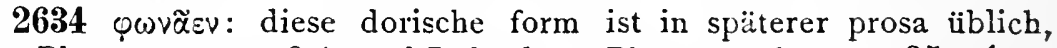
s. z. b. Plut. mor. p. $738 \mathrm{~A}$ und Lobeck zu Phryn. p. 639. - 35 фópet:

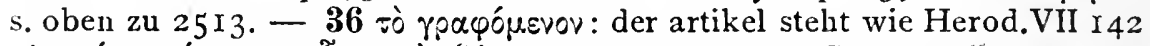

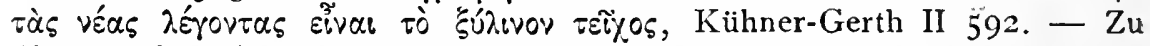
diesen vokalspielereien s. Ant. Zauberger. S. 29. Auch sie sind ein name (ovoux) der göttin. - $37 \mathrm{ff}$. Eine neue anpreisung und warnung, eine doublette zu $22 \mathrm{ff}$, die deutlich zeigt, daß hier $z$ wei verschiedene fassungen

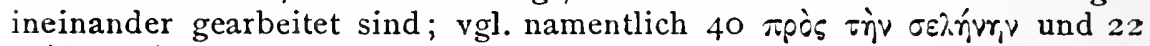

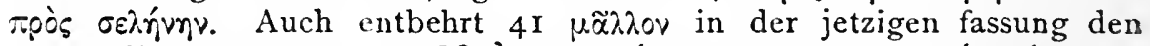

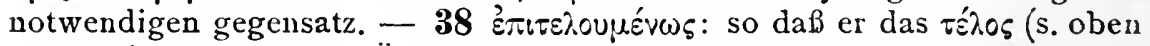
$z u$ 2565) herbeiführt. Ähnliche bildungen des adverbs von einem parti-

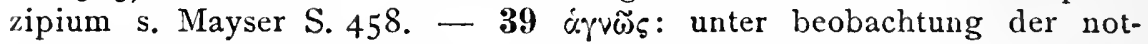
wendigen reinheitsvorschriften, deren aufzählung bei der umredigierung weggefallen ist. S. E. Fehrle, Kultische Keuschheit RGVV VI S. I 49 und

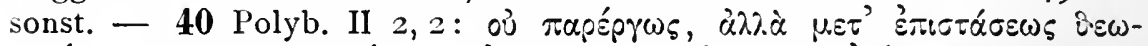

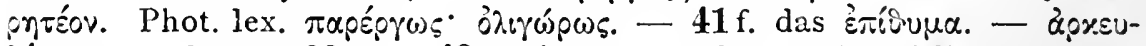

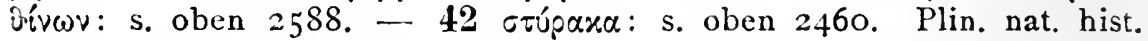
XIl 124 styrax laudatur post supra dicta (Syriam) ex Pisidia, Cypro, Cilicia, Creta. - $43 \mathrm{ff}$. Die redaktion B stammt von einem zauberer, der die vorlage der redaktion A umarbeitete. Er hat gekürzt, an einzelnen stellen einen einfacheren oder treffenderen ausdruck gesetzt, dabei aber manche sprachliche und metrische härte hineingebracht. So ist gleich

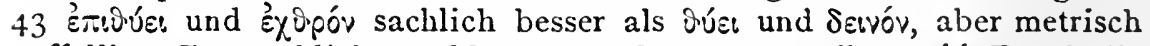
auffällig. Zur sachlichen erklärung s. oben zu $2574 \mathrm{ff}$. - $4 \pm$ Durch die wortstellung von $\mathrm{B}$ wird das unklare $\tau \varepsilon$ von $\mathrm{A}$ vermieden. 


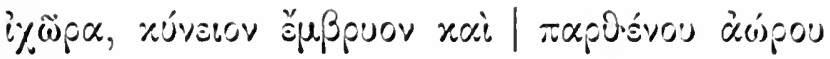

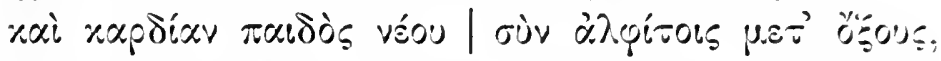

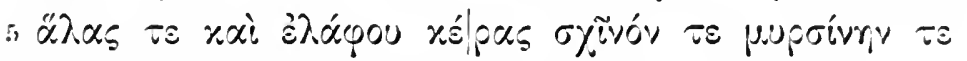

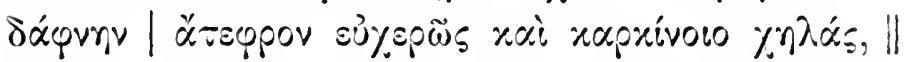

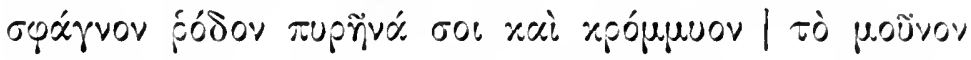

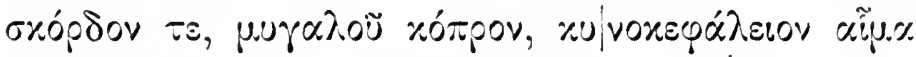

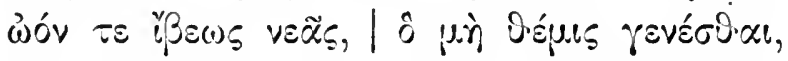

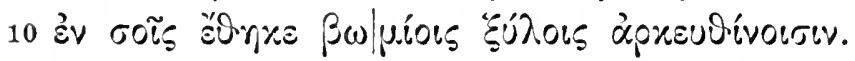

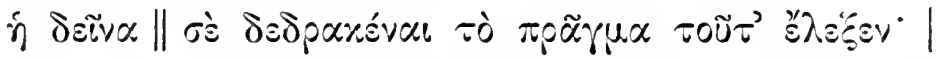

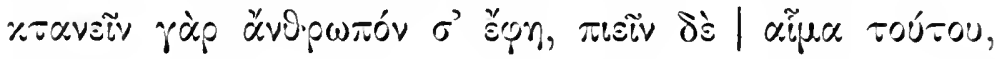

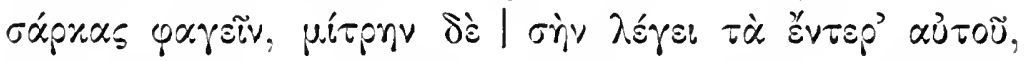

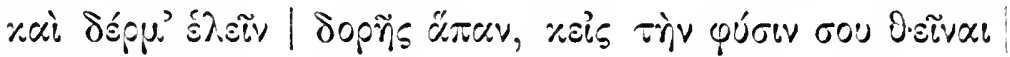

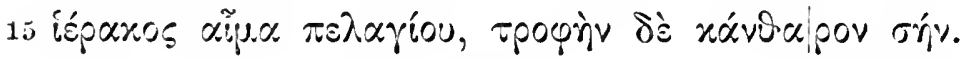

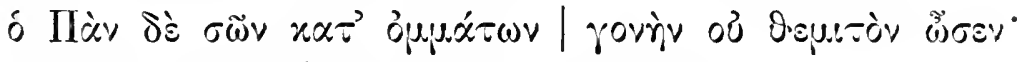

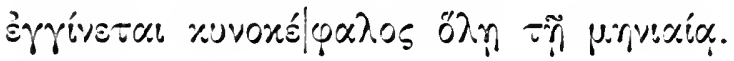

2645 xuviov $\mathrm{P}$, xúveiov Wü. - 50 ธழุaสivov, aber von $\mathrm{P}$ verbessert. -

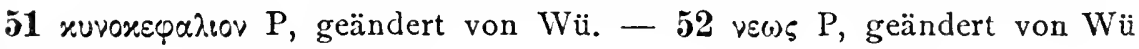

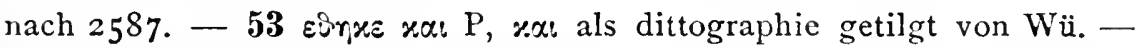

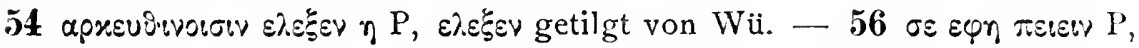

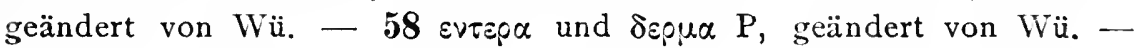
59 xa a

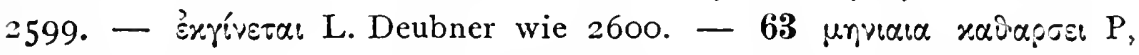

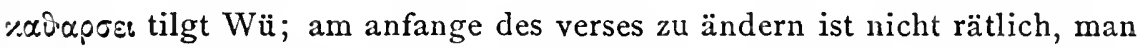
weiß nicht, was der schreiber sich bei seiner änderung (s. oben 260I) gedacht hat.

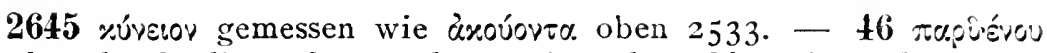
áwou hat durch die änderung den regierenden akkusativ verloren. -

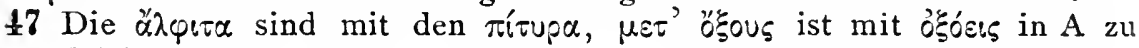
vergleichen. Diese stelle macht es wahrscheinlich, daß $A$, nicht $B$, der ursprünglichen fassung des zauberrezepts näher steht. Denn man versteht wohl, wie durch kürzung $B$, aber nicht, wie durch erweiterung

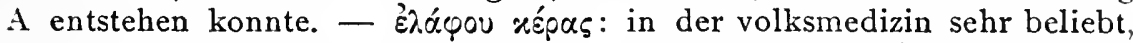
s. Plin. nat. hist. XXVIII I 63 und öfter. - 49 B nimmt an $\ddot{\alpha} \lambda \varphi \iota \tau \alpha$ A anstoß, weil es von ihm schon zwei verse vorher verwendet ist; er setzt dafür

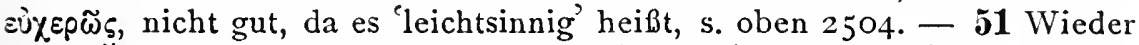

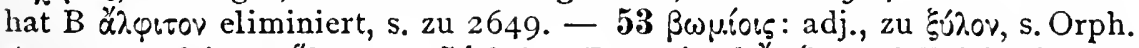

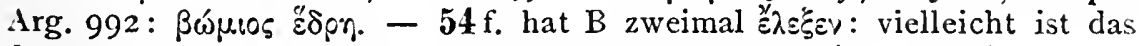
der rest eines zweifachen versuches, umzustilisieren (s. o. 2593). 


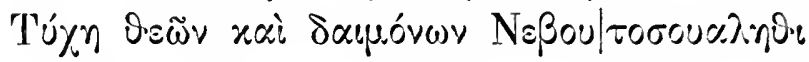

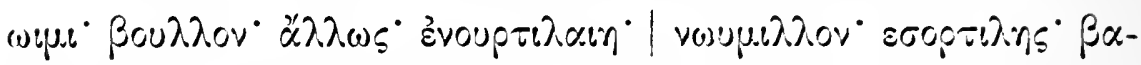

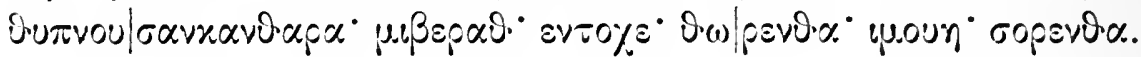

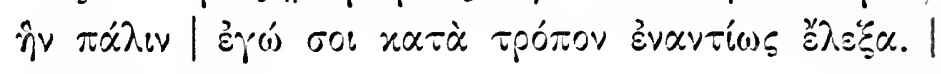

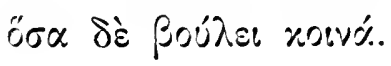

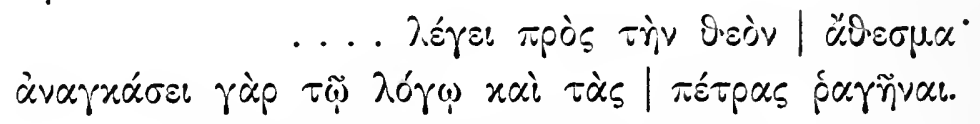

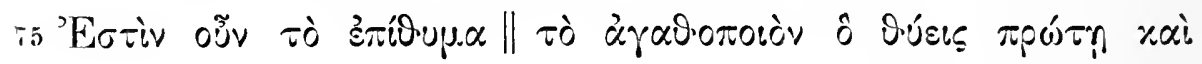

2664 Metrisch richtig póvn, oben 260I; der schreiber hat an den

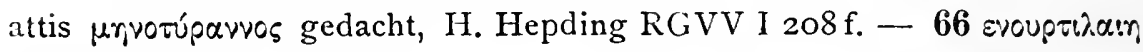

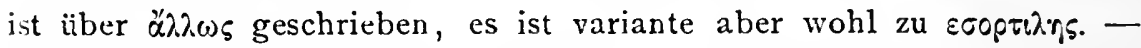

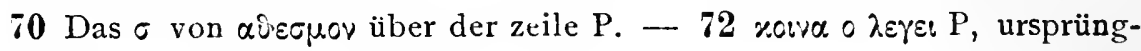
lich etwa $\left\langle\dot{\varepsilon} \lambda \varepsilon^{\prime} \gamma \xi \omega,\right\rangle \ddot{\langle}\langle\sigma \alpha\rangle \lambda \varepsilon \dot{\varepsilon} \varepsilon$, s. $262 \mathrm{I}$.

2666 Der schreiber hat nach we nur noch wenig und das ungenau (s. 2603) abgeschrieben, dann aber aus einer anderen vorlage ( $\alpha \lambda \lambda \omega s$, s. A. Dicterich, Mithrasliturgie ${ }^{2}$ S. 44) eine andere formel eingesetzt. -

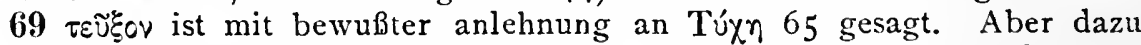

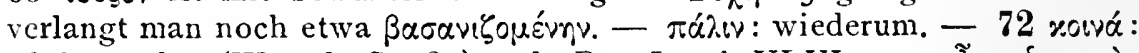

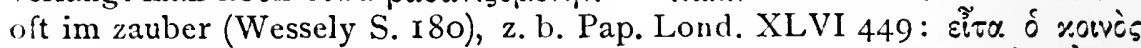

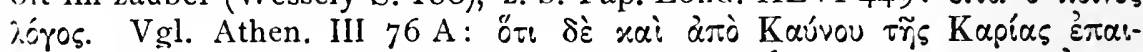
veital, roivóv. Das wort hat aus der bedeutung 'allgemein bekannt' den sinn 'profan' entwickelt: im gegensatz $\mathrm{zu}$ den feststehenden heiligen formeln sind es die nicht kodifizierten wendungen, die der zauberer je nach dem bedürfnis des einzelnen falles hinzufügen darf. Hier hat diese allgemeine formel ein paar verse mit einer speziellen anrufung verdrängt:

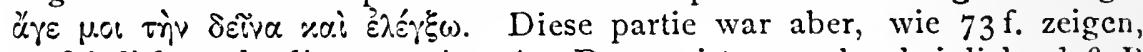
ausfuihrlicher als die rezension A. Darum ist es wahrscheinlich, daß $B$ nicht A selbst, sondern dessen vorlage benutzt hat. 73 Das spalten der

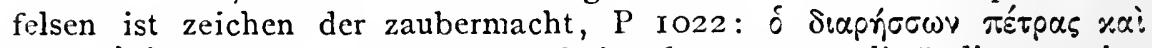

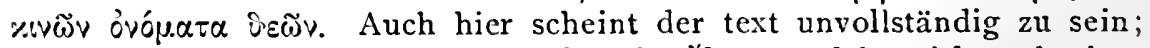
es ist nicht lilar, warum das aussprechen der $\alpha$ $\delta \sigma \mu \alpha$ solche wirkung besitzt,

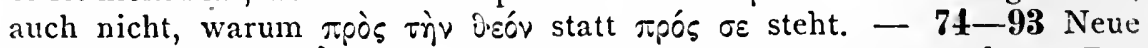

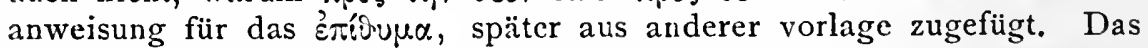
ergibt sich daraus, daß erst jetzt davon geredet wird, daß die $\pi_{\rho} x \gamma \mu \alpha-$ réa drei tage dauert, und daß man am ersten und zweiten ein anderes opfer zu bringen hat als am dritten. Auch das jetzt beziehungslose oủv zeigt, daß der satz früher in einem andern zusammenhang stand, und die wiederaufnahme der ersten worte in 78 ist dadurch notwendig geworden, daß der schreiber, um sie dem neuen text anzupassen, zur not-

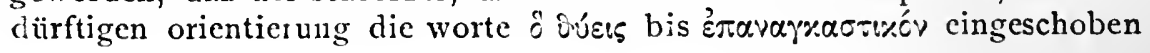




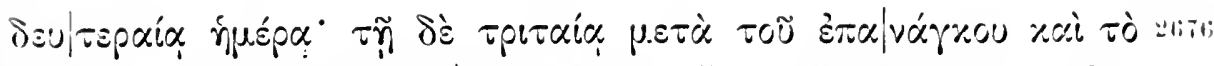

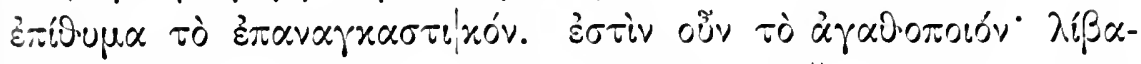

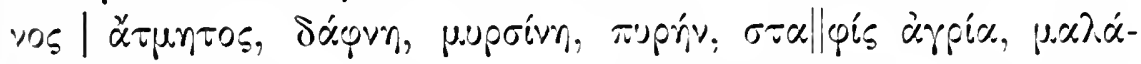

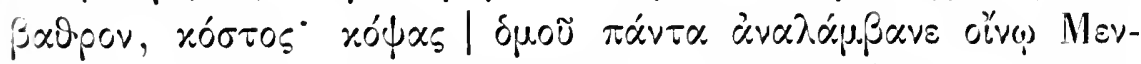

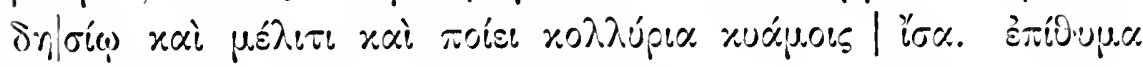

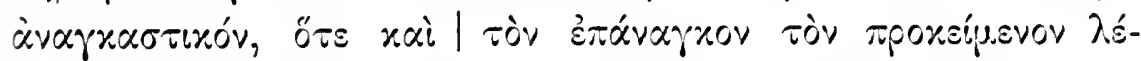

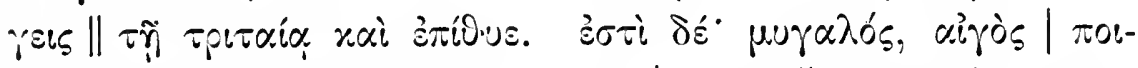

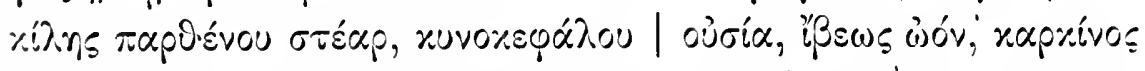

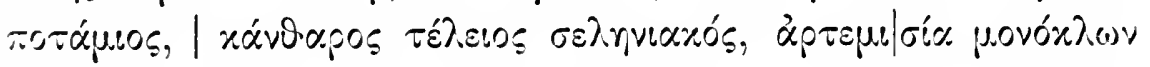

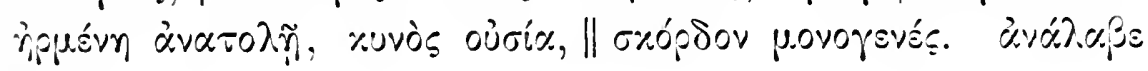

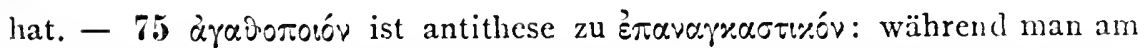
dritten tag der Hekate durch den götterzwang ein übel antut, tut man ihr am ersten und zweiten tag gutes durch ein ihr genehmes érícure. An anderen stellen bezieht sich ¿ara.jotoóós auf menschen; der zauber

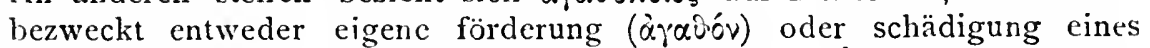

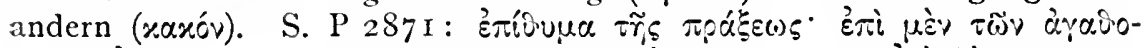

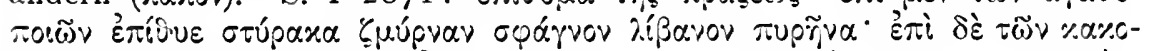

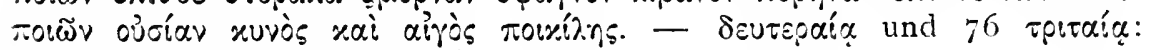

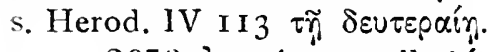

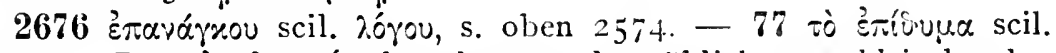
rívera. - Das ayaiororov besteht aus den üblichen wohlriechenden

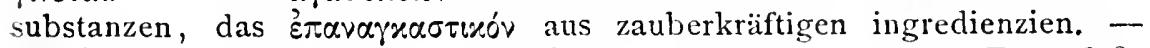

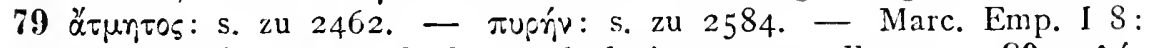
staphidos agrias, quam herbam peduclariam . appellant. - $80 \mu \alpha \lambda \alpha_{-}$ Paipov: Hor. c. If 7,8 mit der bemerkung von Kiessling-Heinze. xóctos: Prop. IV 6, 5: Costum molle date et blandi mihi turis honores. 81 davaix́ $\mu \beta a v \varepsilon$ : 'anmachen mit', s. gleich 9o. Wieder terminus der arznei-

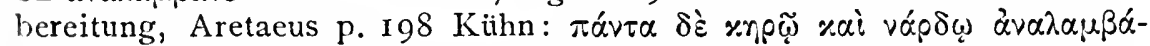
vsıv. - Ein nach derselben ägyptischen stadt genanntes unguentum Mendesizım erwähnt Plinius nat. hist. XIII 4 und öfter. - 82 ro $\lambda \lambda u ́ p \iota \alpha$ : pillen aus teig; Deubner de incub. 47. Unten 9I steht die oft bezeugte neben-

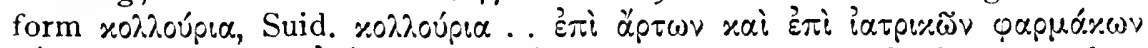

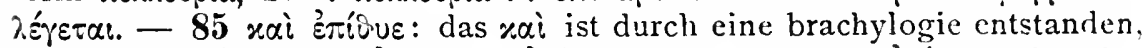

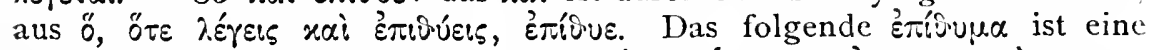

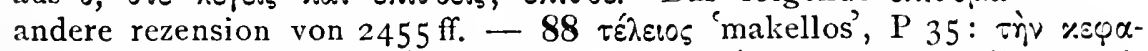

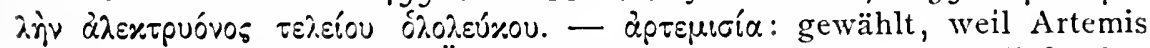
identisch mit Hekate ist. Über den an den beifuß sich anschließenden volksglauben s. Wagler PW III I95f. - Dioskor. III II3 'Apreuroía

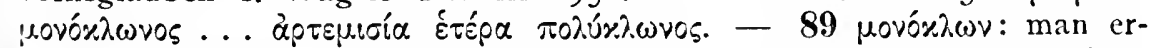
wartet novoxi.wros. Aber s. L. Radermacher, Neutest. Grammatik, Lietzmanns Handbuch zum Ncuen Testament I I 5 f. (Hinweis von L. Deubner),

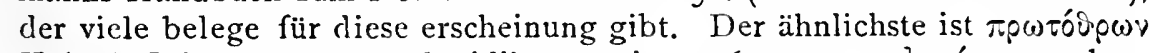
Kaibel Epigr. graeca ex lapidibus conl. 1046, 35. - ñpuém: zauberkräuter durften nur mit bestimmten observanzen gezogen werden, 


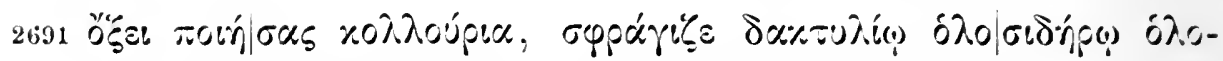

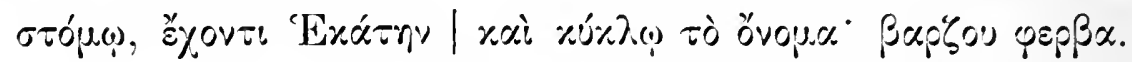

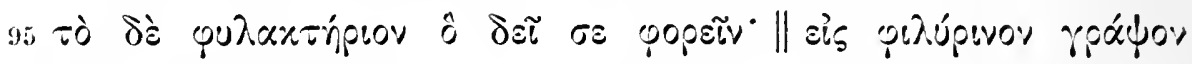

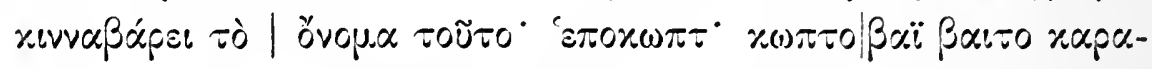

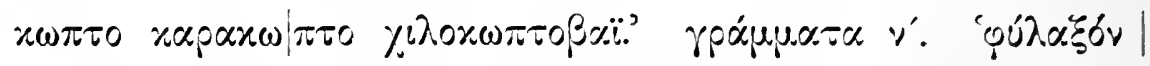

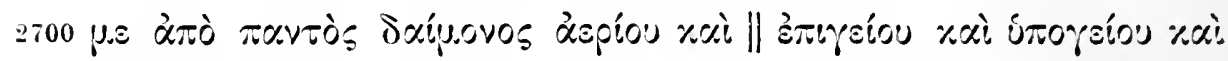

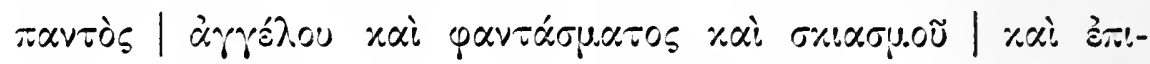

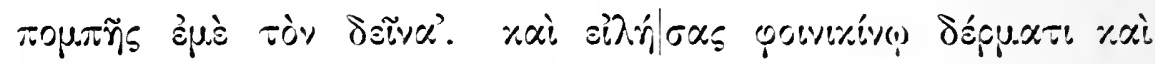

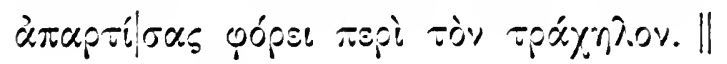

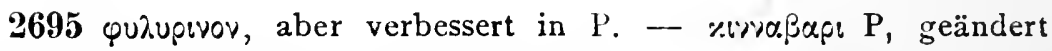

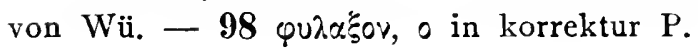

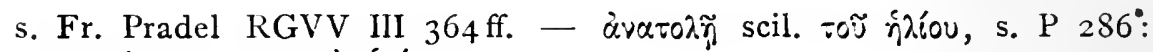

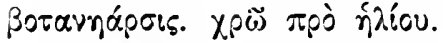

2691 Die zauberkraft der pille wird durch das götterbild gesteigert; s. Arch. für Rel.-wiss. XII 19, wo ein ähnlicher zauberring mit götterbild und umschrift veröffentlicht ist. - ódoó́̊npos: zur magischen kraft des

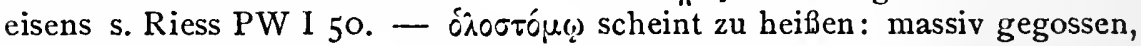
nicht durchbrochen. S. Kyranides Prolog (F. de Mély, Les lapidaires II

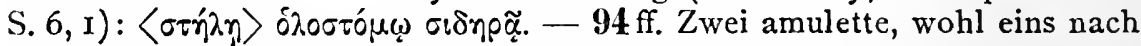

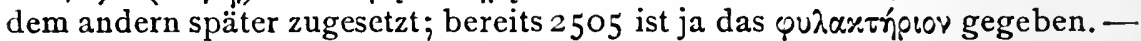

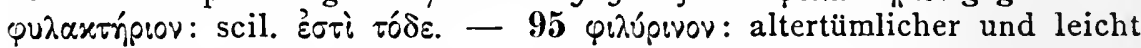
zu beschaffender beschreibstoff, s. C. Dziatzko, Untersuchungen über aus-

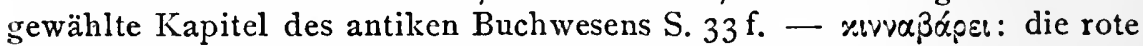
farbe vertritt das zauberkräftige blut, s. Kircher RGVV IX 2, $84 \mathrm{f}$. 97 Horapollo Hierogl. I 7 sagt, $\beta$ aî sei das ägyptische wort für seele. -

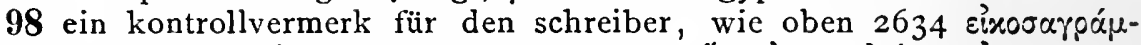

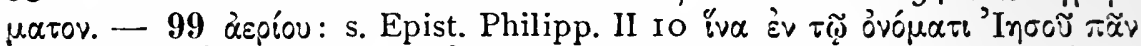

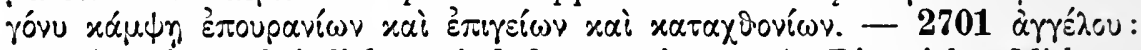
braucht nicht christlicher einfluß zu sein, s. A. Dieterich, Mithrasliturgie $^{2}$ S. 49. - $\varphi \alpha \nu \tau \alpha ́ \sigma \mu \alpha \tau \alpha$ sind trügerische geistererscheinungen,

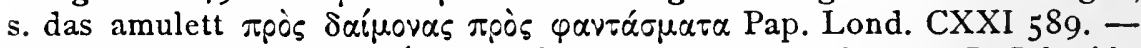

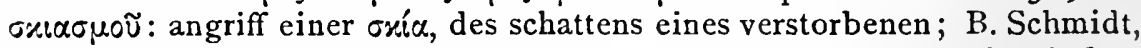
Das Volksleben der Neugriechen I I80, erwähnt den neugriechischen

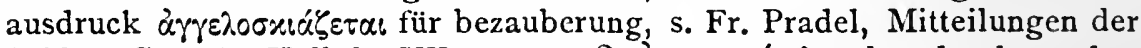

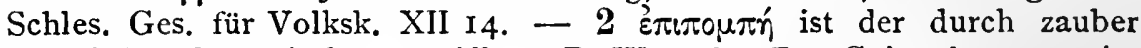
veranlaßte dämonische angriff, s. R. Wünsch, Zur Geistesbannung im Altertum, Festschr. zur Jahrhundertfeier der Universität zu Breslau herausgeg. von Th. Sicbs, S. 16. - 3 yoiviruvos: zur roten farbe im zauber s. Deubner de incub. 25. Rotes pergament war der übliche schutzumschlag auch für bücher; Th. Birt, Antikes Buchwesen $64 \mathrm{f}$. $-\alpha \pi \alpha_{\rho}$ rícas: durch verschnïrung fertigstellen. 


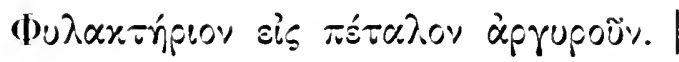

\section{C ${ }^{n}=$ VFFOFV SEX $\Pi \sigma^{\circ}{ }^{\urcorner} \perp$}

2705 Über silbertäfelchen als amulette s. Arch. für Rel.-wiss. XII $24 \mathrm{ff}$. - 6 Zur herkunft solcher sog. charaktere vgl. Antik. Zauberger. $3 \mathrm{Iff}$. Deutbar ist nur der erste, das zeichen der mondgöttin. Mit diesem amulett schließt das rezept, 8 beginnt: $\alpha \bar{\lambda} \lambda . \eta \eta$ 


\section{REGISTER ZU ZAUBER UND RELIGION}

[ 675 bedeutet zeile 2675 usf.]

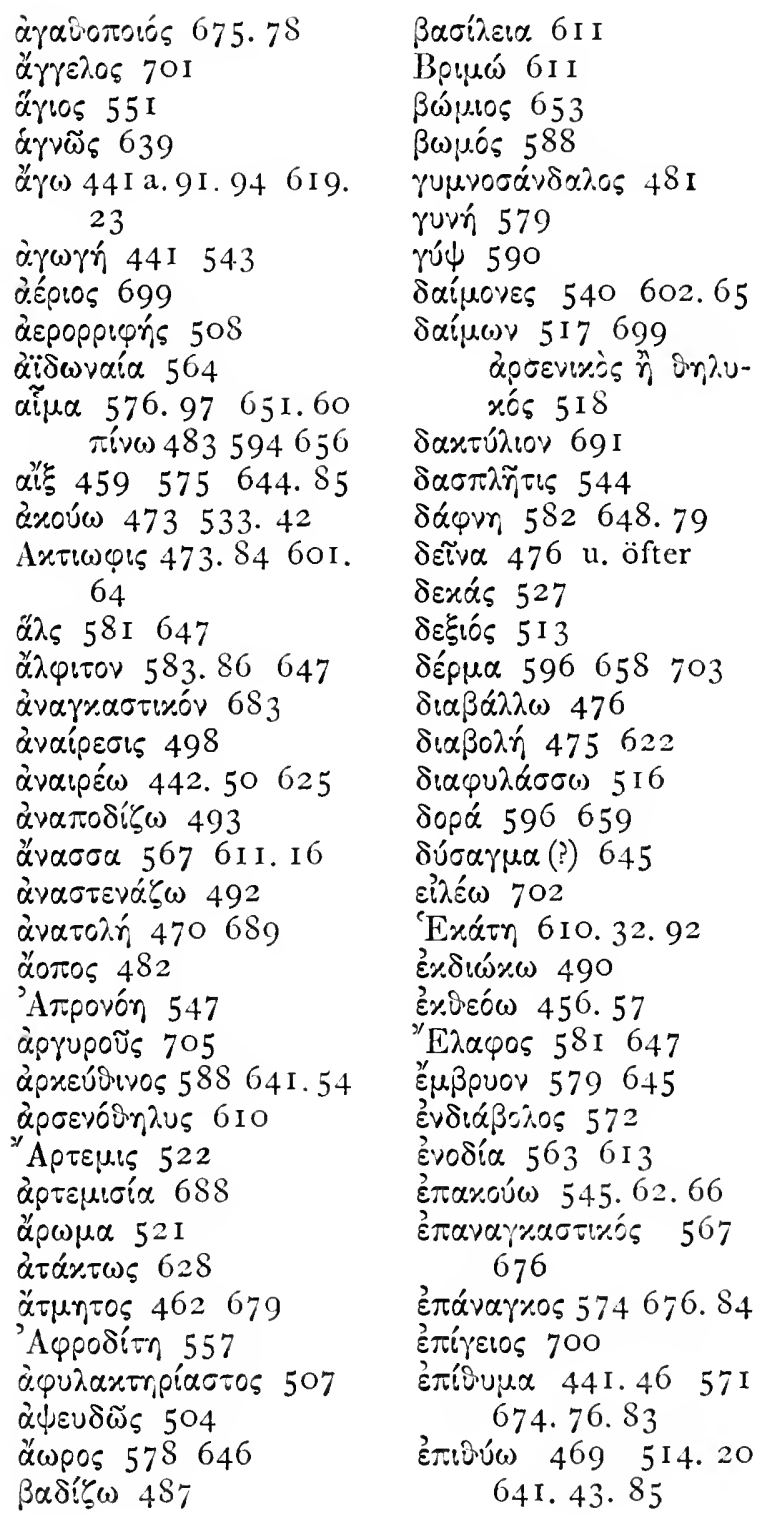

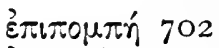

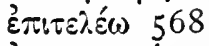

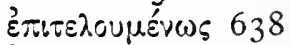

'Epuris 609. I 8

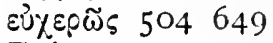

Zeús 522

Suípva $46 \mathrm{I}$

ỹouyos 544

Sєá 532. 61. 75. 92 609. 19.43

Vิeี̃os 449

Uिé́s 473. So 501. O7. 36603.29 .65 .72

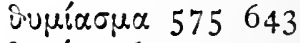

Sucia 565

Búw 492 5I8. 2 I. 74 620.75

Pis $460 \quad 587 \quad 652.87$ ísoós ó $\pi \varepsilon \lambda$ áryos 590 . 97660

iepatixós $5 \mathrm{I} 3$

iepós 474. 77535

i $\pi \pi 0 \times u ́() y, 614$

i $\pi \pi 0 \pi 0 \dot{\sigma} \sigma \omega \pi 05549$

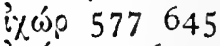

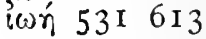

xávìpos 456598660 . 88

\%apdía 577646

r.рxivos $45^{8} 583649$. 87

\%a. 624

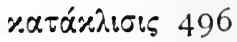

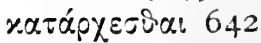

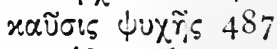
\%iv̛́ápi 695 rolvós 672 xoípavos 601. 64

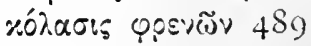




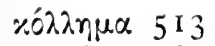

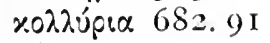

хо́троs $460 \quad 586 \quad 651$

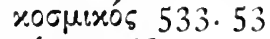

xó

xрóxos $46 \mathrm{I}$

xpónuvov 463584650

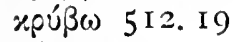

xúvelos 645

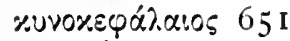

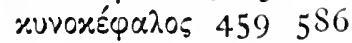
600.62 .86

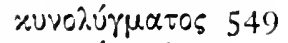

zurepís $46 \mathrm{I}$

xupía 499502

\#úcu 578689

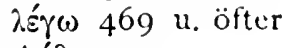

Ańion 534

xíßavos 462678

lóros 470 u. öfier

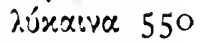

$\lambda \tilde{u} \mu \alpha \quad 580$

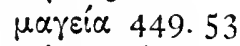

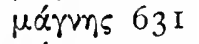

$\mu \alpha ́ x \alpha i p \alpha 542$

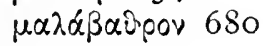

Maplouvn 547

$\mu$. $\lambda_{\lambda !} 682$

Mńm 524. 45609

unviã̃os 600.63

unvioxiov 633

unvía 629

unvorúpavos 664

Meveitin 615

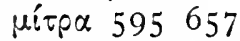

Movorev'́s 462690

uuraxós 455.64 592 65 ז. 85

uúpov 580

Hupoivn $582 \quad 648.79$

$\mu u ́ \sigma \alpha \gamma \mu \alpha \quad 576$

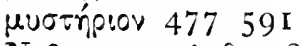

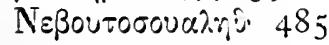
603.65

vexpós $577.78 .8 \mathrm{I}$

vextápios (?) 534

vúpep 6 I4

vuyía 543.50

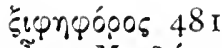

ơvos Meviñotos $6 \mathrm{~S}_{1}$

ónooísinpos $69 \mathrm{I}$

ònórouos 692

Òvipa:trté(1) 444

Òvipatrntón 501

òveiparoTolé() 624

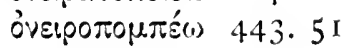
624

òveเротоนти́ 500

óvoua 636.93.96

öรóe:s 580

¿

oupávios 4So 559.62

ouría $578 \quad 687.89$

$\pi \alpha i s 646$

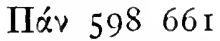

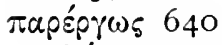

Tарi̊vos 4595776 I 3 . 46.86

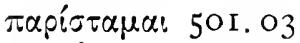

Tapoírpinois $4 \mathrm{~S} 9$

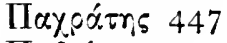

ПЕะó 547

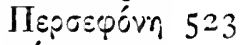

$\pi \varepsilon ́ \tau \alpha \lambda$ ov 705

Títupov 579

TVEบีนC 499

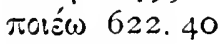

Tólos 480

Tounpós 5I7. IS

$\pi p \alpha \gamma \mu \alpha \tau \varepsilon i \alpha \quad 628.30$

$\pi p \tilde{\alpha} \xi: 5623$

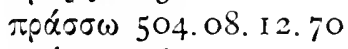

$\pi p a ́ \tau \tau(1) 467$

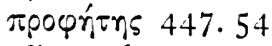

$\pi \tilde{p} \rho 526$

Tuṕn 584650.79

ćósov 584650

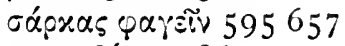

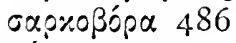

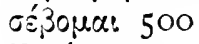

Lèŕvin 558.69 622. 40. 64

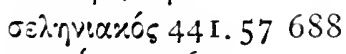

ธหยบ̛́ 441630

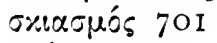

onśc8or 585651.90

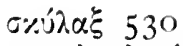

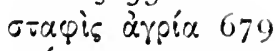

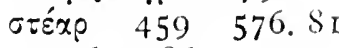
644.86

oríg 606

orúpas 460642

бบัxoข 585

opareás( 59 I

opárvos 584650

opparís 69 I

oyivos 582648

'Táprapa. 535

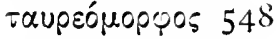

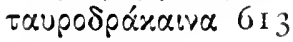

Táyos 544

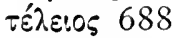

$\tau \varepsilon \lambda \hat{\varepsilon} \omega) \quad 565$

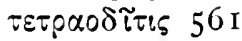

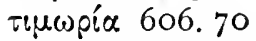

тріxápavos 524. 46

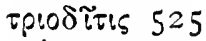

тpíodos 527

ípavyos 602

Iúy 602.65

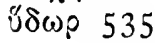
Triraion 456

viós 5 I 8

ŨTVOS 488

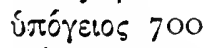

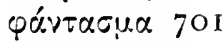

pirúpivos 695

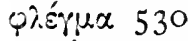

poiviruos 703

p००é(1) $513 \quad 635.94$ 704

ppícow 542

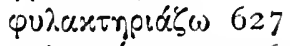

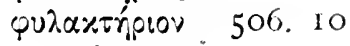
694705

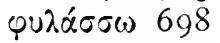

ழ̛́бเs 597659

Xáos 535

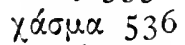

voría $55^{\circ}$

х.реía 465

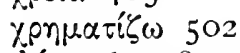

$\begin{array}{llll}30 & 460 & 587 & 652.87\end{array}$ 
A. Marcus u. E. Weber's Verlag, Bonn.

\section{TABVLAE}

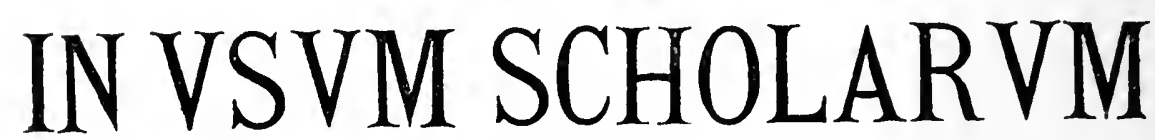

EDITAE SVB CURA IOHANNIS LIETZMANN

Wie die Sammlung der „Kleinen Texte für theologische und philologische Vorlesungen und Uebungen" es sich zur Aufgabe stellt, Quellenschriften von geringem Umfang in einer Form und Ausstattung vorzulegen, die sie zur Grundlage des wissenschaftlichen Unterrichts geeignet erscheinen läßt, so sind diese Tafelwerke dazu bestimmt, das für die historisch-philologischen Fächer wichtigste Anschauungsmaterial in einer Gestalt zu bieten, welche technisch allen Anforderungen der Wissenschaft entspricht und dabei doch einen für den Studenten erschwinglichen Preis anzusetzen gestattet. Denn es ist allerdings für den akademischen Unterricht von höchster Bedeutung, daß der Lernende auch die für die Schulung seines Auges bedeutsamen Lehrmittel selbst besitzt und sie nicht nur gelegentlich auf den Bibliotheken oder in den Museen zu Gesichte bekommt. Der Preis von ca. 6 Mark für das gebundene Exemplar wird deshalb möglichst beibehalten werden.

Erschienen ist:

I. SPECIMINA CODICVM GRAECORVM VATICANORVM collegerunt PIVS FRANCHI DE' CAVALIERI et IOHANNES LIETZMANN. I9IO. XVI S. 50 Tafeln in Lichtdruck. Geb. in Leinenband $6 \mathrm{M}$. Auf Karton gedruckt in Ganzpergament I 2 M. Eine Auswahl von meist datierten griechischen Handschriften des IV. bis XVI. Jahrhunderts der Bibl. Vaticana.

Diese Sammlung bietet Material zum Studium der griechischen Handschriften-Paläographie aus den reichen für diesen $Z$ weck bisher noch nicht benutzten Scłätzen der Vaticana. 7 Tafeln 
zeigen die wichtigsten Uncialtypen vom IV. bis X. Jahrhundert. Auf eine Probe der Minuskelkursive saec. VIII./IX. folgt dann die Entwickelung der Minuskelschrift vom IX. bis XVI. Jahrhundert fast durchweg an daticrten, vielfach auch lokalisierten Handschriften gezeigt. Das IX. Jahrhundert ist durch 4, das X. durch 6, XI. durch 9, XII. durch 5, XIII. durch 7, XIV. durch $4, X V$. und XVI. durch je 3 Tafeln vertreten. Darunter befinden sich 5 Proben der unteritalischen Schrift vom X. bis XIII. Jahrhundert.

2. PAPYRI GRAECAE BEROLINENSES collegit GVILELMVS SCHVBART. 50 Tafeln in Lichtdruck. Geb. in Leinenband 6 M., in Ganzpergament I2 M. Auswahl von Urkunden und literarischen Papyri
des Berliner Museums.

Auf 50 Lichtdrucktafeln werden nahezu 80 Papyrustexte vollständig oder in Proben wiedergegeben und damit die Hauptzüge der Schriftentwicklung vom Ende des 4. Jahrh. n. Chr. bis zum Beginn des 8. Jahrh. v. Chr. vor Augen geführt. Urkunden, Briefe und literarische Stïcke sind ohne Sonderung nach Sachgruppen lediglich nach der Zeitfolge geordnet, wobei den literarischen Texten freilich nur durch Schätzung ihr Platz angewiesen werden kann. Den Hauptzweck, Material zur Einarbeitung in die Paläographie zu bieten, unterstützen die den Tafeln vorausgehenden Textbogen, die für jeden Papyrus Herkunft, Zeit, Inhalt und eventuell die erfolgte Publikation notieren und in beträchtlichem Umfange auch Abschriften der griechischen Texte beifügen, um dem Anfänger die unentbehrliche Hilfe, dem Vorgeschrittenen die Nachprüfung an die Hand zu geben. Eine Gruppierung der Papyri nach der Schwierigkeit für die Entzifferung wird vorangeschickt um den Lernenden auf den rechten Weg zu führen. Neben dem pädagogischen Gesichtspunkte wird das Werk als cin bequemes paläographisches Nachschlagebuch dienen können. Soweit die maßgebenden paläographischen Ziele es zulassen, wird darauf Bedacht genommen, auch inhaltlich wertvolle Stücke abzubilden, so daß die bekanntesten Papyri der Berliner Sammlung fast ausnahmslos vertreten sind. 3. SPECIMINA CODICVM LATINORVM VATI-
CANORVM collegerunt FRANCISCUS EHRLE J. S. et PAULUS LIEBAERT. I9I I. 50 Tafeln in Lichtdruck. In Leinenband $6 \mathrm{M}$. Vorzugsexemplare in Pergament I2 M.

Der Praefekt der vatikanischen Bibliothek P. F. EHRLE S. J. hat in Gemeinschaft mit Abbé LIEBAERT aus den reichen ihm unterstellten Schätzen zum Zweck des akademischen Unterrichts eine Reihe von womöglich datierten Codices ausgewählt, welche die Entwickelung der lateinischen Buchschrift vom IV. Jahrhundert 
bis in die Humanistenzeit darstellen. Auf 50 Lichtdrucktafeln $(18 \times 24 \mathrm{~cm})$ sind 58 Schriftproben in der Gröle der Originale wiedergegeben: die einzelnen Tafeln sind mit Zeilenzählern und erläuternder Unterschrift versehen. Als Text ist beigegeben eine kurze Skizze der Entwickelung der lateinischen Schrift, sodann Beschreibung der einzelnen Handschriften mit reichhaltigen Literaturverweisen und Umschrift aller irgendwie schwierigen Tafeln. Es werden Proben von folgenden Schriftarten geboten: Majuske1: Capitalis (Taf. I-3), Uncialis (4-5), Semiuncialis $(5-7)$; Nationalschriften: Italische Halbcursive (8-9), Norditalische Minuskel (I0), Mittelitalische (Beneventaner) Minuskel saec. IX-XIII (I I-I 7). Gallische Schrift saec. VIII - IX (18-20), Insulare Schrift saec. VIlI-XII (2 I--24), Spanische (Westgotische) Schrift saec. IX-XI (25-26), Deutsche Schrift saec. VIII (27-28). Karolingische Minuskel saec. IX-XI aus Deutschland, Frankreich, Italien, England (29-35). Gothische Schrift saec. XII-IV aus denselben Ländern $(36-45)$ mit besonderer Rücksicht auf die Fachschriften (theologische, juristische, philosophische). Humanistische Schrift saec. XV aus Deutschland, Frankreich, Italien.

\section{Aus den Besprechungen von Nr. I:}

Eine hochwillkommene Gabe in meisterhafter Ausführung, von der eine Belebung des Interesses und des Verständnisses für Handschriftenforschung in den Kreisen der Studierenden sicher ausgehen wird.

THEOLOGISCHE LITERATURZEITUNG I9II, Nr. 6 .

Ein ausgezeichnetes und außerordentlich billiges Hilfsmittel zum Studium der griechischen Paläographie.

\section{BIBL. ZEITSCHRIFT I9II, Heft I.}

Die gut ausgeführten Schrifttafeln beginnen mit Proben des 4. bis 6. Jahrhunderts n. Chr., zeigen die verschiedenartigen Schrifttypen bis zum Jahre 1565 und gewähren somit ein willkommenes Hilfsmittel für philologische und theologische Seminare auf dem Gebiete der griechischen Paläographie.

"LITERARISCHES ZENTRALBLATT" I9II, Nr. II.

Das Buch ist allen Freunden griechischer Handschriftenkunde angelegentlichst $z u$ empfehlen. Wer es sorgsam durchstudiert, wird sich große Leichtigkeit in Lesen der Kodizes erwerben. „STIMMEN AUS MARIA-LAACH" IgII, Heft 2.

Jeder der sich mit griechischer Paläographie befassen muß, Lehrer sowohl wie Schüler, wird den beiden Gelehrten Dank wissen, daß sie in den "SPECIMINA" ein so billiges und bequemes Hilfsmittel zum praktischen Studium geschaffen haben. Weiterer Empfehlung bedarf das Werk nicht. Es empfiehlt sich selber. "LITERARISCHER HANDWEISER" I II I, Nr. 4.

L'album, d'une exécution matérielle parfaite, d'un format commode, est destiné à l'enseignement de la paléographie grecque. „REVUE DES ETUDES ANCIENNES“. 


\section{Allgemeine Religionsgeschichte \\ VOn}

Conrad von Orelli

Dr. phil. et theol., ord. Prof. d. Theol. in Basel

2. Auflage in zwei Bänden

Jeder Band in ungefähr 5 Lieferungen zu je 2 Mark

Von den modernen größeren Werken aus dem Gebiete der Religionsgeschichte ist das Orellische das einzige, welches den gesamten Stoff in einheitlicher Bearbeitung bietet. Das Werk hat in erster Linie die Bedürfnisse der Studierenden und Pfarrer im Auge, ist aber so eingerichtet, daß jeder Gebildete daraus ohne Mühe ein lebendiges Bild der einzelnen Religionen gewinnen kann, was dem Verfasser bei der weit verbreiteten Teilnahme, welche die allgemeine Religionsgeschichte heute findet, von besonderer Wichtigkeit schien, da erst bei wirklich historischen Verständnis der richtige Maßstab zur Beurteilung der einzelnen Erscheinungen vorhanden sein kann.

Die Darstellung hält in der jetzt erscheinenden zweiten Auflage im allgemeinen die gleichen Grenzen inne, welche sich bei der ersten Auflage bewährt haben, doch werden eine Anzahl Kapitel in neuer Redaktion geboten und Erweiterungen da vorgenommen, wo seit dem Erscheinen der ersten Auflage neues Material von Belang hinzugekommen ist. Infolgedessen empfahl sich die Teilung in zwei Bände. Jeder derselben erhält sein besonderes Register.

B and I umfaßt außer der orientierenden Einleitung die Religionen der Chinesen und Japaner sowie der übrigen mongolischen Völker. Ferner die Religion der alten Ägypter, dann die der Babylonier und Assyrer, an welche sich die der Westsemiten, Aramäer, Kanaanäer usw. anreihen, mit Berücksichtigung ihrer Verhältnisse zur Religion Israels und zum Christentum. Ferner wird hier behandelt der Manichäismus und die Mandäische Religion. Endlich die arabische, insbesondere der Islam, bis auf die Neuzeit.

Band 2 stellt die große indogermanische Religionsfamilie dar: die Religionen Indiens: Brahmanismus, Bud- 
dhismus, Hinduismus; darauf den Parsismus, die Religionen der Hellenen, Römer, Kelten, Germanen und Slavèn. Weiterhin kommen zur Behandlung die Religionen der Eingeborenen Afrikas und Amerikas mit besonderer Berücksichtigung Mexikos und Perus sowie die des Südseegebietes, Australiens usw. Am Schluß werden einige Richtlinien für die Probleme der Allgemeinheit, des Ursprungs und der Entwicklung der Religion gezogen.

Band I erscheint in 5 Lieferungen, beginnend im Frühjahr I9II, welche sich rasch folgen sollen. Band 2 wird im Frühjahr I9I2 zu erscheinen anfangen und gleichfalls 5 Lieferungen umfassen. Die erste Lieferung wird von den Buchhandlungen gern zur Einsicht geliefert.

\section{Aus den Beurteilungen der ersten Auflage}

In aller Bescheidenheit ein vorzügliches Buch, musterhaft als Lehrbuch durch das, was geboten wird, und durch das, was beiseite bleibt. Es wird einfach das geschichtlich vorliegende Material in gedrängter Kürze vorgeführt, deutlich und präzis, und bei aller Selbstbeschränkung doch so ausführlich, daß man auch vom Pulsschlag der Religionen noch etwas durchfühlt. Hier hat man überall das Gefühl: es spricht die geschichtliche Wirklichkeit aus der Darstellung zu uns, und wo der Verfasser urteilt, da urteilt ein Mann von vorsichtig nüchternem Urteil, aber ein Mann, der selbst weiß, was Religion ist.

(Evangel. Kirchenblatt für Württemberg.)

In einem Werke von gegen 900 Seiten hat er die reife Frucht seiner umfassenden Studien niedergelegt. Einheitlichkeit der Darstellung und ein fester Gesichtspunkt für die Wertschätzung der religiösen Phänomene ist der sichere Gewinn seines Vorgehens.

(Theol. Jahresbericht, E. Lehmann, Kopenhagen.)

Man wird die neue Publikation Orellis mit Anerkennung des großen Fleißes und ebensolcher Umsicht des Verfassers zur Benutzung angelegentlich zu empfehlen mit Vergnügen sich veranlaßt sehen.

(Allg. Literaturbl., Wien.)

Es wird auch über seinen nächsten $Z$ weck hinaus Liebhaber finden. Es ist durchaus gemeinverständlich abgefa $a t$, vom offenbarungsgläubigen Stundpunkte. Gegenüber dem vielfach profanen Betriebe der religionswissenschaftlichen Forschung wird man mit Genugtuung bemerken, wie gut sich wissenschaftliche Gründlichkeit und christliches Urteil vereinigen.

(Neue Preuf. (Kreuz-) Zeitung, Berlin.)

Dieses bedeutende und hochinteressante Werk ist nicht nur für Studierende und im Amt stehende Geistliche, sondern für alle gebildeten Christen zu empfehlen. (Christlicher Volksbote, Basel.) 
9/30 Res Gestae DIVI Avgvstr, herausgegeben und erklärt von Prof. Dr. Ernst Dichl. 2. Aufl. 40 S. $1.20 \mathrm{M}$.

i Zwer neue Evangeriknfragmente, herausgegeben und erklärt von H. B. Swete. I $5 \mathrm{~S}$. $0.40 \mathrm{M}$.

ARAmärsche URKuninen zur Geschichte des Judentums im VI. und V. Jahrhundert vor Chr., sprachlich und sachlich erklärt von I'rof. Lic. Dr. W. Stacrk. I6 S. $0.60 \mathrm{M}$.

3/34 SUPPLEMENTUN LyRicum, ncue bruchstücke von Archilochus Alcaeus Sappho Corinna Pindar, ausgewählt und erklärt von Prof. Dr. Ernst Dieh1. 2. Auf. 44 S. $1.20 \mathrm{M}$

5 Liturgische Texte III: Die konstantinopolitanische messliturgie vor dem IX. jabrhundert: Uebersichtliche zusammenstellung des wichtigsten quellenmaterials von Dr. An ton Baumstark. I6 S. 0.40 M.

'6 Liturgische Texte IV: Martin Luthers Von ordnung gottesdiensts, Taufbüchlein, Formula missae et communionis 1525 herausgegeben von Prof. D. Hans Lietzmann. 24 S. o.6o M.

7 Liturgische Texte v: Martin Luthers Deutsche Messe 1526, herausgegeben von Prof. D. Hans Lietzmann. i6 S. 0.40 M.

\$/40 Altlateinische Inschriften von Prof. Dr. Ernst Diehl. 64 S. I.80 M:

I/43 Fasti Consulares Imperit Romani von $30 \mathrm{v}$. Chr. bis $565 \mathrm{n}$. Chr. mit Kaiserliste und Anhang bearbeitet von Willy Liebenam. I 28 S. 3 M., gbd. 3.40 M.

H/46 MENANDRI reliquiae nuper repertae herausgeg. von Prof. Dr. Siegfried Sudhaus. 65 S. I.80 M., gbd. $2.20 \mathrm{M}$.

7/49 Lateinische AltKirchliche Poesie ausgewählt von Prof. D. Hans Lietzman. 64 S. I.50 M.

0/5I URKunden ZUR Geschichte DES BAUERnKRIEges. UND DER WiedertäUfer herausgeg. von Dr. H. Böhmer. 36 S. o.80 M. 2/53 FrüHBYZantinische Kirchenpoesie I: Anonyme hymnen des V-VI. jahrhundert ediert von Dr. Paul Maas. 32 S. o.So M.

+ Kleinere geistliche Gedichte des xil. Jahrhunderts herausgeg. von Albert Leitzmann. 30 S. o.So M.

; Meister Eckharts Buch DER GötTlichen Tröstung UND VON DEM EDLEN MENSCIIEN (LIBER BENEDICTUS) herausgegeben von Philipp Strauch. 5I S. I.20 M.

POMPEIANISCHE WANDINSCHRIFTEN UND VERWANDTES, ausgewählt von Prof. Dr. Ernst Diehl. 60 S. I.80 M.

ALTITALISCHE INSCHRIFTEN herausgegeben von $H$. Jacobsohn. 32 S. $0.80 \mathrm{M}$.

Altjüdische Liturgische Gebete herausgegeben von Prof. D. W. Staerk. 32 S. I.0O M.

Der Mišnatraktat Berakhoth in VOKalisierten TeXt herausgegeben von Prof. D. W. Staerk. I6 S. 0.6o M.

EDWARd Youngs GedANkEN ÜBER DIE ORIGINALwerke in einem schreiben an Samuel Richardson übersetzt von H. E. v. Teubern, herausgegeben von $\mathrm{Kurt} \cdot \mathrm{Jahn} .46 \mathrm{~S}$. I.20 M.

Liturgische Texte vi: Die Klementinische liturgie aus den Constitutiones apostolorum VIII mit anhängen herausgeg. von Prof. D. Hans Lietzmann. 32 S. $0.80 \mathrm{M}$. 
62 VUlgärLATEINisChe Inschriften herausgeg. von Prof. Dr. Ern: Diehl. ISo S. Brosch. 4.50 M., geb. 5.- M.

63 Goethes erste Wamarer Gedichtsammlung mit varianten herau gegeben von Albert Leitzmann. 35 S. 0.80 M., geb. I.20 I

64 DiE Oden SAlonos aus dem syrischen übersetzt, mit Anmerkung، von A. Ungnad u. W. Staerk. $40 \mathrm{~S}$. $0.80 \mathrm{M}$.

65 AUs Der ANTIKEN SCHUle. Sammlung griechischer texte auf papyr holztafeln ostraka, ausgewählt und erklärt von Dr. Erich Zi barth. 23 S. $0.60 \mathrm{M}$.

66 ARIsTOPHANES Frösche mit ausgewählten antiken scholien herausg $€$ von Dr. Wilhelm Süss. 90 S. Brosch. 2.- M., geb. 2.40]

67 Dietrici Schernbergs Spiel von Frau Jutten herausgeg. von Pr Dr. Edward Schröder. 56 S. I.20 M.

68 Lateinische SaCRALINSChriften ausgewählt von Dr. Fra Richter. 45 S. $-.90 \mathrm{M}$.

69 POETarvi VeTervm Romanorvm Reliquiae selegit Ernest Dieh 1. I65. S. Brosch. $2.50 \mathrm{M}$., geb. 3.- M.

70 Liturgische Texte vil: Die Preussische Agende im auszug her: von Hans Lietzmann. 42 S. Brosch. O.80 M., geb. I.-

7 I Cicero pro Milone init dem commentar des Asconivs und d Scriolia Bobiensia herausgeg. von Dr. Paul'Wessner. Brosi I.6o M., geb. 2.- M.

72 Die Vitae Vergilianae und ihre antiken quellen herausgegeb von Prof. Dr. Ernst Diehl. 60 S. r.50 M.

73 Die Quelien von Schillens und Goethes Balladen zusammi gestellt von Albert Leitzmann.

74 ANDREas Karlstadt VON ABTUHUNG DER bILDER und das ke bedtler vnther den christen seyn sollen I522 u. d. Wittenber; Beutelordnung herausgeg. von $\mathrm{H}$ ans Lietzmann. $32 \mathrm{~S}$. 0.80

75 Liturgische Texte viII: Die Sächsische Agende im auszug hera gegeben von Hans Lietzmann. Brosch. o.80 M., geb. I.-

76 AUSWAHL aUs Abraham A S. Clara herausgegeben von $\mathrm{K}$ : Bertsche. 47 S. I.- M.

77 Hrppockatis de aere aquis locis mit der alten lateinischen üb setzung herausgegeben von G. Gundermann.

78 RABbINISCHE WUNDERGESCHICHTEN des neutestamentlichen $Z$ alters in vokalisiertem $T$ ext mit sprachlichen und sachlichen merkungen von Lic. Paul Fiebig. 28 S. I.- M.

79 Antike Wundergeschichten zum studium der wunder des $\mathrm{Ne}$ Testaments zusammengestellt von Lic. Paul Fiebig. 27 S. 0.80

80 Vergil AENEIS II mit dem commentar des Servius herausgegel von Ernst Diehl. I3I S. 2.- M., geb. 2.50. M.

8 $\mathrm{I}$ ANTI-XENIEN in auswahl herausgegeben von Dr. Wolfga Stammler. 68 S. r.40 M., geb. 1.80 M.

82 Apollonius Dyscolus De pronominibus pars generalis edidit Paulus Maas. 44 S. I.- M.

83 Origines. Eustathius v. Antiochien und Gregor v. Nys Über die Hexe von Endor, herausg. von Prof. Dr. E. Klosterma 


\section{Giv Winsch, Richard

\section{PLEASE DO NOT REMOVE CARDS OR SLIPS FROM THIS POCKET} UNIVERSITY OF TORONTO LIBRARY 


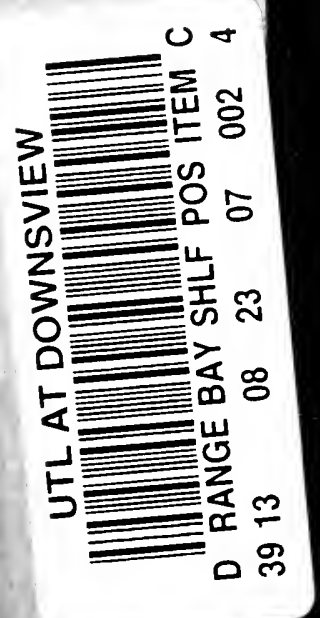

